Portland State University

PDXScholar

Summer 9-5-2017

\title{
The Social Acceptance of Community Solar: a Portland Case Study
}

Anne Weaver

Portland State University

Follow this and additional works at: https://pdxscholar.library.pdx.edu/open_access_etds

Part of the Power and Energy Commons

Let us know how access to this document benefits you.

\section{Recommended Citation}

Weaver, Anne, "The Social Acceptance of Community Solar: a Portland Case Study" (2017). Dissertations and Theses. Paper 3882.

https://doi.org/10.15760/etd.5770

This Thesis is brought to you for free and open access. It has been accepted for inclusion in Dissertations and Theses by an authorized administrator of PDXScholar. Please contact us if we can make this document more accessible: pdxscholar@pdx.edu. 
The Social Acceptance of Community Solar:

A Portland Case Study

by

Anne Weaver

A thesis submitted in partial fulfillment of the requirements for the degree of

\section{Master of Science}

in

Environmental Science \& Management

Thesis Committee:

Max Nielsen-Pincus, Chair

Arnab Mitra

Linda George

Portland State University

2017 


\begin{abstract}
Community solar is a renewable energy practice that's been adopted by multiple U.S. states and is being considered by many more, including the state of Oregon. A recent senate bill in Oregon, called the "Clean Electricity and Coal Transition Plan", includes a provision that directs the Oregon Public Utility Commission to establish a community solar program for investor-owned utilities by late 2017. Thus, energy consumers in Portland will be offered participation in community solar projects in the near future. Community solar is a mechanism that allows ratepayers to experience both the costs and benefits of solar energy while also helping to offset the proportion of fossilfuel generated electricity in utility grids, thus aiding climate change mitigation.
\end{abstract}

For community solar to achieve market success in the residential sector of Portland, ratepayers of investor-owned utilities must socially accept this energy practice. The aim of this study was to forecast the potential social acceptance of community solar among Portland residents by measuring willingness to participate in these projects. Additionally, consumer characteristics, attitudes, awareness, and knowledge were captured to assess the influence of these factors on intent to enroll in community solar. The theory of planned behavior, as well as the social acceptance, diffusion of innovation, and dual-interest theories were frameworks used to inform the analysis of community solar adoption. These research objectives were addressed through a mixed-mode survey of Portland residents, using a stratified random sample of Portland neighborhoods to acquire a gradient of demographics. 330 questionnaires were completed, yielding a $34.2 \%$ response rate. 
Descriptive statistics, binomial logistic regression models, and mean willingness to pay were the analyses conducted to measure the influence of project factors and demographic characteristics on likelihood of community solar participation. Roughly $60 \%$ of respondents exhibited interest in community solar enrollment. The logistic regression model revealed the percent change in utility bill (essentially the rate of return on the community solar investment) as a dramatically influential variable predicting willingness to participate. Community solar project scenarios also had a strong influence on willingness to participate: larger, cheaper, and distant projects were preferred over small and expensive local projects. Results indicate that community solar project features that accentuate affordability are most important to energy consumers. Additionally, demographic characteristics that were strongly correlated with willingness to enroll were politically liberal ideologies, higher incomes, current enrollment in green utility programs, and membership in an environmental organization. Thus, the market acceptance of community solar in Portland will potentially be broadened by emphasizing affordability over other features, such as community and locality.

Additionally, I explored attitudinal influences on interest in community solar by conducting exploratory factor analysis on attitudes towards energy, climate change, and solar barriers and subsequently conducting binomial logistic regression models. Results found that perceiving renewable energy as environmentally beneficial was positively correlated with intent to enroll in community solar, which supported the notion that environmental attitudes will lead to environmental behaviors. The logistic regression model also revealed a negative correlation between community solar interest and 
negative attitudes towards renewable energy. Perceptions of solar barriers were mild, indicating that lack of an enabling mechanism may be the reason solar continues to be underutilized in this region. 


\section{ACKNOWLEDGEMENTS}

I would first like to thank the Portland residents who took the time to complete the Renewable Energy \& Community Solar Questionnaire for my study. Without their help, this research would not have been conducted, thus I'm extremely appreciative of their participation.

Additionally, I'd like to thank my key informants who were kind enough to provide me with useful information and context about community solar and the renewable energy landscape of Portland. The information I captured from these interviews was used to inform the survey questions as well as the introduction sections of this thesis; their insights were vitally important to this study.

I'm extremely grateful to my advisor, Dr. Max Nielsen-Pincus, who not only guided me through this research project, but also offered me invaluable advice on graduate school, coursework, and time management. Max has been an incredible mentor and I cannot thank him enough for the guidance and inspiration he's provided me over the past couple years; I would have been lost without his mentorship.

I would also like to thank my committee members, Dr. Arnab Mitra and Dr. Linda George, for their extremely helpful feedback and comments on my research. Their suggestions greatly improved my study; I'm immensely appreciative of their help.

Further, I'd like to acknowledge Portland General Electric who helped fund and provide feedback on my questionnaire. Additionally, I'm grateful for the additional 
funding from the Bushby Scholarship Fund and the Nielsen-Pincus Natural Resources Policy and Management Lab. I'd also like to thank the Environmental Science and Management Department at Portland State University for offering me the financial opportunity to be a Teaching Assistant.

Many thanks to my research assistants, Emily Quinton, Candice Loveland, and Tyler Mahone, who aided in the implementation and distribution of the survey. Their time and help allowed me to distribute my survey much more efficiently and caused the data collection method of this project to be enjoyable, if not adventurous.

I'm also grateful to the other students (past and present) in the Nielsen-Pincus Natural Resources Policy and Management Lab: Cody Evers, Sabra Comet, Erin Upton, Samantha Hamlin, Matt DeAngelo, and Ashely Vizek. I presented my research to them numerous times in which they offered me useful recommendations and feedback. Additionally, our lab meetings taught me a tremendous amount regarding theoretical frameworks, statistical analyses, and data collection methodologies that inspired me in my own research. My educational experience at Portland State University would not have been the same without these weekly lab meetings. 


\section{TABLE OF CONTENTS}

ABSTRACT

CHAPTER 2. Predicting Market Acceptance of Community Solar by Measuring

Residential Willingness to Participate.......................................... 9

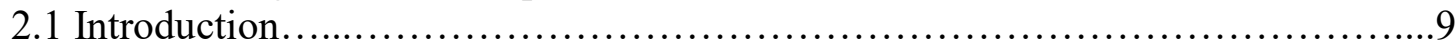

2.1.1 Application of the DOI Theory....................................... 11

2.1.2 Social Acceptance of Community Solar.................................16

2.1.3 Research Objectives................................................ 19

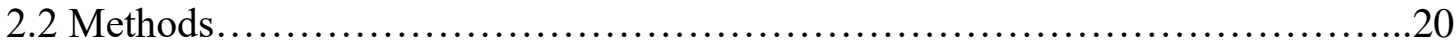

2.2.1 Study Area.............................................................

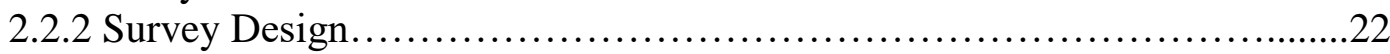

2.2.3 Sampling \& Implementation Strategy................................24

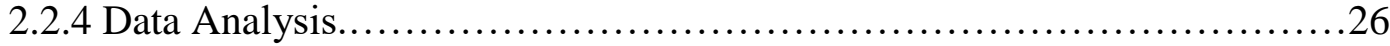

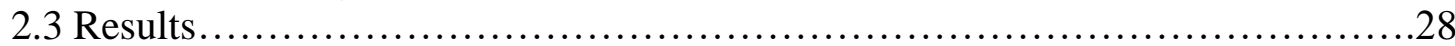

2.3.1 Response Summary...............................................28

2.3.2 Willingness to Participate Regression Results...........................32

2.3.3 Mean Willingness to Pay.............................................. 34

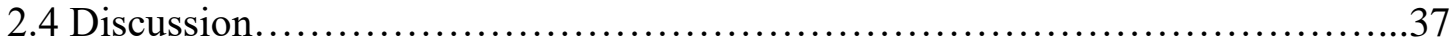

2.4.1 Monetary Influences on Market Acceptance.............................. 37

2.4.2 Influential Project Attributes........................................... 40

2.4.3 Demographic Implications.........................................43

2.4.4 Study Limitations \& Future Research Needed............................44

2.5 Conclusions.............................................................46

CHAPTER 3. Attitudes, Beliefs, and Behaviors as Predictors for Community Solar

Enrollment..............................................................48

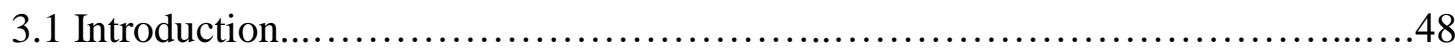

3.1.1 Research Objectives............................................. 51

3.1.2 Theory of Planned Behavior........................................... 52

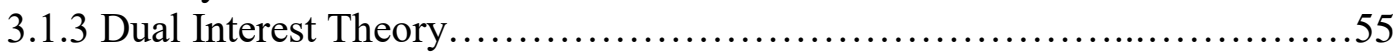

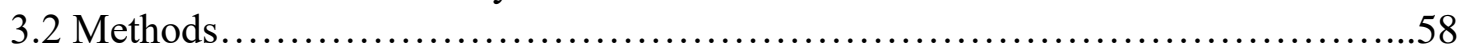

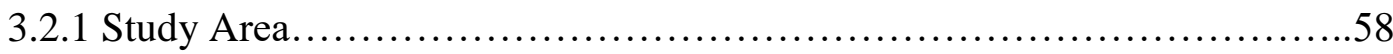

3.2.2 Survey Design..................................................... 59

3.2.3 Sampling \& Implementation Strategy..................................61

3.2.4 Data Analysis.....................................................63

3.3 Results.......................................................... 65 


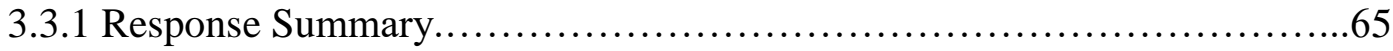

3.3.2 Attitude Logistic Regression Results...............................69

3.4 Discussion............................................................. 74

3.4.1 Awareness as a Barrier.............................................74

3.4.2 Renewable Energy Attitudes \& Community Solar Interest...................77

3.4.3 Study Limitations \& Future Research Needed..............................78

3.5 Conclusions.................................................................... 79

CHAPTER 4. Conclusions...................................................... 81

REFERENCES .............................................................. 85

APPENDIX A. Scale Definitions for Attitude Model Variables........................92

APPENDIX B. Survey Instrument............................................ 94

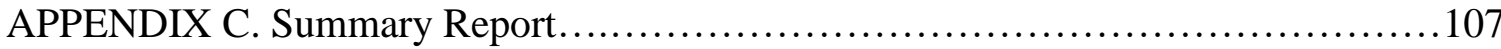

APPENDIX D. Human Subjects Approval......................................... 165 


\section{LIST OF TABLES}

Table 2.1 Respondent Characteristics.......................................29

Table 2.2 Community solar project preferences................................. 31

Table 2.3 Binomial logistic regression results of willingness to participate in community

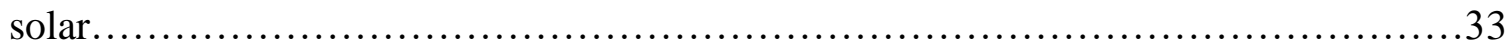

Table 2.4 Logistic regression models for definitely WTP for each scenario..............36

Table 3.1 Descriptive statistics of items used in attitude regression analyses............66

Table 3.2 Attitude regression results of interest in community solar.................71

Table 3.3 Attitude regression results of interest in pursuing solar energy $\ldots . \ldots \ldots \ldots \ldots . . .73$

Table 3.4 Attitude regression results of timing of community solar adoption............74 


\section{LIST OF FIGURES}

Figure 2.1 Map of Portland Neighborhoods...................................25

Figure 2.2 Predicted probability of definitely willing to participate.....................35 


\section{CHAPTER 1: INTRODUCTION}

The global scientific consensus confirms that fossil fuel combustion accounts for the majority of anthropogenic global greenhouse gas (GHG) emissions, contributing significantly to world-wide climate change (IPCC, 2012). Because of this, nations around the world have set ambitious targets to reduce carbon emissions and increase the share of renewable energy to mitigate the potential dire consequences of global warming (Wustenhagen, 2007). Climate Action Plans (CAPs) globally and nationally call for substantial reductions in emissions in the residential electricity sector, a large contributor of GHG emissions, especially in the U.S. (EPA, 2014). According to Bin and Dowlatabadi (2005), household energy consumption in the U.S. accounted for almost $41 \%$ of energy-related carbon dioxide emissions. Consequently, climate change mitigation cannot be truly successful without the acceptance of innovative clean energy and energy efficient practices among the residential electricity sector. In the U.S., 29 states have adopted renewable portfolio standards (RPS) that require utilities to sell a specified proportion of renewable electricity within their energy mix (Abdmouleh et al., 2015). Many of these state energy standard goals are aggressive. For example, the state of Hawaii increased its RPS to $100 \%$ by 2045 and the state of Oregon increased its standard to $50 \%$ by 2040 (NCSL, 2016). Evidently, increasing the share of renewable energy is high on the policy agenda for many U.S. states.

To meet these goals, renewable energy projects- namely wind and solar- must be developed to supplant much of the fossil-fuel generated electricity within utility energy mixes. Distributed generation, e.g. distributed solar, is an example of this. Distributed 
solar is a device that allows small-scale solar projects to feed into the utility grid, while helping to offset peak electricity demand and stabilize the local grid (SEPA, 2016). Other terms that are synonymous with such projects are "community solar", "solar gardens", or “shared solar" (Feldman et al., 2015). Community solar projects are new energy practices that have been adopted by multiple U.S. states and are currently being developed or considered by many more (Maize, 2015; Feldman et al., 2015). Policies and legislation are promoting these renewable energy practices, but the ultimate measure of project success is through consumer adoption rates. Research has shown that the widespread adoption of renewable energy technologies is problematic due to an attitude-behavior gap, in addition to other reasons (Claudy et al., 2013). Fortunately, this presents a research opportunity; exploring consumers' cognitions and reasons to adopt or not adopt renewable energy systems could clarify our understanding of the diffusion process. (Westaby, 2005).

The focus of this study is on the development of community solar, considered an innovation in many energy systems because it's a practice unfamiliar and perceived as new by most electricity users. Thus, as a new renewable energy practice, it's forecasted to diffuse throughout many U.S. energy systems over the upcoming years (Brehm et al., 2016). The success of this diffusion depends on a web of factors relating to the characteristics of community solar projects, the cultural and political setting in which the diffusion takes place, and the innovators interested in adoption. The remaining sections of this introductory chapter outline the background, history, and development of community 
solar both in the U.S., as well as in Portland, the area in which this study takes place. A concluding section will summarize the objectives of the research.

\subsection{HISTORY OF COMMUNITY SOLAR IN THE U.S.}

Over the last several years, the cost of solar photovoltaics (PV) has dropped substantially, driving impressive growth in installments. Despite cost reductions, solar still accounts for a tiny proportion of overall U.S. electricity generation: $1 \%$ in 2015 (Brehm et al., 2016). The majority of American households are excluded from this residential rooftop solar PV market due to financial hardships and siting obstacles (SEPA, 2016). Many barriers exist for the widespread adoption of home solar systems, including long simple payback periods, high capital costs, and a lack of trust in the reliability of systems (Faiers and Neame, 2006; Margolis and Zuboy, 2006). On the other end of the solar spectrum is utility-scale solar, which is when electricity from large solar projects is sold to wholesale utility buyers, rather than to end-use consumers (O’Shaughnessy et al., 2014). There are many benefits to such a system, such as providing fixed-price electricity during peak demand when other sources are more expensive (SEPA, 2016). Utility customers can opt-in to these programs and pay a premium to help fund these projects (in order to bring more renewables into the grid), but in most cases, no financial benefits are provided for participation (O’Shaughnessy et al., 2014).

Community solar falls between these two solar categories, where an untapped opportunity for growth lies (Brehm et al., 2016). These projects, which have an array of model structures, are centralized solar facilities owned or leased by residents (as well as 
businesses and institutions) who receive a monthly utility bill credit for their share of power produced (Coughlin et al., 2010). Essentially, community members share both the costs and the benefits of these solar arrays (Feldman et al., 2015). In the mid-2000s, these projects were primarily targeted for niche markets; green customers willing to pay more for a solar product (SEPA, 2016). However, this model has transitioned from only focusing on solar-friendly consumers to a mass market target due to lower participation costs and wider availability through utility programs. In states where legislation has required utilities to provide community solar options to their customers, many of these solar programs have been widely successful, such as Colorado or Minnesota (Maize, 2015). The passage of the 2010 Community Solar Gardens Act in Colorado was a bill that pioneered the community solar movement in the U.S. The structure and design of the community solar garden program in Colorado allowed it to be broadly adoptable by utilities, energy consumers, and solar developers, simultaneously expanding renewable energy access to a broader segment of the state's population (Colorado House Bill 101342). Other states, such as Minnesota, California, and now Oregon, have modeled their community solar bills after Colorado's program (Maize, 2015). It was during and after 2010 when the growth of community solar programs across the U.S. was apparent; primarily due to the enablement from state policy. Policy-induced change in terms of renewable ener

Clearly, community solar policies have been created in response to the traditional barriers obstructing the consumer adoption of PV systems (Jager, 2006). This barrier removal opens the solar market to include the $85 \%$ of U.S. energy consumers who are 
either renters, homeowners with shaded or inadequate roofs, or citizens who cannot afford home solar systems (SEPA, 2016). These projects are versatile innovations that include a variety of designs, structures, and scenarios; usually larger than individual rooftop systems but smaller than utility-scale solar farms (Feldman et al., 2015).

Financing options also vary: some models utilize a leasing payment plan, a member pays a monthly subscription fee; or an ownership plan, where a member can own a share or several blocks within the array by putting down an upfront investment.

The state of Oregon recently passed a bill that will promote the development of community solar, therefore, it's a setting that will experience the diffusion of this energy innovation in the upcoming years. Many other states in the U.S. are also considering the idea of community solar or undergoing the same program development process. The next section describes the history and background of the community solar program in Oregon.

\subsection{COMMUNITY SOLAR IN OREGON}

Oregon first contemplated the concept of community solar in 2014 when local environmental nonprofits and interested solar stakeholders floated the idea to legislators, after learning about the success of Colorado's community solar program. In 2015, after many amendments and alterations, a House Bill was introduced that included a section on community solar development. This provision was essentially a study bill that tasked the Oregon Public Utility Commission (OPUC) with investigating the prospects of a successful Oregon community solar program and reporting back to the legislature by the end of 2015. This study bill provided the language, and was essentially the precursor, for the community solar section of Senate Bill (SB) 1547, passed in March 2016. 
Titled the "Clean Electricity and Coal Transition Plan", SB 1547 increases the state RPS to $50 \%$ by 2040 and phases out coal-fired generation for investor-owned utilities, Portland General Electric and Pacific Power, by 2035. Community solar is a mechanism that will help Oregon achieve these goals and is a provision in SB 1547. This provision directs the Oregon Public Utility Commission (OPUC) to establish a community solar program for investor-owned utilities by July 1st, 2017. Community solar projects in Oregon must be larger than $25 \mathrm{~kW}$, (the maximum size limit has not yet been determined), located anywhere within the state, and requires an inclusionary $10 \%$ low-income target, among other rules being established in the rulemaking process. The rulemaking procedure has included both informal and formal sessions where stakeholders collaborate to come up with policies and rules that will provide the most benefits to eligible participants.

The bill credit rate is an important aspect of the community solar program in Oregon, and likely in other state community solar policies as well. This rate is essentially the value of solar energy applied to each participant's proportional generation produced from a community solar array. The rate is under investigation in Oregon's community solar program, but is required to reflect the "Resource Value of Solar" (RVOS). The RVOS is a complex value that takes into account the costs and benefits of solar energy. This value has not yet been established, but is being investigated by Oregon policymakers. The RVOS will either be less valuable, equivalent, or more valuable than the retail rate of power used for investor-owned utilities in Oregon. Thus, a high RVOS will result in a high bill credit rate. A high bill credit rate for the community solar participant 
means consumers will see net savings in their utility bill; over time, their investment in the project will be paid back and they'll save money in the long term. A low bill credit rate reflects a low RVOS, which in turn will cause community solar members' bills to have minimal savings and long payback periods for their investments. Energy consumers will likely perceive the bill credit rate as either an economic cost or benefit, hence, the financial implications of the RVOS and subsequently the bill credit rate are profound.

\subsection{RESEARCH OVERVIEW \& CONTEXT}

The objective of this thesis project is to assess which factors may influence consumer intent to adopt community solar in Portland, OR; a market that is relatively unfamiliar with this energy practice. The passage of SB 1547 will require the development of a community solar program for investor-owned utilities, thus the citizens of Portland will likely be offered the option for future participation in community solar projects. This research explores how policy and features of the community solar program will drive the success of community solar projects in addition to providing an analysis of residential attitudes and perceptions of this energy practice. The evolution of fossil-fuel dominated utility grids to more distributed blends of renewables is a transition expected to occur in energy systems nationally and globally (Edenhofer et al., 2011). An investigation of the social acceptance of this transition will provide solutions for other localities also experiencing this change.

My overarching research objectives are to (1) investigate the factors, such as project designs, features, and consumer demographics, that will likely influence the 
social acceptance of community solar in the Portland market, and (2) assess the attitudinal characteristics of Portland residents that may drive intent to participate in community solar projects. I evaluate these questions in the following two chapters; chapter two relates to my first objective, where I will be investigating the factors influencing the market acceptance of community solar in Portland. In the first chapter I consider the external factors (the characteristics of community solar that are governed by policy and utility) such as the costs and benefits of enrollment and other project attributes such as size and location. Market acceptance will be measured through a willingness to participate analysis, where a stated preference experiment assesses the likelihood of consumer participation contingent on utility bill savings and different plausible project design scenarios. Demographic characteristics of Portland residents are also captured and applied in the willingness to participate analysis. Chapter three focuses on my second research objective, where I will be exploring the attitudes of the innovators (internal factors of Portland residents) in regards to community solar and renewable energy. More specifically, I'll address how awareness, knowledge, energy and climate change beliefs, community engagement, and perceived solar barriers influence reported interest and intent to enroll in community solar. Finally, chapter four summarizes my conclusions from the entire project. 


\section{CHAPTER 2: PREDICTING MARKET ACCEPTANCE OF COMMMUNITY SOLAR BY MEASURING RESIDENTIAL WILLINGNESS TO PARTICIPATE}

\subsection{INTRODUCTION}

The challenge of wide-spread energy transformation lies in developing programs that provide the most benefit for all relevant stakeholders while simultaneously achieving the environmental goal of climate change mitigation. Community solar, a solar energy practice currently being developed in many U.S. states, can serve as one mitigatory tool in a suite of other policy and technology mechanisms in the climate change mitigation movement. Community solar is a way to accelerate the growth of renewable energy in utility grids by helping to offset electricity generation from fossil fuels (SEPA, 2016). Portland, OR is a metropolitan region that's planning to integrate a community solar program into the utility system. A recent state senate bill ("Clean Electricity and Coal Transition Plan") was passed that directs the Oregon Public Utility Commission (OPUC) to establish a community solar program for Investor-Owned Utilities (IOUs). These programs consist of multiple shared solar electric systems where community members can buy or subscribe to the energy generated from the solar arrays; allowing the "owners" or "leasers" to share both the costs and the benefits of the solar energy (Maize, 2015). Projects range in size, from small $25 \mathrm{~kW}$ systems to large "solar farms" generating 30 MW of power. There are a diversity of project scenarios that include varying tradeoffs, such as size, cost, and location (Feldman et al., 2015). Other project factors that vary across community solar programs are the project managers, payment plans, length of contracts, and most importantly, the bill credit rate. 
The bill credit rate, which is applied to the utility bills of community solar participants, is essentially the rate per kilowatt-hour used to value the owner or subscriber's proportion of a community solar project electricity generation (Oregon Administrative Rule 603, 2017). Thus, members get paid back over time for their upfront or monthly investment in the community solar array. In Oregon, the bill credit value will reflect the "Resource Value of Solar" (RVOS), a complex value that incorporates the true costs and benefits of solar power. While the RVOS is currently being investigated in Oregon, the RVOS will either be lower, roughly equivalent, or higher than the current retail rate of power. A low RVOS corresponds to a low bill credit, which causes the payback period for the return on investment in a community solar project to be lengthy. Furthermore, a low bill credit rate in combination with a community solar subscription fee will likely result in a monthly utility bill more expensive than a customer's default utility bill. If the RVOS is almost equal to the default rate of power, then the payback period will be shorter and the utility bill may be unchanged. Finally, if the RVOS study finds that the true cost of solar is valuable relative to other forms of energy, then the bill credit rate will be higher than the retail rate of power. In this case, customers will likely see a lower monthly utility bill and savings in a shorter period of time. Consequently, the RVOS and bill credit have important implications for the affordability of community solar enrollment, which is imperative to the successful diffusion of this practice specifically throughout the Portland market as well as the broader energy landscape of the U.S. 
The degree to which community solar can be a successful energy practice both within Portland and more broadly depends on a multitude of factors. These factors include issues specific to the innovation itself, characteristics of the innovators that intend to adopt community solar, and the setting in which the innovation will be adopted, whether that's the metropolitan area of Portland or across all utility systems within the U.S. These three variables are covered in the Diffusion of Innovation (DOI) Theory (Rogers, 1995), which is a process through which an innovation is spread through members of society over time until it is widely adopted by the public. The DOI theory is a common theoretical framework used to assess the spread of new energy technologies (Jager, 2006). Related to the concept of DOI is the notion of social acceptance; a term that covers three interdependent dimensions of acceptance of an energy innovation: socio-political acceptance, community acceptance, and market acceptance (Wustenhagen et al., 2007). Forecasted social acceptance and intent to adopt renewable energy technologies can be predicted by measuring willingness to participate in new energy practices as well as through consumer attitudes and behaviors (Mallett, 2007). This study focuses on investigating which features of community solar programs will enhance the perceived benefits of participation, which may ultimately influence intent to enroll. Additionally, the factors that most strongly influence willingness to participate in community solar should be marked as the most important policy considerations, as the features of such projects are governed by policy and utility stakeholders. 


\subsubsection{APPLICATION OF THE DIFFUSION OF INNOVATION THEORY}

Community solar can be considered an innovation because it's viewed as a new energy practice. Thus, it's forecasted to undergo a diffusion throughout Portland's energy system due to the recent legislative policies that have enabled its growth. It's unlikely that community solar will achieve a widespread market penetration in Portland simply because the utility structure of default electricity generation is deeply rooted in our energy system. Utilizing the default energy provided by the utility is a behavior fundamental to most energy consumers. Additionally, the application of renewable energy projects and technologies can be considered an inherently more complicated diffusion process than other new consumer products because these projects are bound to existing infrastructures (utility systems) (Wustenhagen et al., 2007). However, because one of the primary goals of community solar development is to transform solar power from a premium product into a practice accessible by all economic tiers, a reasonable market penetration is anticipated with the right policy incentives (SEPA, 2016).

As an innovation, the diffusion of community solar in Portland can be examined through the lens of the DOI theory. This theory states that the adoption of an innovation occurs in five stages, which is influenced by communication channels and characteristics of the potential adopters (Rogers, 1995). Additionally, the attributes of the innovation itself as well as the setting in which the diffusion occurs effect the rate of adoption (Rogers, 2005). This chapter focuses on the characteristics of the innovation; the factors external to the consumer govern the mechanics and logistics of community solar projects. 
The successful adoption of community solar by the market of Portland residents depends on the perceived advantages and disadvantages of enrolling in a community solar project.

Individuals undergo a decision process when they first learn about an innovation. This learning process, initiated by a surge of information via communication channels, helps consumers overcome uncertainties about a product (Wejnert, 2002). The communication process provides evidence about the value of an innovation. This value, measured by the product's relative advantage, compatibility, trialability, complexity, and observability, is perceived by consumers in different ways depending on a consumer's innovativeness and social norms (Rogers, 1995). We can apply these innovation characteristics to community solar by investigating the costs and benefits of enrollment. First, community solar must be perceived as relatively advantageous compared to other energy options, i.e., the default electricity generated by utilities. These advantages can be financial, social, or environmental. For example, if a consumer holds an ecological worldview and places high value on environmental sustainability, then participating in a community solar project can be considered relatively environmentally advantageous over using default utility energy. This is a likely perception because solar energy is widely viewed as a cleaner and more environmental energy source (Bird and Sumner, 2011). On the other hand, if a consumer has high concern for the short-term monetary consequences of joining a renewable energy project, then they might perceive community solar enrollment as relatively financially difficult compared to utilizing default utility electricity. Therefore, consumers who hold dissimilar social norms and values will likely perceive the relative advantages and disadvantages of community solar differently 
(Wejnert, 2002), Assuming money is likely the strongest motivator for residents, it's important for policy-makers to create community solar programs that are perceived as cost-competitive and relatively affordable to ensure successful acceptance among the public. The affordability of community solar is partially dependent upon policy-makers because they're responsible for setting the RVOS, which ultimately affects the bill credit given to community solar participants. Moreover, as community solar is an energy practice designed to be accessible to all socioeconomic classes, prioritizing monetary advantages such as affordable subscription fees and short pay-back periods may be important in the development process (SEPA, 2016).

In line with the notion that consumers hold varying norms and beliefs is the idea that an innovation must be perceived as compatible with an adopter's existing values or needs for successful acceptance (Wejnert, 2002). If participation in community solar does not fit well with a person's energy usage patterns or value systems, then the likelihood of intent to enroll is low. Moreover, if a consumer has high self-interest and does not perceive environmental issues as important, their intent to enroll in community solar may be nonexistent due to incompatibility. Alternatively, community solar enrollment may be another reflection of an individual's environmental values or identity. A diversity of project scenarios offered within a community solar program may increase the compatibility factor for more consumers. The trialability and observability of an innovation are other characteristics important in the diffusion process (Wejnert, 2002). The trialability of the community solar program in Oregon is unknown, as projects have not been developed yet, but trial periods for customers may be considered as many 
consumers will likely be very unfamiliar with this energy practice. Observability is particularly relevant to solar devices because residential solar arrays are quite visible and have been known to be "contagious" (Graziano and Gillingham, 2014). When consumers can observe a technology in use, as well as visibly see the benefits of an innovation, the likelihood of adoption is enhanced (Jager, 2006). This is evident with the case of residential solar PV systems, where seeing others use rooftop solar influences interest in adoption because of the "green envy" phenomenon (Bollinger and Gillingham, 2012). Participation in community solar will not be as observable as directly owning an array because projects are not sited on individual roofs, but using home window stickers to advertise participation (similar to enrollment in voluntary green utility programs) or yard signs may increase the visibility factor.

Lastly, the complexity of an innovation is another attribute that influences a person's decision to adopt (Jager, 2006). If an innovation is easily integrated into a consumer's existing routine and no significant efforts are needed to learn how to use the product, heightened intent to adopt is observed (Rogers, 1995). For example, the process of buying a residential rooftop solar PV system has been perceived as a complicated procedure that requires significant research and time; this complexity likely deters many consumers and acts as a barrier to solar energy adoption (Jager, 2006). Community solar projects may alleviate the complexity factor of solar energy innovations because consumers don't need to learn about the intricate mechanics and logistics behind such programs. 


\subsubsection{SOCIAL ACCEPTANCE OF COMMUNITY SOLAR}

An imperative factor in the successful implementation of new energy technologies and practices is societal acceptance, a concept related to the DOI theory. This

phenomenon is essentially a dynamic social process that influences a consumer's intent to utilize a new technology, where social networks, institutions, and NGOs disseminate information about an innovation which is then exchanged by participating stakeholders (Wustenhagen et al., 2007). The three tiers of social acceptance are socio-political acceptance, the broadest dimension, community acceptance, and market acceptance, the most specific (Wustenhagen et al., 2007). While this study focuses on market acceptance, it's important to acknowledge that all forms of social acceptance are important for the adoption of community solar.

As a new energy practice, the diffusion of community solar in the Portland market can be observed through the social acceptance lens. After projects are developed and sited, success will be measured through participation rates, dependent on whether community solar is accepted by Portland residents, authorities, and investors. Community solar is unique compared to other solar energy options, such as green utility programs or residential rooftop PV systems, because all societal dimensions within the market are affected by its installment. Green utility programs isolate market adoption from the broader social acceptance because consumers are not actually involved in the installment process or physical generation (Bird et al., 2002) but intrafirm and shareholder acceptance are still required support. On the other end of the spectrum of solar options is residential rooftop PV systems, where the appropriate acceptance needed for a successful 
market is the market acceptance by consumers. This individual purchasing decision doesn't greatly impact political or institutional actors; it's a personal consumer choice that benefits the environment. Community solar, which falls in the middle between these two categories, epitomizes the intricacy of the application of renewable energy technologies because all forms of acceptance must occur for its successful diffusion.

Socio-political acceptance, which is the broadest level of social acceptance, covers acceptance by the public, policies, key stakeholders, and policy-makers (Wustenhagen et al., 2007). In a sense, community solar has already been accepted politically in Oregon, as seen by the establishment of the "Clean Electricity and Coal Transition Plan" (SB 1547) and specifically the community solar provision in the bill. Key stakeholder acceptance is a critical component of this pillar, where utilities, solar companies, and project developers must perceive community solar as a worthwhile investment, rather than as a minimum requirement of following the law.

In addition to socio-political acceptance is community acceptance, which narrows the acceptance scope to a more local setting (Wustenhagen et al., 2007). If impacted directly or indirectly, local residents and authorities must approve and accept an energy project before it is successfully sited and installed. The "Not In My Backyard" (NIMBY) notion is argued to be an obstacle in the community acceptance of energy technologies, where residents will state general acceptance for renewable energy, but won't support the project if it's "in their backyard", i.e. within distance of their residence (Wolsink, 2000). This proximity factor of renewable energy has been found to strongly influence public attitudes regarding local projects. The strength and scale of this spatial effect varies 
according to land values and local context (Devine-Wright, 2011). Community solar may embody this effect, where projects localize the energy generation and exemplify the nature of community energy, but also cause problems in the case of using up valuable land. The NIMBY argument for acceptance hindrance, however, has been somewhat replaced with a time dimension of community acceptance. Residential support will follow a "U" curve over time, with initial support in the project planning, lower acceptance during the construction, and then increased support when the project is up and running (Wolsink, 2005). There are other factors that also influence community acceptance of an innovation, such as the procedural and distributional justice of its development (Wustenhagen et al., 2007). Related to these factors are the elements of trust and perceived fairness, which are built on the flexibility, openness, and local involvement of facility owners and investors. Encouraging engagement and collaboration with community members during the planning process for a new energy project can heighten the trust perceived by potential adopters.

The most specific dimension of social acceptance is market acceptance, where consumers and investors are the key players in the market adoption of an innovation. Heiskanen et al. (2013) identified two classifications of market acceptance: "acceptance in principal" and "acceptance in actual adoption and use". These categories are related to the Attitude-Behavior gap; there's a disconnect between favorable attitudes and the actual adoption of renewable energy practices (Claudy, 2013). "Acceptance in principle" may be predicted by assessing attitudes towards renewable energy, a relationship that will be explored in the third chapter of this study. While "acceptance in actual adoption and use" 
is difficult to predict, assessing a consumer's willingness to participate in a renewable energy project is an important precursor to actual adoption. Market acceptance of community solar can be measured and predicted by assessing residents' willingness to participate in these projects. In this paper, "willingness to participate" will be synonymous with "willingness to pay", where participation represents intent to enroll in different community solar project scenarios with respective financial implications. Willingness to participate likely fluctuates with varying costs and benefits of community solar enrollment, which are related to the characteristics of the program itself. Evaluating which features of community solar most strongly influence intent to enroll will have significant inferences for developers and managers of future community solar projects in Portland.

\subsubsection{RESEARCH OBJECTIVES}

The existing literature on the connection between social acceptance and renewable energy practices has recognized an under-researched angle in the renewable energy field; can local initiatives, e.g. renewable energy policies, be translated into a successful market acceptance given very low familiarity among consumers? This investigation is directly relevant to the case study of Portland, where Oregon's Senate Bill 1547 has created an opening for community solar, but the market acceptance of such projects is unknown. The aims of this research study are to contribute to the conceptual understanding of willingness to participate in community solar among Portland residents. Further, I capture the demographic characteristics of Portland residents to assess which factors are influential in predicting willingness to participate. Evaluating the demographic 
and household factors of Portland residents will establish an understanding of the cultural setting in which community solar will be developed. The specific research question guiding this section of the study is: what are the impacts of project features, designs, and demographic factors on Portland residents' willingness to participate in community solar projects?

\subsection{METHODS}

\subsubsection{STUDY AREA}

The City of Portland has the largest population of residents eligible for participation in community solar projects in the state of Oregon, with a population of 632,309 residents (U.S. Census, 2015). Portlanders are served by two Investor-Owned Utilities (IOUs): Portland General Electric (PGE) and Pacific Power, the electricity providers that will be developing community solar programs for their customers. PGE is the largest IOU in the state of Oregon, with most of its service territory located in Portland. Pacific Power serves a smaller proportion of Portland, but has pockets of other territories throughout Oregon and five other Western states. Both utilities are national leaders in terms of voluntary green power program enrollment; PGE has ranked first in the nation for percent of customers enrolling in green programs (roughly 15\%) (OPUC, 2014). High participation rates in green energy programs among Portland citizens may indicate that these residents are willing to pay more for renewable energy. However, most of these green programs emphasize wind energy. Additionally, the climate of Portland is mild and cloudy for portions of the year, where sunshine is mostly concentrated in the 
summer months. The usage of solar power in the form of community solar in Portland may seem infeasible to many residents due to perceived lack of sun resources. Because of these reasons, assessing Portlanders' willingness to participate in community solar projects when solar energy is an underutilized resource in this region is important to the robust development of a community solar program.

Further, the culture of Portland is notorious for being left-leaning and progressive. These cultural characteristics are reflected in a demographic snapshot of the city, where election results for Multnomah county (the county where Portland is located) depict an overwhelming majority (near 75\%) voting for democratic candidates. Craig (2016) found that democrats are more likely to be supportive of clean energy and pro-environmental initiatives than Republicans, thus evaluating willingness to participate in community solar among Portland residents, who are predominantly liberal, will either support or counter this argument.

Another reason I deemed Portland as an appropriate study area for this research is because the city has been a pioneer in climate action planning. The Portland Climate Action Plan (CAP) is a comprehensive document that provides mitigative and adaptive strategies for residents, industry, and businesses to adopt to address climate change. These strategies are suggested to help Portland accomplish an 80 percent reduction in local carbon emissions by 2040 (Anderson et al., 2015). There's a brief section in the Portland CAP that suggests community solar as a potential mechanism to help achieve this goal. Therefore, predicting the market acceptance of community solar may help determine if this practice is valuable in helping Portland achieve its emission reductions. 


\subsubsection{SURVEY DESIGN}

The primary qualitative and quantitative data used in this research were collected through a questionnaire designed for Portland residents. Much of the information used to

develop the survey questions and to provide context for Portland's energy landscape was collected through key informant interviews. These interviews were semi-structured in format and captured information about the legislative and regulatory context for community solar in Oregon, the program details such as location, cost, and size, the potential barriers hindering adoption, and general information on the utility structure and system in Portland. These interviews helped to inform the willingness to participate and community solar portions of my survey, where information regarding the RVOS, bill credit, and project features was used to create realistic, though hypothetical community solar scenarios. Key informants were selected by researching active organizations and participants involved in the community solar rulemaking process. Six key informant interviews were conducted and recorded, each lasting roughly an hour.

The questionnaire, organized into six sections, contained a total of 38 questions, which were divided into categories on general energy, solar energy, community solar, climate change, energy use, and demographics. Most questions used a 5-point Likertscale, ranking, multiple choice, or text-entry structure. The sections of the questionnaire pertinent to the research objectives of this study were the community solar and demographic sections. Prior to the third section of the questionnaire (the community solar segment), I provided a supplementary information page that outlined the basics of community solar, as well as the benefits of enrolling in one. The community solar section 
measured general interest in community solar, preferences for project factors such as management, size, and location (measured on a 5-point bipolar Likert-scale from "Strongly Disagree" to "Strongly Agree"), awareness, timing of adoption, and peer influence on adoption. Perceived complexity was also measured by examining if residents agreed or disagreed that community solar projects would be too complex to work in their neighborhood.

In addition, I asked a willingness to participate question that was structured as a stated preference question. Using this stated preference method, I asked respondents to rate their willingness to join a community solar project contingent on three project scenarios and seven different changes in their utility bill (ranging from $10 \%$ cheaper to $10 \%$ more expensive). These utility bill changes reflected the potential bill credit rates applied to community solar members' electricity bills, where a lower monthly utility bill corresponded to a high bill credit rate and a higher monthly utility bill corresponded to a low bill credit rate. The three scenarios varied based on the location, upfront cost, and size of different plausible community solar project designs. The first scenario was a small community solar project located in a Portland neighborhood that cost $\$ 1,200$ to join upfront. The second scenario was a medium-sized project located in an adjacent rural county that cost $\$ 600$ to join upfront. The third project scenario was a large community solar project located in Eastern Oregon that cost $\$ 300$ to join. The questionnaire ended with a demographic section capturing information about income, education, political views, and other household data. 


\subsubsection{SAMPLING \& IMPLEMENTATION STRATEGY}

As I wanted to include a gradient of demographics within my survey sample and I wanted to cover all geographic regions of Portland, I chose to stratify my sample by choosing two neighborhoods within each of Portland's seven neighborhood districts. These neighborhood districts each have their own specific neighborhood coalition: Central Northeast Neighbors, East Portland Neighborhoods, Northeast Coalition of Neighborhoods, North Portland Neighborhoods, Neighbors West-Northwest, Southwest Neighbors Inc., and Southeast Uplift Neighborhoods. These fourteen Portland neighborhoods were included in the study area to capture a gradient of demographics. Some neighborhoods were lower-income, while others had higher median incomes. As community solar is an energy practice intended to be inclusive of all economic classes, I wanted to include a variety of neighborhoods that had varying economic profiles. I selected the 14 neighborhoods in my sample by numbering every neighborhood listed under each district and then randomly selecting two neighborhoods using a random number generator. The neighborhoods selected were Linnton, Hillside, Kenton, Overlook, Sabin, Sullivan's Gulch, Rose City Park, Madison South, Russell, Hazelwood, North Tabor, Foster-Powell, Multnomah, and West Portland Park (Figure 2.1). 


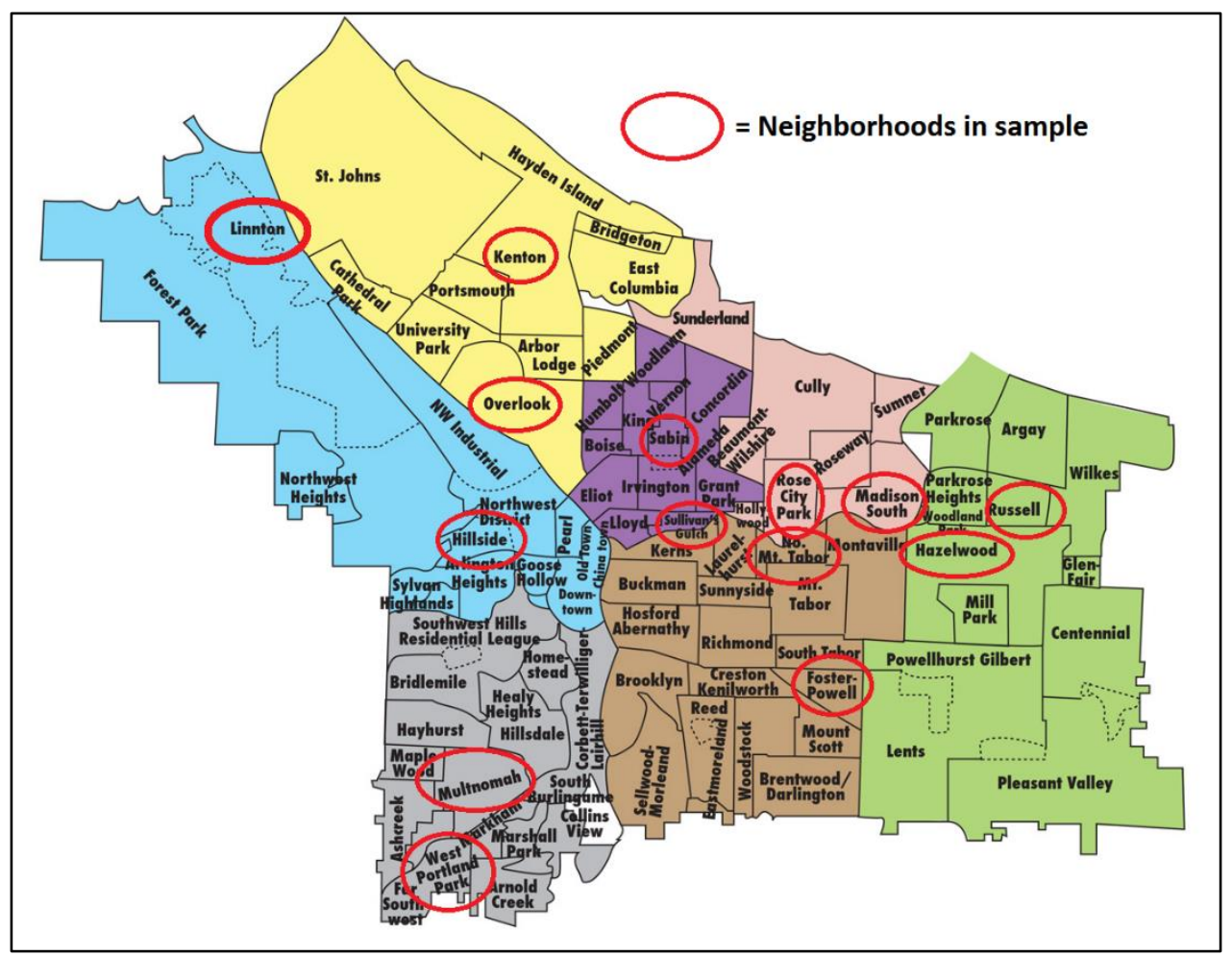

Figure 2.1. Map of randomly selected Portland neighborhoods in survey sample (red circles). This map includes all seven neighborhood districts: Central Northeast Neighbors (pink), East Portland Neighborhoods (green), Northeast Coalition of Neighborhoods (purple), North Portland Neighborhoods (yellow), Neighbors West-Northwest (blue), Southwest Neighbors Inc. (grey), and Southeast Uplift Neighborhoods (brown).

To select eligible households randomly in each neighborhood, I used imagery from Google Maps to number every residential street in each selected neighborhood.

Using a random number generator, I randomly selected five streets in each neighborhood and then numbered each home on every selected street and randomly selected 15 households per street. I recorded the addresses of each selected home in a household database. Thus, there were 75 homes per neighborhood, totaling 1,050 households. This sampling strategy was used to comply with Dillman's (2000) suggestions for representative sample sizes. Eligible survey participants were Portland residents over the 
age of 18 who were the primary utility-bill payers of their household. These residents were either customers of PGE or Pacific Power, as well as homeowners or renters.

The questionnaire was distributed from September to December 2016 using a hybrid distribution approach. Surveys were delivered to households via a modified "Drop-Off/Pick-Up" method (Steele et al., 2016) for the first two rounds of contact. In teams, survey packets containing the paper questionnaire, cover letter, and business reply envelope were either hand delivered to survey participants at their home or dropped off on their front door (if participant was not home) during the first round of contact. One to two weeks later, if a participant had not completed a survey and if they hadn't refused participation, a door-hanger was given to them as a reminder. The survey delivery methodology then transitioned to the Tailored Design Method (Dillman, 2000) for the last two rounds of contact, mailing survey packets and postcards as additional reminders. The survey modes offered were paper or web-based. Surveys were retrieved via three different approaches: picked up in person from the participants' home two days after drop-off (completed survey was left on the front door in a plastic bag provided by the research team), mailed back in a business reply envelope, or completed online.

\subsubsection{DATA ANALYSIS}

Descriptive analyses were performed on multiple response sets for community solar questions to report the response frequencies. Response frequencies of demographic and household variables were also calculated. Additionally, I constructed a logistic regression model to assess how willingness to participate was influenced by project 
factors and demographic characteristics. This analysis doesn't contain stringent rules regarding normality or data continuity. To utilize this statistical method in terms of willingness to participate, I transformed my flat-file data set (structured latitudinally) into a panel form (structured longitudinally) to create a repeated measure database. While longitudinal data sets typically involve repeated observations for each respondent over a period of time, my repeated measure was the utility bill savings or costs associated with enrolling in a community solar project, essentially the "treatment" across seven different percent changes to the respondent's utility bill. The outcome of each treatment was willingness to participate; first measured on a 5-point Likert scale from "Definitely Not" to "Definitely Yes", with "Unsure" in the middle, then recoded to become a dichotomous scale: "Definitely Willing" (1) or "Not Definitely Willing" (0), where "willing" was coded for definitely yes responses and "not definitely willing" all others. This binary response variable was then tested against both demographic variables and project factors to assess their influence on willingness to participate.

For model selection, I built reduced models by eliminating variables from the full model that increased the model Aikake Information Criterion (AIC, a backward step-wise approach). To check for multi-collinearity issues among variables in the model, I calculated the Variance Inflation Factor (VIF). Pseudo r-squared (Nagelkerke r-squared) was calculated to assess the predictive power of the model. In addition to reporting the slope coefficients of each covariate in the model, I also converted the coefficients into odds ratios to evaluate the importance of the variables in the model. These ratios were 
reported along with the confidence intervals. Further, three other logistic regression models were constructed to assess willingness to pay for each project scenario.

These additional regression models were conducted to (1) investigate differences in the mean willingness to pay by scenario and (2) explore how different variables influenced willingness to pay across the three project scenarios. Each model was reduced using the backward step-wise approach to eliminate variables that increased the model AIC or had insignificant p-values. The standard error, mean, and scale of each significant variable were also reported. The VIF was calculated to check for multi-collinearity among variables and revealed no values above 2 . Pseudo r-squared and mean willingness to pay were computed for each model. The equation, $\left(-\left(\alpha+\sum \bar{x} \beta\right) / \beta W T P\right)$, was used to estimate the mean willingness to pay, where $\alpha$ is the intercept constant, $\sum \overline{x \beta}$ is the sum of the products of the covariate means and slope coefficients, and $\beta W T P$ is the slope coefficient of the change in utility bill (presented as a percentage). All statistical analyses were performed in R Studio (Version 3.3.2).

\subsection{RESULTS}

\subsubsection{RESPONSE SUMMARY}

I received a total of 330 completed questionnaires yielding a response rate of $34.2 \%$. The total sample size was reduced from 1,050 households to 965 ; homes that were vacant or had ineligible survey participants were eliminated from the sample. The demographic and household characteristics of the survey respondents are displayed in Table 2.1. 
Table 2.1. Respondent Characteristics. $\mathbf{N}=330$

\% PGE Customers
$\%$ PacifiCorp Customers
$\%$ Enrolled in Green Utility Program
$\%$ Member of Env. Organization
$\%$ Owner-Occupied
Median House Size (in sq. feet)
Median Household Size (\# of residents)
$\%$ Planned length of residence longer than 5
years

$\begin{array}{lll}72.9 \% & \% \text { Living in detached home } & 90.2 \% \\ 26.2 \% & \% \text { Male } & 52.7 \% \\ 36.2 \% & \text { Median Age } & 50 \\ 24.4 \% & \% \text { Bachelor's Degree or higher } & 73.2 \% \\ 80.9 \% & \% \text { Conservative } & 9.7 \% \\ 1,550 & \% \text { Liberal } & 75.4 \% \\ 2 & \% \text { Below \$50k annual income } & 24.1 \% \\ 60.9 \% & \% \text { Above \$150k annual income } & 19.0 \%\end{array}$

Most survey respondents were customers of PGE who resided in single-family detached homes. While Portland has a diversity of renters and homeowners living in all types of households (attached or detached homes, duplexes, condominiums, and apartments), the nature of my survey methodology allowed me to sample primarily from the single-family household demographic.

$45.5 \%$ of survey-takers responded through the mail-based mode, while $48.2 \%$ responded via the web. A very small proportion (6.4\%) opted for the "pick-up" method. The median age of my survey respondents was 50 , which is older than the median age of Portland residents (36.4). An older segment of the population was more represented in my survey likely because utility-bill payers of households tend to be older than the overall age profile of a city. Further, older citizens are usually more likely to take a survey than a younger demographic (Etter and Perneger 1997). 53\% of survey respondents identified as male and $44 \%$ identified as female.

The median house size of my sample was 1,550 square feet, with a median household size consisting of 2 residents. Most respondents believed they would stay in their current residence for at least 5 or 10 years $(61 \%)$, while $15 \%$ were unsure about the 
length of residence. Almost one-quarter of survey respondents reported they were members of an environmental organization, and over $36 \%$ were already enrolled in a voluntary green energy program through their utility. Commonly reported utility programs among respondents were the "Blue Sky" program through PacifiCorp or the "Green Source" program through PGE.

An area of potential bias among survey respondents was educational attainment: $73 \%$ of survey-takers reported having a Bachelor's degree or higher. This statistic is higher than census data of Portland, which reports $45.5 \%$ of citizens older than 25 have a Bachelor's degree or higher. This result is in line with findings that show that survey respondents are more likely to be older and educated (Etter and Perneger 1997). Additionally, survey respondents were very politically liberal; 75\% chose somewhat or very liberal, while $10 \%$ chose somewhat or very conservative. This reflects the liberal and progressive culture of Portland, which is observed in the most recent 2016 election results where three-quarters of Multnomah voters voted for a democratic candidate. As for income, most respondents chose income bins that fell in the middle of the range: $74 \%$ had total household incomes between $\$ 25,000$ and $\$ 150,000$.

Prior to asking specific questions about community solar features, I gauged the participant's level of familiarity by asking if they had any prior knowledge about community solar. Results from this question exposed low awareness among survey respondents: $52 \%$ had never heard of community solar, $47 \%$ had either a little or moderate amount of knowledge, and $1 \%$ felt knowledgeable about community solar. Preferences for different project factors were not extreme, as evident in the response 
distributions in Table 2.2. Larger projects were preferred over smaller community solar projects, where $48 \%$ of respondents agreed that projects should be industrial-scale for affordability and only $19 \%$ agreed that projects should be on the smaller side.

Affordability was more important than proximity to community: $50 \%$ of respondents agreed that projects should be located wherever it's most affordable, even if they're out of sight, while $12 \%$ agreed that they should be visible to the community. Slightly more respondents preferred a community solar project managed by their utility than a private third-party; $33 \%$ and $26 \%$, respectively. Lastly, $36 \%$ of survey-takers agreed with the statement that a monthly subscription plan would be the preferred form of payment for community solar enrollment. Neutral answers made up the bulk of all response distributions. Though not displayed in Table 2, the statement that said "community solar sounds too complex to work in my neighborhood" saw the lowest proportion of agreement and neutrality among all community solar statements: $52 \%$ of respondents disagreed.

Table 2.2. Community solar project preferences

\begin{tabular}{|c|c|c|c|c|}
\hline Project Factor & $\frac{\%}{\text { Agree }}$ & \% Neutral & \% Disagree & $\underline{\mathrm{N}}$ \\
\hline Most affordable location (far from consumer) & $50.00 \%$ & $43.00 \%$ & $7.00 \%$ & 320 \\
\hline Most affordable size (industrial-scale) & $47.80 \%$ & $40.00 \%$ & $12.20 \%$ & 320 \\
\hline Payment through subscription & $36.20 \%$ & $52.00 \%$ & $11.80 \%$ & 320 \\
\hline Managed by utility & $33.10 \%$ & $56.00 \%$ & $10.90 \%$ & 323 \\
\hline Managed by third-party & $26.10 \%$ & $55.00 \%$ & $18.90 \%$ & 322 \\
\hline Relatively small in size & $19.10 \%$ & $63.00 \%$ & $18.20 \%$ & 319 \\
\hline Sited on ground close to community & $11.60 \%$ & $61.00 \%$ & $27.40 \%$ & 320 \\
\hline
\end{tabular}


Frequency analysis of willingness to join among respondents based on utility bill savings or costs across all three projects revealed higher willingness for a lower utility bill (e.g. a bigger bill credit). Project scenario also played a critical role in predicting a respondent's willingness to pay. 57\% of survey respondents were willing to join Project 1, a small-scale local, but relatively more expensive project upfront, if it meant their monthly utility bill would be $10 \%$ lower. That proportion decreased to $19 \%$ if the utility bill would be unchanged and down to $6 \%$ if the utility bill was $10 \%$ higher each month. This negative trend was apparent across all project scenarios. A higher proportion of respondents were probably or definitely willing to join Projects 2 and 3 at a 10\% lower utility bill: $69 \%$ and $84 \%$, respectively. The proportion of respondents unwilling to join rationally followed the inverse pattern, where a low proportion of respondents were unwilling to join at $10 \%$ savings across all scenarios.

\subsubsection{WILLINGNESS TO PARTICIPATE REGRESSION RESULTS}

The output of the binomial logistic regression model (Table 2.3) reveals which project and demographic variables are associated with WTP. WTP was a binary response variable, where $1=$ definitely willing to join, and $0=$ all other responses. Variables that either had insignificant $\mathrm{p}$-values or caused the AIC to increase were removed. The variable that had the strongest influence on WTP was the change in utility bill. The slope coefficient for the bill change was extremely significant, while the Odds Ratio (OR) was very small. The negative slope coefficient (-19.24) and small OR (4.4e-09) indicate a sharp decline in the probability of WTP as changes in the utility bill move from negative (10\% lower) to positive (10\% higher). Other covariates revealed significant slope 
coefficients and Odds Ratios. Project scenario had a significant positive impact on WTP, which represents lower probability of WTP for Project 1 and higher for Project 3. Size of community solar projects was another significant factor that was influential on WTP. If a respondent agreed that community solar projects should be small, the probability of reporting definitely willing to join decreases (also apparent in the corresponding low OR). The opposite is seen when a preference for industrial-scale community solar projects is observed; a higher probability for WTP is associated with the belief that community solar should be sized whatever is most affordable.

Table 2.3. Binomial logistic regression results of willingness to participate in community solar. Pseudo $\mathbf{r} 2=0.34$.

\begin{tabular}{|c|c|c|c|c|c|c|c|}
\hline & Variable & $\beta$ & S.E. & $V I F$ & OR & $\begin{array}{l}2.5 \% \\
C I\end{array}$ & $\begin{array}{l}97.5 \% \\
C I\end{array}$ \\
\hline \multirow{10}{*}{ 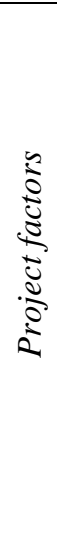 } & Change in Utility Bill & $-\overline{19.24 * * *}$ & 0.85 & 1.08 & $\begin{array}{l}4.4 \mathrm{E}- \\
09\end{array}$ & $\begin{array}{l}8.2 \mathrm{E}- \\
10\end{array}$ & $2.3 \mathrm{E}-10$ \\
\hline & Project Scenario & $0.82 * * *$ & 0.06 & 1.05 & 2.27 & 2.03 & 2.53 \\
\hline & Managed by a utility & 0.07 & 0.06 & 1.17 & 1.07 & 0.95 & 1.21 \\
\hline & Managed by a third party & -0.05 & 0.06 & 1.13 & 0.95 & 0.85 & 1.07 \\
\hline & Small in size & $-0.31 * * *$ & 0.06 & 1.20 & 0.73 & 0.65 & 0.82 \\
\hline & Large in size & $0.22 * * *$ & 0.05 & 1.30 & 1.24 & 1.11 & 1.38 \\
\hline & Close to community & $-0.18 * *$ & 0.06 & 1.20 & 0.83 & 0.74 & 0.94 \\
\hline & $\begin{array}{l}\text { Emphasize affordability; far from } \\
\text { PDX }\end{array}$ & $-0.19 * * *$ & 0.06 & 1.32 & 0.83 & 0.73 & 0.93 \\
\hline & Subscription plans should be used & $0.19 * * *$ & 0.06 & 1.18 & 1.21 & 1.08 & 1.36 \\
\hline & Own or rent home & $-0.33 * *$ & 0.13 & 1.45 & 0.72 & 0.55 & 0.94 \\
\hline \multirow{7}{*}{ 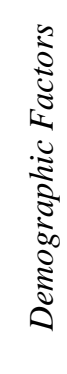 } & Education & $-0.25 * *$ & 0.09 & 1.20 & 0.78 & 0.64 & 0.93 \\
\hline & Political view & $0.40^{* * *}$ & 0.06 & 1.12 & 1.49 & 1.33 & 1.66 \\
\hline & Income & $0.13 * * *$ & 0.03 & 1.43 & 1.14 & 1.08 & 1.20 \\
\hline & Age & -0.03 & 0.04 & 1.34 & 0.97 & 0.91 & 1.04 \\
\hline & $\begin{array}{l}\text { Member of environmental } \\
\text { organization }\end{array}$ & $0.62 * * *$ & 0.10 & 1.16 & 1.86 & 1.53 & 2.26 \\
\hline & Enrollment in green utility option & $0.61 * * *$ & 0.10 & 1.12 & 1.84 & 1.54 & 2.21 \\
\hline & Home square feet & -0.03 & 0.03 & 1.05 & 0.97 & 0.92 & 1.01 \\
\hline
\end{tabular}


Variance Inflation Factors are below 2. Odds ratios are reported along with the corresponding confidence intervals. WTP measured by definitely willing (1) or not (0).

In terms of demographic factors, most characteristics were found to have significant slope coefficients in the model, especially political view, income, environmental organization membership, and green utility program enrollment. A higher political view value represented a liberal-leaning affiliation, thus the more liberal the respondent, the higher probability of WTP. Income has a similar influence, though with less strength. Even more so than income or political view, participation in a voluntary green utility program and membership in an environmental organization were strong predictors for WTP (very significant slope coefficients and high ORs). These results, higher probability of WTP among liberal and higher income residents, are in line with similar findings where WTP for renewable energy is positively correlated with income and politically liberal views (Ek, 2005). Further, the strong positive coefficients of enrollment in environmental organizations and green utility options in the logistic model are related to other findings that show that higher WTP corresponds with environmental awareness and other environmental behaviors (Ek, 2005).

\subsubsection{MEAN WILLINGNESS TO PAY}

Mean willingness to pay was calculated for each project scenario and was reported as a percentage corresponding to change in utility bill. The mean WTP for Project 1 was $-17.1 \%$. This can be interpreted as: the average respondent will report "definitely" willing to join Project 1 if it means their monthly utility bill is $17.1 \%$ lower.

For Project 2, the mean WTP is $-13.1 \%$. And for Project 3, the mean WTP is $-7 \%$; almost 1.5 times higher than the mean WTP for Project 1 . Therefore, the mean WTP increases as 
you move from Project 1 to Project 3, which reflects the negative percent change moving in a positive direction. Table 4 displays the results of three logistic regression models predicting WTP in each project scenario. Pseudo r-squared was calculated to assess the predictive power of each model; Project 3 had the highest r2 (0.341).

The predicted probability of definitely WTP for each project and percent change in utility bill is displayed in Figure 2. The probability of definitely WTP for Project 1 at a $10 \%$ lower utility bill is $27 \%$, while it's over $64 \%$ for the same savings in Project 3 . The probability of WTP decreases dramatically as savings decrease.

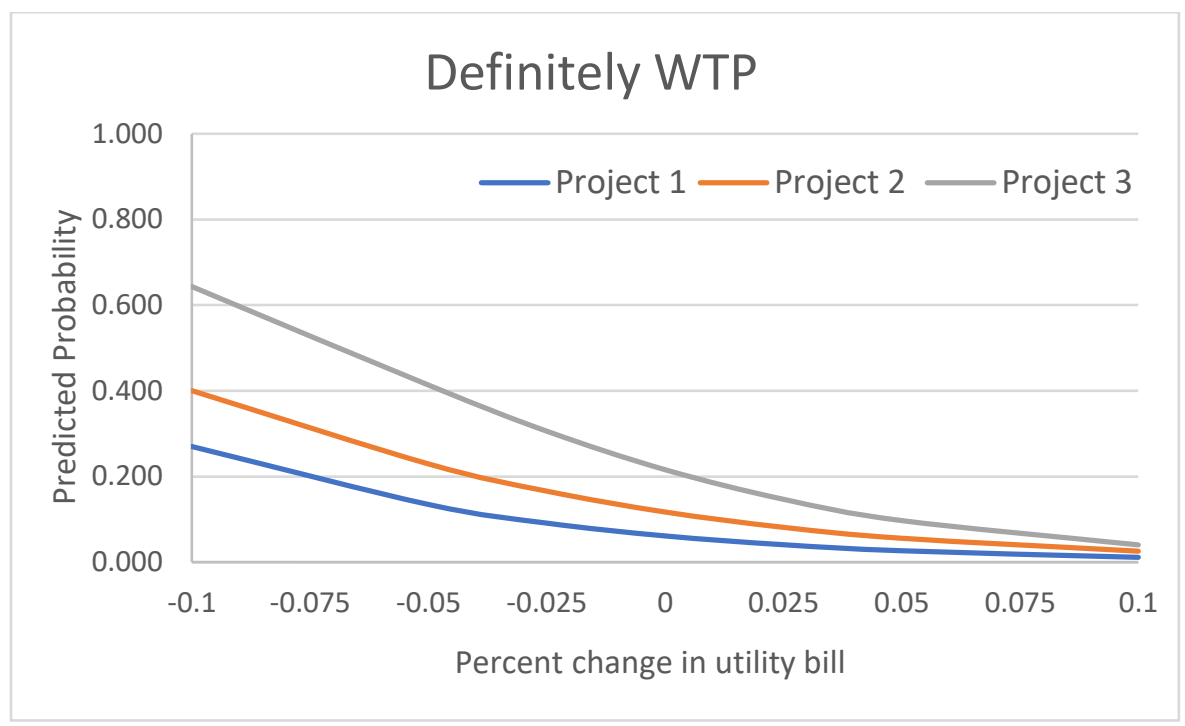

Figure 2.2. Logistic regression model predicting probability of definitely willing to pay at each utility bill change. Lines represent each project scenario. N ranged from 297 to 316.

Most model parameters in the logistic regressions were significant and there were multiple variables that were significant across all three models. Change in utility bill was the strongest factor influencing WTP for every project. Political view was also consistently significant in predicting the WTP probability, although it had a higher positive slope coefficient in Project 1 than the other projects. Thus, politically liberal 
views may be more influential on willingness to join a project that has relatively expensive upfront costs. This is also true in the case of income; it's another significant variable in predicting WTP across all projects, but is most influential in Project 1 and least significant in Project 3, where upfront cost is much lower. Enrollment in an environmental organization and green utility program were other influential variables in all projects that had significant slope coefficients.

Table 2.4. Logistic regression model results of definitely WTP in each project scenario

\begin{tabular}{|c|c|c|c|c|}
\hline \multicolumn{5}{|c|}{ Project 1 WTP. Mean WTP $=-17.1 \%$ change in utility bill, pseudo $r 2=0.275$} \\
\hline$\underline{\text { Variable }}$ & $\underline{\beta}$ & S.E. & $\frac{\text { Variable }}{\text { means }}$ & $\underline{\text { Scale }}$ \\
\hline Change in Utility Bill & $-19.01 * * *$ & 1.84 & $\overline{\mathrm{N} / \mathrm{A}}$ & -0.10 to 0.10 \\
\hline Emphasize affordability; far from PDX & $-0.24^{\dagger}$ & 0.13 & 0.55 & -2 to 2 \\
\hline Small in size & $-0.45 * * *$ & 0.12 & -0.02 & -2 to 2 \\
\hline Large in size & $0.41 * * *$ & 0.12 & 0.47 & -2 to 2 \\
\hline Education & $-0.51 * *$ & 0.20 & 0.43 & 0 to 1 \\
\hline Political view & $0.56^{* * * *}$ & 0.13 & 4.06 & 1 to 5 \\
\hline Income & $0.21 * * *$ & 0.05 & 4.13 & 1 to 8 \\
\hline Member of environmental organization & $0.45^{*}$ & 0.20 & 0.24 & 0 to 1 \\
\hline Enrollment in green utility option & $0.82 * * *$ & 0.19 & 0.36 & 0 to 1 \\
\hline Planned length of stay in current residence & -0.14 & 0.09 & 3.35 & 1 to 5 \\
\hline \multicolumn{5}{|c|}{ Project 2 WTP. Mean WTP $=-13.1 \%$ change in utility bill, pseudo $\mathrm{r} 2=0.279$} \\
\hline Change in Utility Bill & $-17.77 * * *$ & 1.46 & N/A & -0.10 to 0.10 \\
\hline Emphasize affordability; far from $P D X$ & $-0.28 * *$ & 0.10 & 0.55 & -2 to 2 \\
\hline Close to community & $-0.17^{\dagger}$ & 0.10 & -0.23 & -2 to 2 \\
\hline Small in size & $-0.41 * * *$ & 0.10 & -0.02 & -2 to 2 \\
\hline Large in size & $0.17^{\dagger}$ & 0.09 & 0.47 & -2 to 2 \\
\hline Subscription plan should be used & $0.31 * * *$ & 0.10 & 0.22 & -2 to 2 \\
\hline Education & -0.26 & 0.16 & 0.43 & 0 to 1 \\
\hline Political view & $0.37 * * *$ & 0.10 & 4.06 & 1 to 5 \\
\hline Income & $0.15^{* * *}$ & 0.04 & 4.13 & 1 to 8 \\
\hline Member of environmental organization & $0.67 * * *$ & 0.17 & 0.24 & 0 to 1 \\
\hline Enrollment in green utility option & $0.63 * * *$ & 0.16 & 0.36 & 0 to 1 \\
\hline Own or rent home & -0.34 & 0.22 & 0.81 & 0 to 1 \\
\hline
\end{tabular}

Project 3 WTP. Mean WTP $=\mathbf{- 7 \%}$ change in utility bill, pseudo $\mathrm{r} 2=\mathbf{0 . 3 4 1}$

Change in Utility Bill

Managed by a third-party

\begin{tabular}{c|c|c|c|}
\hline$-20.5 * * *$ & 1.29 & N/A & -0.10 to 0.10 \\
$-0.14^{\dagger}$ & 0.09 & 0.07 & -2 to 2
\end{tabular}




\begin{tabular}{|c|c|c|c|c|}
\hline Close to community & $-0.15^{\dagger}$ & 0.09 & -0.23 & -2 to 2 \\
\hline Small in size & $-0.19 *$ & 0.09 & -0.02 & -2 to 2 \\
\hline Large in size & $0.15^{*}$ & 0.07 & 0.47 & -2 to 2 \\
\hline Subscription plan should be used & $0.17 *$ & 0.08 & 0.22 & -2 to 2 \\
\hline Political view & $0.36 * * *$ & 0.08 & 4.10 & 1 to 5 \\
\hline Income & $0.08^{*}$ & 0.04 & 4.13 & 1 to 8 \\
\hline Member of environmental organization & $0.60 * * *$ & 0.15 & 0.24 & 0 to 1 \\
\hline Enrollment in green utility option & $0.52 * * *$ & 0.14 & 0.36 & 0 to 1 \\
\hline Own or rent home & $-0.57 * *$ & 0.18 & 0.81 & 0 to 1 \\
\hline House square footage & $-0.08 *$ & 0.04 & 3.18 & 0 to 8 \\
\hline
\end{tabular}

\subsection{DISCUSSION}

\subsubsection{MONETARY INFLUENCE ON MARKET ACCEPTANCE}

The overarching conclusion from the willingness to participate analysis in this study is that the cost of enrollment will likely be the driving force behind the market acceptance of community solar in Portland, which parallels my hypothesized notion that economic incentives or disincentives are the strongest motivators in a purchasing decision. Several economic aspects of community solar, including the potential costs and benefits of enrollment, are demonstrably the most influential variables in predicting the probability of willingness to participate. The stated preference experiment in the questionnaire revealed that the change in utility bill is the strongest predictor for willingness to participate in community solar. This is evident in all logistic regression models that were constructed as well as simply looking at the frequency response distributions of each community solar project scenario.

The change in a consumer's utility bill can be considered either a benefit or cost associated with community solar enrollment. The utility bill change will largely be 
determined by policy on RVOS, which will result in either a negative change in electricity bill (a benefit), a positive change from additional electricity bill expenses (a cost), or no change. In all logistic regression models, the change in utility bill had an extremely significant negative impact on willingness to pay. The likelihood of willingness to participate declined sharply when savings moved from 10\% to 5\% in all project scenarios, the proportion of respondents probably or definitely willing to participate dropped by $\sim 19 \%$ (on average) across all projects. This decline was more extreme in Project 1, where upfront cost was most expensive. Because change in utility bill was the most influential variable on willingness to participate, it can be said that the bill credit rate will likely be the most important determinant in the market acceptance of community solar in Portland. While the bill credit rate ultimately reflects the RVOS, which is in the hands of policy-makers, the economic implications of the bill credit in conjunction with other fees associated with community solar are significant and should be highlighted for project developers and policy makers.

Less so than the bill credit rate but still highly influential on willingness to participate was the project scenario, which had varying size, location, and upfront cost features. Project 3 had a higher probability of willingness to pay than Project 1. This means that larger projects located away from the consumer (in eastern Oregon) that require an affordable one-time fee are favored over small and local projects that have an expensive upfront fee. Based on the results from Table 2.2, where features such as size and location of projects had high frequencies of neutral responses, it's clear that costs were likely the most important predictors for willingness to participate. Qualitative 
analysis of text-entry comments in the questionnaire also revealed a common theme of cost being the imperative aspect in intent to enroll in community solar.

From these results, I can conclude that market acceptance will be highest among consumers if the economic benefits of enrollment are maximized and the costs are minimized; where the utility bill credit acts as a benefit (high rate associated with high RVOS) and the upfront cost is affordable (several hundred dollars, rather than several thousand). The combined economic effect of minimum costs and maximum benefits will likely result in consumers perceiving community solar as a relatively advantageous energy practice. If the RVOS study finds that solar energy is not valuable compared to other energy sources, then community solar developers must use relatively affordable upfront fees if they want projects to be accepted by the general population. Affordable sign-up fees are realistic in the case of large community solar projects not sited within Portland, due to economies of scale and more affordable land prices. On the other hand, if the RVOS finds that solar energy is valuable relative to other energy sources, then the need for affordable upfront fees is less pronounced. Finding the appropriate balance of economic benefits and costs for community solar enrollment will be challenging for program developers, but will ultimately dictate a successful market acceptance. Of course, the economic benefits of enrollment (the bill credit) lie in the hands of policymakers, thus utilities and project developers will have to adopt project features that will maximize market penetration. These project features are discussed in the next section. 


\subsubsection{INFLUENTIAL PROJECT ATTRIBUTES}

While the five innovation attributes of the DOI theory were not all directly measured in this research, three out of five of the characteristics were implicitly evaluated in the questionnaire: the relative advantage, observability, and complexity of community solar enrollment. The perceived relative advantage was indirectly assessed in the willingness to participate analysis, where economic benefits and costs were found to be vital in causing community solar to be perceived as relatively advantageous compared to other energy options. Other project features relate to the observability and complexity of community solar.

First, the location of a community solar project is related to the observability of the innovation. Projects can be sited locally or far from the consumer. The advantage of a local community solar project is that it localizes the electricity generation and transforms it into a communal product (inherent to the name "community" solar). Local projects would likely have to be small due to limitations on available land in Portland, and thus expensive to develop and participate in. Survey results indicate a very low proportion of respondents agreeing that community solar should be located on a site visible to the community, while most respondents agreed that the site should be at a location most affordable. This trend was also apparent in the willingness to participate analysis, where large and distant community solar projects were preferred over small and local projects. Perhaps the preference for distant projects is related to the NIMBY argument, where residents may have a fear that local solar projects will have an obtrusive presence in Portland neighborhoods, even though most residents support renewable energy in 
principle (Faiers et al., 2007). These results point to the notion that the observability of community solar may not be imperative to the market acceptance of this innovation. Electricity generation has historically and continues to be a product that is invisible and intangible to consumers, which may be the reason the observability of this product isn't an essential feature to its perceived benefits.

Preferred project size was another community solar factor measured in this study. Results indicate that, like project location, affordability takes precedence over other options. Respondents preferred hypothetical community solar projects that were industrial-scale, if it meant that enrollment was cheaper. This pattern is observed again in the willingness to participate analysis, where preferences for smaller projects correlated with lower probability of WTP, while a preference for large projects was associated with higher probability of WTP. Further, Project 3 was ultimately more popular among survey respondents than the other project scenarios because the distant location and large size of the project design allowed the enrollment fee to be affordable. Therefore, larger projects will likely accelerate the market acceptance of community solar because affordability is accentuated and larger projects will reach a larger number of consumers than smaller projects.

Another DOI attribute assessed in this study was the complexity of community solar. One question asked respondents to rate their level of agreement about whether community solar sounds too complex to work in their neighborhood. Most respondents disagreed, indicating they don't perceive community solar as a complicated innovation. The fact that respondents were very unfamiliar with community solar, and yet still didn't 
perceive it as too complex shows that perhaps even with more information, respondents will think of community solar as simple energy practice, ultimately enhancing the potential for market acceptance.

Most respondents reported neutral responses about other community solar project features, such as management and payment plans. The high frequency of neutral answers is likely because community solar is an energy practice so new to consumers, they don't know what they would prefer in a project, since they've never enrolled in one before (as evident in the large proportion of residents reporting no prior knowledge about community solar). Making consumer decisions about electricity is likely a purchasing behavior not common among most citizens, because renewable energy programs are typically opt-in, rather than opt-out. The nature of such programs requires additional action on behalf of the consumer, which causes opt-in programs to see lower participation rates than opt-out. I saw many neutral responses about community solar in my study simply because most consumers don't make decisions about their energy source, thus assessing their preferences for renewable energy projects was likely an unfamiliar cognitive process they had to make. Nudging consumers to actively make decisions about their energy source may help bring renewable energy into the conversation, allowing it to be tangibly accepted by the consumer, rather than just accepted in principle. Of course, community solar projects will have an opt-in structure, but offering these programs in addition to other voluntary green utility programs may compel more consumers to actively make decisions about renewable energy. Further, Portland's energy mix has a high proportion of hydropower which causes default electricity to be relatively affordable 
and possibly perceived as relatively renewable. Studies have shown that WTP for clean energy (non-hydro) is lower in areas that have a high share of hydropower in the electricity mix, which may be the case in Portland (Faiers and Neame, 2006).

\subsubsection{DEMOGRAPHIC IMPLICATIONS}

Four demographic and household characteristics had significant positive influences on willingness to participate in community solar projects. The most powerful predictors for WTP in the logistic regression models were current enrollment in voluntary green utility programs and membership in an environmental organization. These factors can be related to environmental behaviors, because they are purposeful individual actions intended to alleviate environmental issues. While one of the underlying goals for the community solar program in Oregon was to not undermine current renewable energy programs, these results indicate that the same demographic segment interested in paying more for renewable energy will likely be interested in community solar. As community solar is an environmentally beneficial practice, it's likely that environmentally-minded consumers will perceive community solar as an attractive innovation.

Income and political view were other significant predictors for willingness to participate in community solar, though political view had a stronger influence. Income had a significant positive correlation to WTP in each project scenario, though it was more substantial in Project 1 than in the other projects. Thus, if a community solar project has a steep upfront cost to join, then income will be a strong determinant in who decides to enroll. Community solar is intended to expand access to renewable energy and transform 
solar power into an attainable product for all economic tiers. Thus, if a project requires an expensive upfront fee, then lower-income residents might automatically be excluded from the market since the payback period for their investment is unreasonable. Offering financing options or payment plans may alleviate this issue, though project developers should be aware that steep upfront costs act as barriers to many residents. Political view was also positively correlated to WTP, which supports other findings that show that politically-liberal consumers are more likely to invest in renewable energy or environmentally-beneficial initiatives (Polis et al., 2017). Another interesting result from the logistic regression models was that renting your home was influential in predicting WTP in Project 3, which suggests that affordable and large projects may appeal to the renter segment of the market more than small and expensive community solar projects. It should also be noted that demographic and household variables had stronger influences on WTP in Project 1 and 2 than in Project 3, which shows that specific demographic segments will likely accept more expensive community solar projects, but a broader segment of the market (with less focus on economic class or political view) will accept affordable community solar projects.

\subsubsection{STUDY LIMITATIONS \& FUTURE RESEARCH NEEDED}

The results of this study may not be generalizable to the overall population of Portland because a large segment of the market, namely renters, were excluded from the sample. This was due to the nature of the survey distribution methodology: the door-todoor survey delivery of the "Drop-off/Pick-up" method excludes multi-family unit apartment complexes because the main entry into these buildings are often locked. As a 
result of this limitation, single-family detached homes (therefore homeowners) were the dominant demographic in the survey, who are also more likely to have higher incomes (Segal and Sullivan, 1998). Another reason my sample cannot be used to represent the general population of Portland is because highly educated residents were overrepresented in my survey. This is likely due to the theory that older, more educated citizens are more likely to respond to a survey, in addition to being related to the notion that home ownership is affiliated with higher educational attainment (Segal and Sullivan, 1998). Despite these limitations, I believe my survey was adequate at representing the singlefamily, owner-occupied, utility-bill payer demographic segment of the Portland population. Another limitation of my research relates to the stated preference experiment contained in the questionnaire. I chose to utilize a stated preference design rather than a "revealed preference" method because consumers are less likely to have had market experiences with community solar that could be used to "reveal" their true preferences (Polis et al., 2017). The disadvantage of using state preferences to measure willingness to participate is the fact that it's based on consumer intent, rather than observing their actual choices or behaviors. The accuracy of the willingness to participate analysis may be uncertain because Portland residents simply don't fully understand the mechanics and features of community solar, and thus are unknowledgeable about how these projects work. Hence, preferences may not be fully realized until consumers become more familiar with this practice. The accuracy of the willingness to participate analysis was increased, however, by using only definitely willing responses and recoding all other responses as not definitely willing. 
The adoption of community solar as an energy practice is an area in energy policy and research that is understudied, as community solar is such a new method of using solar power. Therefore, there are countless avenues of research needed to fully understand this phenomenon. Specifically, community solar is intended to reach the renter market, because it's currently an untapped opportunity for solar power. This study underrepresented renters, thus I believe additional research is needed to evaluate renter's perceptions and willingness to participate in community solar. Many community solar programs have low-income provisions, including Oregon's program. Research is needed to assess how low-income residents perceive community solar and what additional mechanisms are needed to allow it to be accessible to such consumers. Program evaluation of community solar projects after they are launched in Oregon should occur to measure participation rates and improve possible logistic or mechanical glitches.

\subsection{CONCLUSIONS}

The community solar program in Oregon will help the state and the city of Portland achieve climate change mitigation goals by replacing fossil-fuel generated electricity in the utility grid with a renewable source. Achieving this goal, however, is dependent on how well community solar is accepted by the Portland market, as consumers will be the primary investors of these projects. This study revealed that the economics of enrolling in community solar is the strongest factor influencing consumers' decisions to join a project. More specifically, if the bill credit rate is high enough to lower a participant's utility bill by $10 \%$ or more, then the payback period is likely short enough to appear attractive to the customer. Upfront cost is another influential variable in 
determining market acceptance; expensive one-time fees will likely deter a broad segment of the market. Community solar project features should emphasize affordability, even it means projects are located far from the consumer. Evidently, the "community" aspect of community solar is less important to consumers; community solar projects don't need to be visible to the community or sited locally. This finding may support the theory that NIMBY undermines the observability factor of an energy innovation, or perhaps cost is simply the most dominant motivator.

For community solar to be a successful energy practice that's accessible to renters and low-income residents, economic benefits need to be magnified, which falls in the hands of policy makers. The economic benefit of community solar participation lies in the bill credit rate, which ultimately depends on the RVOS. Thus, if policy-makers, utilities, and project developers seek a successful market acceptance of community solar, equity and environmental benefits must be considered in the RVOS to maximize the bill credit rate, subsequently expanding access to renewable energy. 


\section{CHAPTER 3: ATTITUDES, BELIEFS, \& BEHAVIORS AS PREDICTORS FOR COMMUNITY SOLAR ENROLLMENT}

\subsection{INTRODUCTION}

Climate change is a phenomenon now widely acknowledged by citizens all over the world. However, consumers still do not fully equate their electricity usage with the environmental impact of its generation and consumption (Ellabban and Abu-Rub, 2016). Extreme weather events and climatic variability are predicted outcomes of global warming (already being observed), which are linked to increased demand for electricity, primarily for cooling. Electricity demand for cooling is expected to increase substantially in the U.S. (Mideska and Kallbekken, 2010), following the forecast of increased residential energy use. Carbon emissions from the residential electricity sector are predicted to increase to $21 \%$ of total U.S. emissions by 2020 (up from 17\%) (Langevin et al., 2013). Further, residential energy use accounts for $22 \%$ of total energy consumption in the U.S. (Craig and Allen, 2014). Thus, engagement with residential energy users through policy and practice will be crucial for emission reductions in this sector (Craig, 2016).

Innovative practices and programs in the energy sector will need to be implemented to transition into a cleaner electricity grid (Eleftheriadis and Anagnostopoulou, 2015). New energy practices can be considered innovations, hence it's practical to evaluate the entities involved in the innovation-adoption process, including the potential adopters (consumers) of the innovation. Ratepayers, or customers of 
utilities, can be considered legitimate and salient stakeholders in utility systems because their collective behavior contributes significantly to carbon emissions (Craig and Allen, 2014). Understanding the reactions of ratepayers to joint programs established by utilities and governments is important in forecasting ratepayer energy behaviors. Thus, as utilities across the nation begin to consider new, diversified energy mixes comprised of renewable sources to address our energy challenges, it's important to evaluate ratepayers' preferences and attitudes towards renewable energy (Craig and Allen, 2014).

Community solar, a new energy practice that's typically developed as a joint utility-government program, has been adopted by a number of U.S. states and is being considered by many more. Oregon recently passed senate bill (SB 1547) increasing the state Renewable Portfolio Standard to 50\% by 2040 and is adopting a community solar program for Investor-Owned Utilities (IOUs) under a provision in this bill. The provision directs the Oregon Public Utility Commission to establish a community solar program for IOUs by the summer of 2017, thus the rulemaking process for the program is currently underway. Community solar programs consist of multiple shared solar electric systems where community members can buy or subscribe to the energy generated from the solar arrays; allowing the "owners" or "leasers" to share both the costs and the benefits of the solar energy (Maize, 2015). Community solar participants get paid back over time for their upfront or monthly investment in the community solar array through a monthly bill credit, a financial benefit. Projects range in size, from small $25 \mathrm{~kW}$ systems to large "solar farms" generating $30 \mathrm{MW}$ of power. There will likely be a range of projects available, because smaller (and local) community solar systems are more expensive to 
implement, while larger solar farms (sited far from the consumer) will be more affordable due to economies of scale and land value. Thus varying tradeoffs such as size, cost, and location will produce a diversity of potential project scenarios. Assessing the attitudes and preferences of ratepayers in relation to community solar projects and renewable energy will help identify attitudinal and demographic determinants of potential adoption.

Participation in a community solar project can be considered a positive energy behavior, in addition to being a pro-environmental action, because it's a behavior that's intentionally pursued to reduce the impact of human activity on the natural world (Stern, 2000). Community solar participation is an energy behavior that positively impacts the global climatic system because it reduces the amount of emissions released from fossilfuel generated electricity. Diffusion of relevant information through effective communication modes are necessary to accelerate the development of this energy behavior. The dissemination of this information and the subsequent obtainment of knowledge and awareness about community solar among residents can be related to the theory of planned behavior (TPB) (Ajzen, 1991). The complex interaction between awareness, knowledge, beliefs, and norms influence a consumer's intention and action related to an energy behavior. The TPB can be useful for identifying determinants of proenvironmental behavior, thus it's a suitable theoretical framework to utilize when evaluating which attitudinal variables hold predictive value in measuring interest to community solar adoption. Beyond the TPB lies the Dual-Interest Theory; a framework that conceptualizes the internal competing interests that motivate behavior (Czap et al., 2012). This theory can also be applied to the evaluation of consumer motivations and 
attitudes towards renewable energy and community solar adoption. The interplay between these two theories, in combination with the added complexities of the attitudebehavior gap for environmental behaviors (Claudy, 2013), will help establish an understanding of the relationship between consumer attitudes towards energy-related issues and potential interest in pursuing a positive energy behavior: community solar participation.

\subsubsection{RESEARCH OBJECTIVES}

The objective of this study is to capture the attitudes of potential future participants of community solar and improve our understanding of the relationship between environmental attitudes and environmental behaviors in terms of a renewable energy innovation. Gauging the awareness of residents in Portland, a city that has politically accepted community solar as a new energy practice, will highlight the knowledge and familiarity levels of future community solar adopters. Assessing the relationship between interest and familiarity with community solar will determine whether awareness and knowledge are important predictive elements in intent to participate in an environmental behavior such as community solar. As many other reports have found, I expect knowledge and awareness about renewable energy and community solar to be low among consumers (Bird and Sumner, 2011). Further, testing the connection between attitudes towards energy, climate change, and interest in community solar will determine whether positive energy attitudes are predictors of intent to enroll. Applying the dual-interest and TPB frameworks to the relationship between community solar interest and energy attitudes will advance our conceptual understanding of 
attitudinal influences. The specific research question being addressed in this study is: what are the characteristics of Portland residents that drive intent to participate in community solar projects? Factors such as awareness and knowledge of renewable energy, solar energy, and community solar specifically are not explicitly asked in the above research question, but I aim to also assess the influence of such variables on attitudes and interest in community solar. Additional investigation of how the TPB and dual-interest theory apply to the adoption of community solar is explored in the subsequent sections.

\subsubsection{THEORY OF PLANNED BEHAVIOR}

The TPB is a framework commonly used to assess the motivations and attitudes behind intent and actual exhibition of pro-environmental behaviors. Therefore, I thought it was a suitable theory to apply to the unestablished connection between interest in community solar enrollment and attitudes towards renewable energy. The TPB is an extension of the Theory of Reasoned Action (TRA) (Ajzen and Fishbein, 1980), with the inclusion of an important element called the perceived behavioral control, which refers to how an individual perceives the ease or difficulty of performing a particular behavior or adopting a practice. The TPB states that behavior occurs as a result of behavioral intention, which is influenced by norms and perceived behavioral control. Perceived behavioral control focuses on how an individual perceives the behavior; the advantages, disadvantages, compatibility, and complexity of a practice, product, or service. These perceptions are also related to the perceived attributes of an innovation in reference to the Diffusion of Innovation Theory (DOI). When an individual perceives an innovation as 
easy to use, compatible with one's beliefs and habits, and relatively advantageous, then their intention to perform or adopt is heightened (Arts et al., 2011).

Subjective norms are other elements that have been found to motivate human action. According to Cialdini (2003), there are two categories of social norms that influence an individual's motivation to perform a behavior. Injunctive norms relate to behaviors that are perceived as socially acceptable or unacceptable, while descriptive norms refer to behaviors that are commonly exhibited, i.e., popular. In his study on normative messaging in environmental communication, Cialdini (2003) found that setting these two social norms in line with each other, rather than against each other, when communicating messages about pro-environmental behavior has significant implications for successful social influence. Further, social influence and strong social norms have been found to be prerequisites for the adoption of pro-environmental behavior (Ozaki, 2011).

In addition to subjective norms and perceived behavioral control, there are other factors that determine environmental behavior. These include environmental awareness, environmental knowledge, and environmental attitudes (Lin, 2015). Research has shown a positive correlation between environmental knowledge and environmental attitudes and behaviors. Tanner and Kast (2003) found that when consumers hold significant knowledge of environmental issues, the execution of positive environmental behavior is to be expected. Unfortunately, the link between environmental knowledge, attitudes, and actual behaviors is not so simple, as reflected in the gap between general public support for renewable energy and the relative short supply of successfully implemented 
renewable energy projects. The mismatch between a consumer's expressed preferences for green products and practices and their actual unwillingness to adopt is termed the “attitude-behavior gap" (Claudy, 2013). The TPB thus fails to account for this gap, because it states that environmental attitudes are key predictors of pro-environmental behaviors. Investigating the reasons behind the attitude-behavior gap could help highlight the barriers for adoption of certain behaviors, such as renewable energy technology application.

Participation in a community solar project can be considered a pro-environmental behavior because it aids in mitigating climate change through reducing fossil fuel usage. Thus, according to the TPB, the likelihood of community solar adoption and interest in enrollment would increase when preceded by community solar awareness and knowledge, and positive perceptions about renewable energy. Additionally, potential interest in community solar would also be influenced by participant's social norms in regards to pursuing a solar energy option and their perceptions of the practice. Other potential motivators for community solar adoption relate to environmental norms, such as the belief that climate change has serious implications for all life on Earth and needs to be dealt with in some way. Related to this normative belief is the notion that proenvironmental behaviors often involve personal sacrifices that help the long-term interest of the public. This can be applied to enrollment in community solar projects: adoption may involve some short-term economic sacrifice (upfront cost to join) that will ultimately aid in the fight against climate change, which provides collective, long-term benefits for humanity and the environment. Environmental norms influence consumers' preference 
orderings as well; people typically hold either private preferences, where they value goods that affect their personal utility, or public preferences, which reflect moral values about what they believe is right for society or the environment (Sagoff, 1988). This divide between public and private is related to the Dual-Interest theory, which is explored in the next section.

Investigating the link between attitudes towards energy, climate change beliefs, awareness and knowledge of renewable energy, solar energy, and community solar, and potential interest in joining community solar will establish an understanding of how the diffusion of community solar will be influenced by attitudes, norms, and beliefs. While the imperfections of the TPB were outlined above, it should be noted that many studies have found that when consumers report intent and interest in adopting an innovation, the likelihood of actually purchasing is still higher (Ajzen, 2001). However, to address the potential attitude-behavior gap apparent between reported interest in community solar and solar energy and actual adoption rates, perceived barriers associated with the purchase of solar energy options will be measured to gauge the potential obstacles hindering solar adoption.

\subsubsection{DUAL INTEREST THEORY}

Human behavior is argued to be one of the lead contributors to our modern ecological problems. Thus, viewing behavior change as a solution for resolving environmental issues is logical (Beretti et al., 2013). It should be noted that behavioral solutions for our environmental problems should be explored in conjunction with other 
possible tools, such as regulatory and technological innovations. Behavioral change can be related to the term 'behavioral capital', which refers to the notion that altering citizens' behaviors can affect improvement in environmental quality (Beretti et al., 2013). Behavioral research has found that behaviors can be explained and interpreted through underlying norms and interests that often compete with one another. The dual interest metaeconomics framework includes a theory that recognizes two human tendencies that act as motivating forces in behavior: egoistic-hedonistic based self-interest and empathysympathy based other-interest (Czap et al., 2012). The egoistic-hedonistic self-interest contributes to behaviors that enhance financial and personal utility; relating to a private dimension. The empathy-sympathy other-interest is a force that contributes to "stewardly" or "social" behaviors, which improve the community. The adoption of proenvironmental behaviors puts an emphasis on the importance of the other-interest because mitigating environmental problems through individual behavior will benefit the public, rather than just the self. These internal forces coexist in the individual and help determine intentions in decision-making.

The dual-interest theory is relevant to the adoption of community solar because it forces individual decision-makers to evaluate the tradeoffs of community solar enrollment. Participating in community solar includes both self and other-interest benefits, but they are temporally-dependent. Self-interest puts value on how much a good, service, or behavior increases the utility of an individual. This utility relates to the perceived costs and benefits associated with adopting the particular product or behavior. Financial motives are most commonly considered self-interest forces. The financial 
dimension of participating in community solar may be perceived as damaging to the economic self-interest, because the up-front cost of enrollment is more expensive than simply opting to use the default utility electricity. However, the economic value of community solar enrollment may be heightened when the time frame is considered; an individual may save money in the long term if the bill credit rate is substantial enough (the bill credit is the rate at which community solar members are paid back for their proportional share of solar electricity generation). More specifically, the return on investing in a community solar project may have a relatively short pay-pack period, which will ultimately benefit the economic self-interest of participating individuals. Other personal benefits of community solar participation involve the Renewable Energy Certificates owned by the participants as well as potential tax advantages. Therefore, selfinterests such as long-term financial incentives can be significant motivating factors in community solar enrollment.

Participating in renewable energy projects also benefits the community and the environment. Thus, the other-interest may act as a strong motivating factor in community solar participation. Enrolling in a community solar project will help bring more renewables online for the utility, which will consequently supplant coal-fired electricity in the grid. Reducing fossil-fuel generated energy subsequently decreases the emissions (carbon, methane, and pollutants) associated with generation, and therefore aids in climate change mitigation. Climate change globally impacts all communities, thus engaging in a project or behavior that potentially lessens the effects of such a harmful phenomenon can be considered a socially and environmentally beneficial action. 
Residents who perceive climate change as a serious threat and who hold a positive attitude about renewable energy may also contain a strong other-interest motivation to join a community solar project. As both internal motivators will likely come into play when residents are making a decision about enrolling in community solar, using the dualinterest framework will be helpful in conceptualizing how self-interests and otherinterests shape attitudes towards renewable energy and potential interest in enrolling.

\subsection{METHODS}

\subsubsection{STUDY AREA}

The City of Portland has the largest population of residents eligible for participation in community solar projects in the state of Oregon, with a population of 632,309 residents (U.S. Census, 2015). Portlanders are served by two Investor-Owned Utilities (IOUs): Portland General Electric (PGE) and Pacific Power, the electricity providers that will be developing community solar programs for their customers. PGE is the largest IOU in the state of Oregon, with most of its service territory located in Portland. Pacific Power serves a smaller proportion of Portland, but has pockets of other territories throughout Oregon and five other Western states. The climate of Portland is mild and cloudy for portions of the year, where sunshine is rare during most of the year. The usage of solar power in the form of community solar in Portland may seem infeasible to many residents due to perceived lack of sun resources. Assessing interest in community solar among Portland residents, because solar energy is an underutilized 
resource in this region, is important to the development of a successful community solar program.

Another reason I deemed Portland as an appropriate study area for this research is because the city has been a pioneer in climate action planning. The Portland Climate Action Plan (CAP) is a comprehensive document that provides mitigative and adaptive strategies for residents, industry, and businesses to adopt to address climate change. These strategies are suggested to help Portland accomplish an 80 percent reduction in local carbon emissions by 2040 (Anderson et al., 2015). There's a brief section in the Portland CAP that suggests that community solar could be one mechanism to help achieve this goal. Therefore, assessing the familiarity of Portland residents in terms of the Portland CAP will possibly reveal the baseline awareness of this plan and whether residents are aware that community solar is considered a climate change mitigation tool.

\subsubsection{SURVEY DESIGN}

The primary qualitative and quantitative data used in this research were collected through a questionnaire designed for Portland residents. Much of the information used to develop the survey questions and to provide context for Portland's energy landscape was collected through key informant interviews. These interviews were semi-structured in format and captured information about the legislative and regulatory context for community solar in Oregon, the program details such as location, cost, and size, the potential barriers hindering adoption in Portland, and general information on the utility structure and system in Portland. Key informants were selected by researching active 
organizations and participants involved in the community solar rulemaking process as well as local solar companies and environmental nonprofits. Six key informant interviews were conducted and recorded, each lasting roughly an hour.

The questionnaire, organized into six sections, contained a total of 38 questions, which were divided into categories on general energy, solar energy, community solar, climate change, energy use, and demographics. Most questions used a 5-point Likertscale, ranking, multiple choice, or text-entry structure. The questions in the survey that measured variables relevant to this study inquired about knowledge, awareness, perceived barriers, energy attitudes, climate change beliefs, community involvement, and peer influence. The dependent variable was measured through a question asking the respondent to rate their level of interest in joining a community solar project.

Awareness, familiarity, and knowledge of energy topics were evaluated in six questions. Awareness was measured using a 5-point Likert scale that asked respondents to report their level of familiarity with four solar options (from 'Not at all familiar' to 'Very familiar'): voluntary green utility programs, community solar programs, leasing rooftop solar panels, and owning rooftop solar panels. Further measurement of community solar awareness was conducted through a question asking respondents to report how much prior knowledge they had about community solar (from 'Never heard of them' to 'I know a great deal'). Knowledge was assessed in three questions, asking respondents to rate their knowledge level in terms of renewable energy in general and solar energy. Further, I asked respondents to choose the correct proportion of renewable energy (non-hydro) in Portland's electricity mix to gauge how knowledgeable they were 
about Portland's usage of renewable energy. Finally, I asked my survey respondents to rate their awareness level of the Portland CAP.

Attitudes and beliefs towards energy and climate change were other variables I wanted to test against my variable of interest. I provided positive and negative statements about renewable energy, climate change, and local impacts of climate change and then asked respondents to rate their level of agreement. Further, to assess whether there are significant perceived barriers to utilizing solar energy among the Portland market, I included a bank of barrier statements and asked respondents to rate their agreement. The purpose of capturing the barriers of solar energy was to investigate what may possibly hinder the diffusion of community solar and other forms of solar energy in Portland, whether it's a lack of information available or for economic reasons. Lastly, elements of social influence and community engagement were measured to examine whether interest in community solar was heightened among residents actively involved in community activities or if they knew their peers were participating in community solar as well.

\subsubsection{SAMPLING \& IMPLEMENTATION STRATEGY}

As I wanted to include a gradient of demographics within my survey sample and I wanted to cover all geographic regions of Portland, I chose to stratify my sample by choosing two neighborhoods within each of Portland's seven neighborhood districts. These neighborhood districts each have their own specific neighborhood coalition: Central Northeast Neighbors, East Portland Neighborhoods, Northeast Coalition of Neighborhoods, North Portland Neighborhoods, Neighbors West-Northwest, Southwest 
Neighbors Inc., and Southeast Uplift Neighborhoods. Fourteen Portland neighborhoods were included in the study area to capture a gradient of demographics. Some neighborhoods were lower-income, while others had higher median incomes. As community solar is an energy practice intended to be inclusive of all economic classes, I wanted to include a variety of neighborhoods that had varying economic profiles. I selected the 14 neighborhoods in my sample by numbering every neighborhood listed under each district and then randomly selecting two neighborhoods using a random number generator. The neighborhoods selected were Linnton, Hillside, Kenton, Overlook, Sabin, Sullivan's Gulch, Rose City Park, Madison South, Russell, Hazelwood, North Tabor, Foster-Powell, Multnomah, and West Portland Park.

To select eligible households randomly in each neighborhood, I used imagery from Google Maps to number every residential street in each selected neighborhood. Using a random number generator, I randomly selected five streets in each neighborhood and then numbered each home on every selected street and randomly selected 15 households per street. I recorded the addresses of each selected home in a household database. Thus, there were 75 homes per neighborhood, totaling 1,050 households. This sampling strategy was used to comply with Dillman's (2000) suggestions for representative sample sizes. Eligible survey participants were Portland residents over the age of 18 who were the primary utility-bill payers of their household. These residents were either customers of PGE or Pacific Power, as well as homeowners or renters.

The questionnaire was distributed from September to December 2016 using a hybrid distribution approach. Surveys were delivered to households via a modified 
“Drop-Off/Pick-Up" method (Steele et al., 2016) for the first two rounds of contact. In teams, survey packets containing the paper questionnaire, cover letter, and business reply envelope were either hand delivered to survey participants at their home or dropped off on their front door (if participant was not home) during the first round of contact. One to two weeks later, if a participant had not completed a survey and if they hadn't refused participation, a door-hanger was given to them as a reminder. The survey delivery methodology then transitioned to the Tailored Design Method (Dillman, 2000) for the last two rounds of contact, mailing survey packets and postcards as additional reminders. The survey modes offered were paper or web-based. Surveys were retrieved via three different approaches: picked up in person from the participants' home two days after drop-off (completed survey was left on the front door in a plastic bag provided by the research team), mailed back in a business reply envelope, or completed online.

\subsubsection{DATA ANALYSIS}

Exploratory Factor Analysis (EFA) was the process I used to explore the structures of various attitudes and beliefs in my survey in order to create aggregated response variables for logistic regression analysis. EFA is an appropriate tool to use for survey data analysis because it aids in understanding the underlying dimensions of bankstructured survey questions that contain multiple statements. It's important to be aware that EFA comes with several assumptions, such as a large sample size, tested using the Kaiser-Meyer-Olkin index, correlated data (checked through the Bartlett test of sphericity), and multivariate normality. This last assumption cannot be satisfied through Likert-style survey data, thus there are risks associated with the instability of parameter 
estimates. However, given the usefulness of EFA in extracting factors for use in regression, I deemed it a suitable mechanism for analysis.

I utilized EFA for three different questions in my survey to explore whether variables loaded on to each other to form factors. Specifically, I conducted EFA to investigate attitudes towards energy, hypothesizing that my statements would capture "positive", "negative", "indifferent" and "expensive" beliefs about energy. Additionally, I used EFA to explore attitudinal dimensions of climate change beliefs, as well as perceived barriers of solar energy use. To select factors among these variables, I used both a scree test and parallel analysis, and the "varimax" rotation for estimating the factors. Eigenvalues, which measure the variance in all the variables under the selected factor, were also calculated to assess the explanatory power of the factors. If variables loaded well on to each factor, then I created a new index of the mean responses for each question accounted for in the factor. These indices were then applied as independent variables in my attitude logistic regression model.

I constructed a logistic regression model to assess how interest in community solar was influenced by energy attitudes, awareness, knowledge, climate change beliefs, perceived barriers, and general interest in solar power. I used logistic regression analysis because I was able to transform my dependent variable into a binary response variable: very interested or somewhat interested responses were coded as "Interested" (1) and all other responses coded as "Uninterested" (0). Additionally, this analysis doesn't contain stringent rules regarding normality or data continuity. Following the Aikake Information Criterion (AIC), I built a reduced attitude model by eliminating variables from the full 
model that increased the model AIC (a backward step-wise approach). To check for multi-collinearity issues among variables in the model, I calculated the Variance Inflation Factor (VIF). Pseudo r-squared (Nagelkerke r-squared) was also calculated to assess the predictive power of each model. I converted the slope coefficients of each variable into odds ratios to assess the strength of each variable on predicting interest in community solar. Descriptive analyses were also conducted to report the response frequencies, central tendencies, and spreads of the variables used in the attitude models. All statistical analyses were performed in R Studio (Version 3.3.2).

\subsection{RESULTS}

\subsubsection{RESPONSE SUMMARY}

I received a total of 330 completed questionnaires yielding a response rate of $34.2 \%$. Table 3.1 displays the scale, central tendency, spread, and count of each item evaluated in the attitude logistic models.

Most survey respondents reported being slightly or moderately knowledgeable about renewable energy in general, solar energy, and the proportion of renewable energy in Portland's electricity mix. Knowledge about the Portland Climate Action Plan was much lower, in fact almost $85 \%$ of respondents reported being not at all or not very informed about the Portland CAP. Energy conscientiousness was also measured, where 
Table 3.1. Summary of items used in attitude logistic model. Energy attitudes, climate change beliefs, and solar barriers were truncated to form new response variables used in the model.

\begin{tabular}{|c|c|c|c|c|}
\hline \multicolumn{5}{|l|}{ Knowledge } \\
\hline Renewable Energy & $0-4$ & 1.511 & 0.783 & 327 \\
\hline Solar Energy & $0-4$ & 1.505 & 0.785 & 329 \\
\hline PDX Renewable Energy Proportion & $0-2$ & 1.07 & 0.85 & 275 \\
\hline Climate Action Plan & $0-4$ & 0.72 & 0.78 & 319 \\
\hline \multicolumn{5}{|l|}{ Conservation } \\
\hline General Conscientiousness & $0-4$ & 2.340 & 0.634 & 329 \\
\hline \multicolumn{5}{|l|}{ Energy Attitudes } \\
\hline Aids in preventing $C C$ & -2 to 2 & 1.206 & 1.103 & 326 \\
\hline Helps transition away from fossil fuels & -2 to 2 & 1.332 & 0.981 & 325 \\
\hline Reduces our impact & -2 to 2 & 1.388 & 1.033 & 327 \\
\hline $\begin{array}{l}\text { Continue use of fossil fuels because they're } \\
\text { cheaper }\end{array}$ & -2 to 2 & -1.07 & 1.11 & 327 \\
\hline Makes no difference for $C C$ & -2 to 2 & -1.083 & 1.152 & 324 \\
\hline Solar \& wind are costly & -2 to 2 & 0.196 & 1.019 & 326 \\
\hline Plenty of fossil fuels left & -2 to 2 & -0.541 & 1.272 & 327 \\
\hline Renewable energy is overrated & -2 to 2 & -1.492 & 0.930 & 323 \\
\hline Maintenance \& installation are costly & -2 to 2 & 0.463 & 0.946 & 326 \\
\hline Too busy to think about it & -2 to 2 & -1.022 & 1.017 & 325 \\
\hline Never comes to mind & -2 to 2 & -0.884 & 0.993 & 327 \\
\hline Don't care as long as it's affordable & -2 to 2 & -1.206 & 0.977 & 325 \\
\hline \multicolumn{5}{|l|}{ Awareness } \\
\hline Voluntary green utility programs & $0-4$ & 1.673 & 1.261 & 327 \\
\hline Community Solar & $0-4$ & 0.688 & 0.710 & 327 \\
\hline Leasing rooftop solar panels & $0-4$ & 0.789 & 0.976 & 327 \\
\hline Owning rooftop solar panels & $0-4$ & 1.220 & 1.077 & 327 \\
\hline Prior knowledge about community solar & $0-4$ & 0.633 & 0.757 & 324 \\
\hline \multicolumn{5}{|l|}{ Climate Change Beliefs } \\
\hline Not as bad as it's portrayed & -2 to 2 & -1.188 & 1.172 & 314 \\
\hline Nothing we can do to stop it & -2 to 2 & -0.981 & 1.173 & 315 \\
\hline It's a natural phenomenon & -2 to 2 & -0.578 & 1.331 & 313 \\
\hline It's a hoax and conspiracy & -2 to 2 & -1.786 & 0.686 & 313 \\
\hline Dire consequences for all life & -2 to 2 & 1.637 & 0.794 & 317 \\
\hline It's caused primarily by humans & -2 to 2 & 1.194 & 1.095 & 314 \\
\hline \multicolumn{5}{|l|}{ Barriers to solar use } \\
\hline Roof not suited & -2 to 2 & -0.06 & 1.24 & 327 \\
\hline No time & -2 to 2 & -0.49 & 1.17 & 317 \\
\hline Rent my home & -2 to 2 & -1.17 & 1.54 & 305 \\
\hline Not interested & -2 to 2 & -1.14 & 1.05 & 322 \\
\hline Costs too high & -2 to 2 & 0.33 & 1.09 & 321 \\
\hline Too much hassle & -2 to 2 & -0.27 & 1.12 & 321 \\
\hline Lack of knowledge & -2 to 2 & 0.26 & 1.21 & 321 \\
\hline Planning on moving soon & -2 to 2 & -0.23 & 1.38 & 323 \\
\hline Too new to the market & -2 to 2 & -0.74 & 1.02 & 323 \\
\hline Concerns about reliability \& maintenance & -2 to 2 & 0.24 & 1.24 & 325 \\
\hline \multicolumn{5}{|l|}{ Community } \\
\hline Peer Influence & $0-4$ & 1.90 & 1.12 & 319 \\
\hline
\end{tabular}




\begin{tabular}{ccccc} 
Community involvement $* *$ & & & & 329 \\
Interest- dependent variables & $0-7$ & 1.88 & 1.99 & 327 \\
Interest in solar energy & $0-4$ & 2.56 & 0.96 & 324 \\
Interest in community solar & $0-4$ & 2.66 & 0.99 & 324 \\
Timing of community solar adoption & $0-4$ & 2.53 & 0.89 & 321 \\
\hline
\end{tabular}

*Scale definitions for each variable can be found in Appendix A. **Community involvement was calculated by adding number of days spent each year on a community activity and then coding (0 to 7 ) based on frequency.

over $90 \%$ of respondents rated themselves as somewhat or very energy conscious.

Awareness levels were low among respondents: almost $90 \%$ of respondents were unfamiliar with community solar, $81 \%$ were unfamiliar with leasing solar panels, $62 \%$ were unfamiliar with owning solar panels, and $47 \%$ were unfamiliar with voluntary green utility programs. $52 \%$ of respondents had no prior knowledge about community solar before participating in the survey (34\% had a little).

For attitudes towards renewable energy, the majority of respondents agreed with positive statements about energy and disagreed with negative energy statements. Neutral responses were common for statements reflecting the belief that renewable energy is too expensive to utilize. Statements that stressed indifference towards renewable energy were also unpopular among survey respondents. Beliefs towards climate change followed a similar environmentally-leaning pattern; most respondents disagreed with statements that paralleled a denial attitude, while agreed with statements that stressed the seriousness of climate change.

Perceived barriers of solar energy use were not extreme: most respondents reported neutral or negative responses to barrier statements. Though the two barriers that had the highest proportion of respondents agreeing with them were economic and lack of knowledge barriers. Most respondents disagreed with the barrier stating they were not 
interested in pursuing home solar, which is in line with the finding that $50 \%$ of respondents reported being very or extremely interested in having access to solar energy.

Most respondents felt that if they knew a peer who was enrolled in a community solar project, they would be somewhat more likely to join. About $27 \%$ of respondents believed their likelihood of joining would be a lot higher if they knew someone already enrolled, while $\sim 33 \%$ believed their enrollment decision wouldn't be influenced if they already knew someone participating in a project. Another measure of community engagement asked respondents to report their frequency of participating in community activities, such as volunteering at a local school or nonprofit. A total community involvement score was calculated by summing the number of days respondents reported for each activity; e.g. a weekly frequency was given a score of 52 or a once per year frequency was given a score of 1 . These values were added together and then recoded from 0 to 7 ( $0=0$ days, $7=151$ days or more each year). Most respondents engaged in a community activity 0 to 5 days each year $(n=181)$, with volunteering at a local community center or nonprofit being the most frequently selected activities.

The dependent variable used in the logistic regression model was general interest in joining a community solar project. $11 \%$ of respondents reported being not at all or not very interested in community solar, $30 \%$ were unsure, and 59\% were somewhat or very interested in enrollment. There was variability among interest levels across different neighborhoods as well, with some neighborhoods having almost $70 \%$ of respondents interested in community solar and others having less than $40 \%$. To further evaluate interest in community solar, a question was asked to measure the timing of adoption if a 
community solar project was available right now. $7 \%$ of respondents said they would enroll immediately, 58\% would likely enroll after a few months of additional research, $22 \%$ would wait a year to see how projects turned out, and $13 \%$ would likely never enroll.

\subsubsection{ATTITUDE LOGISTIC REGRESSION RESULTS}

Exploratory factor analysis was conducted on three response banks to explore the underlying structure of the items and to investigate whether variables loaded well onto

new factors. These factors were then applied as new variables in the attitude models. EFA for attitudes towards renewable energy demonstrated four factors accounted for the twelve attitude items. The energy "attitude" factors were beliefs that renewable energy is environmentally beneficial, unnecessary, too expensive, or personally irrelevant (indifference). EFA was also conducted for solar barriers and climate change beliefs, which also had items load well onto factors. The solar barrier factors were: household barriers, time barriers, economically and logistically burdensome barriers, and lack of trust and information barriers. The climate change factors were beliefs related to climate change denial and beliefs that climate change is a serious threat. Two other climate change items didn't load onto the factors; thus they were kept as separate variables. To account for these new factors, the mean was calculated for each item loaded onto the factor, creating an index used in the attitude models.

Two attitude models were created to predict interest in community solar, one being a full model that included all attitude, awareness, belief, knowledge, and barrier 
items, and the other being a reduced model built through the AIC backward-step approach (also eliminating items that had insignificant p-values). Table 3.2 displays the results of the logistic regression, where model coefficients are presented as odds ratios to reveal the predictive strength of each item. Pseudo r-squared was calculated for each model, with the full model having an $r^{2}$ of 0.50 and the reduced model an $r^{2}$ of 0.47 . An ANOVA test revealed no significant difference between the two models.

The regression results revealed that having a general interest in solar energy is the strongest predictor for having interest in community solar $(\mathrm{OR}=3.83, \mathrm{p}=2.9 \mathrm{e}-08)$. Attitudes towards renewable energy were other items that were influential in predicting community solar interest. The belief that renewable energy is environmentally beneficial had a strong positive influence on community solar interest $(\mathrm{OR}=2.02, \mathrm{p}=0.001)$, while the belief that renewable energy is unnecessary (negative attitude) had a strong negative influence on community solar interest $(\mathrm{OR}=0.29, \mathrm{p}=4.7 \mathrm{e}-05)$. The belief that renewable energy is costly compared to other energy sources also had a negative influence on interest in community solar, though not as significant as the other attitude items.

Awareness and familiarity were somewhat influential on community solar interest as well. Specifically, being familiar with community solar was negatively associated with having an interest in community solar. This result may be due to the fact that almost all respondents reported being unfamiliar with community solar (1\% reported familiarity with community solar). Being familiar with owning solar panels had a positive influence on predicting interest in community solar. Additionally, knowledge regarding the Portland CAP had a slightly positive predictive strength in community solar interest. An 
interesting result from the model revealed that energy conscientiousness was negatively associated with interest in community solar. Again, this may be because there was little variability in these responses; almost all respondents reported being either somewhat or very energy conscious.

Items categories that were not influential in the logistic regression model were climate change beliefs, solar barriers, and community involvement. No solar barriers had significant p-values and their corresponding odds ratios were all close to 1 . This is likely because solar barriers were not perceived as significant; most survey respondents disagreed or felt indifferent about the listed barriers.

Table 3.2. Results of logistic regression coded to predict interest in community solar. Somewhat or very interested $=1(n=192)$, all others $=0(n=132)$. Significant levels: ${ }^{\prime}$ $(<0.1), *(<0.05), * *(<0.01), * * *(<0.001)$. Coefficients are presented as odds ratios. Nagelkerke $R^{2}$ presented.

\begin{tabular}{|c|c|c|}
\hline & Full Model & Reduced Model \\
\hline \multicolumn{3}{|l|}{ Knowledge } \\
\hline Renewable energy knowledge & 0.82 & \\
\hline Solar knowledge & 1.53 & \\
\hline CAP knowledge & $1.89 *$ & $1.54^{\dagger}$ \\
\hline PDX renewable energy knowledge & 0.98 & \\
\hline \multicolumn{3}{|l|}{ Awareness \& Familiarity } \\
\hline Prior CS knowledge & 0.77 & \\
\hline Familiarity with $C S$ & $0.42 *$ & $0.40 *$ \\
\hline Familiarity with leasing solar & 0.94 & \\
\hline Familiarity with owning solar & 1.38 & $1.44^{*}$ \\
\hline Familiarity with green utility programs & 0.99 & \\
\hline \multicolumn{3}{|l|}{ Renewable Energy Attitudes } \\
\hline Environmentally beneficial & $2.03 * *$ & $2.02 * *$ \\
\hline Too expensive & $0.61 *$ & $0.62 *$ \\
\hline Indifference & 1.39 & \\
\hline Unnecessary & $0.20 * * *$ & $0.29 * * *$ \\
\hline \multicolumn{3}{|l|}{ Climate change beliefs } \\
\hline It's out of our hands & 1.30 & 1.28 \\
\hline It's a natural phenomenon & $1.33^{\dagger}$ & 1.28 \\
\hline It's a serious threat caused by humans & 1.18 & \\
\hline Denial & 1.26 & \\
\hline
\end{tabular}




\begin{tabular}{|c|c|c|}
\hline \multicolumn{3}{|l|}{ Perceived Solar Barriers } \\
\hline No time & 0.82 & \\
\hline Economically and logistically burdensome & 1.21 & \\
\hline Uncertainty about info and reliability & 1.14 & \\
\hline Moving or renting & 0.91 & \\
\hline \multicolumn{3}{|l|}{ Community items } \\
\hline Peer influence & 1.17 & \\
\hline Community involvement & 1.06 & \\
\hline Interest in solar energy & $4.37 * * *$ & $3.83 * * *$ \\
\hline Energy Conscientiousness & $0.45^{*}$ & $0.48 *$ \\
\hline$N=253$ & $r^{2}=0.50$ & $r^{2}=0.47$ \\
\hline
\end{tabular}

Two additional regression models were constructed to further examine the relationship between attitudes and interest in community solar or solar energy. One regression model used "interest in solar energy" as the binary dependent variable. Table 3.3 displays the results of the reduced model predicting interest in solar power.

Perceiving the use of solar energy as economically and logistically burdensome had a significant negative influence on predicting interest in solar, which is different from the community solar interest model where no barriers were negatively influential. Climate change denial was another strong predictor that negatively influenced interest in solar energy. The variables in the model that had significant positive impacts on solar interest were familiarity with solar panel ownership and peer influence. 
Table 3.3. Binomial logistic regression model predicting interest in pursuing solar energy. Pseudo r-squared: 0.42. Binary response codes: $1=$ very or extremely interested in solar, $O=$ neutral or not interested in solar. $N=252$. Significant levels: ${ }^{\dagger}(<0.1)$, * $(<0.05), * *(<0.01), * * *(<0.001)$.

\begin{tabular}{l|cccc}
\hline Variable & $\boldsymbol{\beta}$ & S.E. & VIF & OR \\
\hline Knowledge about RE & $-0.43^{\dagger}$ & 0.24 & 1.44 & 0.65 \\
Familiar with owning solar panels & $0.40^{*}$ & 0.17 & 1.22 & 1.50 \\
Knowledge about the Portland CAP & $-0.37^{\dagger}$ & 0.22 & 1.30 & 0.69 \\
Peer influence & $0.36^{*}$ & 0.15 & 1.05 & 1.43 \\
Solar barrier: economically \& logistically burdensome & $-1.49^{* * *}$ & 0.24 & 1.10 & 0.23 \\
Attitude: Indifference towards RE & -0.39 & 0.21 & 1.15 & 0.68 \\
Belief: climate change denial & $-0.75^{* *}$ & 0.28 & 1.03 & 0.47 \\
\hline
\end{tabular}

The other binomial regression model explored which variables had significant influence on predicting the timing of community solar adoption; whether enrollment would be immediate (if a project was already available) or after time was spent researching and observing the practice of community solar. Table 3.4 displays the reduced model outputs. Covariates that had significant positive influence on timing of adoption were familiarity with green utility programs, prior knowledge about community solar, and the belief that climate change is a natural phenomenon. Variables that were negatively associated with the timing of community solar enrollment were knowledge about solar power, the perception that lack of information and trust were barriers to solar energy utilization, and the attitude that renewable energy is unnecessary. 
Table 3.4. Logistic regression model predicting intended timing of community solar enrollment. Pseudo $r$-squared: 0.45 . Binary response variable codes: $1=$ immediate enrollment, $O=$ enrollment after several months or years. $N=224$. Significant levels: ${ }^{\dagger}$ $(<0.1), *(<0.05), * *(<0.01), * * *(<0.001)$.

\begin{tabular}{l|cccc}
\hline Variable & $\boldsymbol{\beta}$ & S.E. & VIF & OR \\
\hline Knowledge about solar power & $-1.26^{*}$ & 0.49 & 1.81 & 0.29 \\
Familiar with green utility programs & $0.67^{* *}$ & 0.25 & 1.29 & 1.95 \\
Familiar with owning solar panels & $-0.56^{\dagger}$ & 0.33 & 1.43 & 0.57 \\
Prior knowledge about community solar & $0.87^{*}$ & 0.40 & 1.41 & 2.39 \\
Barrier: not enough time & 0.46 & 0.28 & 1.46 & 1.59 \\
Barrier: lack of trust \& information & $-1.87^{* * *}$ & 0.50 & 2.13 & 0.15 \\
Attitude: RE is environmentally beneficial & 0.80 & 0.52 & 1.29 & 2.22 \\
Attitude: RE is expensive & -0.58 & 0.34 & 1.28 & 0.56 \\
Attitude: RE is unnecessary & $-1.10^{\dagger}$ & 0.71 & 1.20 & 0.33 \\
Belief: Climate change is natural & $0.73^{* *}$ & 0.25 & 1.48 & 2.06 \\
\hline
\end{tabular}

\subsection{DISCUSSION}

\subsubsection{AWARENESS AS A BARRIER}

Familiarity and awareness of community solar were measured by two questions in the survey and descriptive statistics revealed that for both questions, survey respondents were very uninformed about community solar. The attitude model demonstrated a negative relationship between awareness of community solar and interest in joining a project. This relationship causes Ajzen's Theory of Planned Behavior to be unclear in the context of community solar. Additionally, my model results don't support other findings (Craig, 2016) that energy program awareness is linked to higher likelihood of participation. Awareness should precede attitudes about a product, which causes intent that dictates a certain action. Because community solar is an innovation that many people have never heard of, and because it has not been implemented yet, consumers have not had the opportunity to form attitudes about community solar. Measuring the link between 
community solar awareness, attitudes, and intent to enroll cannot truly be conducted until the community solar program in Oregon has been implemented and is offered to customers.

The low level of awareness revealed in the survey demonstrates that outreach and marketing campaigns about community solar will be imperative to educating consumers about this energy practice. As gathering knowledge about a practice or product is the first step in forming an attitude about something, as related to both the DOI theory and TPB, disseminating information about community solar quickly will hasten the diffusion process. This trend was also evident when I measured the hypothetical timing of adoption of a community solar project if one was available right now. A very low proportion of respondents stated they would enroll immediately, while the majority said they needed additional time to gather more information about the product. This was also apparent in the timing-of-adoption logistic regression model, where the lack of information and trust barrier of solar adoption was negatively influential in predicting immediate enrollment. Therefore, lack of information could act as a significant barrier to community solar adoption.

Lack of information was one of the most significant barriers perceived among survey respondents in terms of utilizing solar energy. Though the proportion of respondents agreeing with this barrier was still not extreme. Other barriers had high distributions of disagreement and neutrality among survey respondents. Further, there was no relationship between interest in community solar and perceived solar barriers. The overarching observation I made from examining the response distributions of the 
perceived solar barriers was that personal barriers are unlikely the leading reason solar energy is underutilized in Portland. Rather, enabling mechanisms are needed to supply Portland residents with more solar energy options. Thus, community solar policy can potentially act as an enabling mechanism that will increase the utilization of solar energy in Portland.

Perceived solar energy barriers were also measured to assess whether these obstacles are reasons for the attitude-behavior gap among consumers. To reiterate, the attitude-behavior gap states that residents who hold a positive attitude about renewable energy or some other environmental initiative will likely not act upon that attitude due to some barrier blocking the behavior (Claudy et al., 2013). Economic and lack of information barriers were most significant among consumers in terms of solar energy, but the attitude-behavior gap apparent in community solar adoption can't accurately be assessed until community solar projects have been developed. Respondents have already expressed interest in community solar, but true adoption won't be measured until projects have been sited and offered to customers. From the survey results, it may be suggested that if an attitude-behavior gap exists for community solar enrollment, perhaps it's due to a lack of information and knowledge, as this was the most significant barrier for general utilization of solar energy. It can be said that my research findings support the notion that the TPB becomes complicated in the case of energy attitudes and behaviors because of the disconnect between perceptions and actions (Craig, 2016). 


\subsubsection{RENEWABLE ENERGY ATTITUDES \& INTEREST}

The results of the attitude logistic regression model indicate that attitudes towards renewable energy are strong predictors for having an interest in joining a community solar project. The energy attitudes that highlight the positive environmental benefits of utilizing renewable energy can be considered pro-environmental attitudes. These results support other findings that show that environmental concern tends to be a determinant of solar adoption (Schelly, 2014). The energy attitudes that emphasize the costs and burdens of using renewable energy can be considered anti-environmental because they stress the advantages of continued use of fossil fuels (which is inherently harmful to the planet). Thus, these energy attitudes can be related to the internal dual-interests that motivate individuals: the other-interest and the egoistic self-interest.

Holding the belief that renewable energy is environmentally beneficial, essentially carrying a positive attitude about renewable energy, can be considered an injunctive norm because renewable energy use is a socially acceptable practice that benefits society in the long term. This parallels the notion that utilizing renewable energy satisfies the otherinterest because it benefits not just the self, but also our society and environment. The strong positive correlation between interest in community solar and perceiving renewable energy as environmentally beneficial suggests that individuals will distinguish community solar as an environmentally-friendly practice. Therefore, individuals who have environmental attitudes and who hold a strong other-interest are more likely to be interested in enrolling in community solar. 
On the other hand, a strong self-interest may be the motivating factor behind the belief that renewable energy is too expensive and not economically advantageous compared to other energy sources. The logistic regression results demonstrated a strong negative relationship between interest in community solar and believing renewable energy is unnecessary. Perhaps individuals with this belief perceive community solar as too expensive or relatively invaluable compared to using default energy. Or, they believe community solar is simply not necessary because they don't prioritize environment over economics. For these individuals, marketing community solar as an economically advantageous practice will be vital in accelerating the adoption of this innovation. To satisfy the self-interest of these consumers, financial incentives and benefits of community solar participation need to be maximized. As consumers have varying degrees of environmental norms and beliefs, it will be important to educate citizens about the economic benefits of community solar enrollment, not just the environmental benefits.

\subsubsection{STUDY LIMITATIONS \& FUTURE RESEARCH NEEDED}

Assessing the potential attitude-behavior gap of community solar adoption before projects are developed may be helpful in forecasting enrollment barriers, but true evaluation of this phenomenon must occur when the program has been implemented and participation rate data is available. Thus, community solar program evaluation should occur once the projects are up and running; evaluation research could provide solutions and improvements for the local program as well as offer insights for other states or regions developing community solar programs. 
My survey respondents were highly educated, with most reporting having a Bachelor's degree or higher. This high proportion of educated residents does not reflect the education census data of Portland as a whole, thus it should be noted that attitudes expressed in this study may not be generalizable to the entire population of Portland. Despite this, I believe my analysis can provide adequate support for the notion that environmentally-minded individuals are more likely to be interested in community solar than citizens who have a negative attitude about renewable energy. Though renters and multi-family unit dwellers comprised a small proportion of my overall sample, I believe my sample was adequate at representing the single-family household segment of the market, as home owners are affiliated with higher educational attainments and higher incomes (Segal and Sullivan, 1998).

\subsection{CONCLUSIONS}

The objective of this research was to investigate what characteristics of Portland residents drive intent to participate in community solar projects. The logistic regression analysis revealed that pro-environmental attitudes are good indicators of interest in community solar. Enrolling in a community solar project can be considered an environmental behavior, thus the link between environmental attitudes and intent to perform an environmental behavior is supported in this study. However, true measurement of community solar adoption cannot be evaluated until the program in Oregon has been finalized and projects have been sited. Consequently, the potential attitude-behavior gap in the context of community solar is unknown. Yet the analysis of perceived barriers of solar energy show that lack of knowledge and economic reasons are 
the most significant barriers hindering adoption of solar energy, which may potentially apply to community solar adoption as well.

However, most respondents disagreed with the provided barriers about solar energy, which suggests that solar utilization is not hindered through obstacles, but rather through a lack of enabling mechanisms. Educating the public about community solar and disseminating information about the economic advantages of community solar enrollment, with some environmental highlights, could make community solar the enabling tool needed to increase the utilization of solar energy in Portland, as well as the proportion of renewable energy in the utility grid. 


\section{CHAPTER 4: CONCLUSIONS}

Exploring the ways in which energy consumers perceive and accept community solar as a viable energy option will solidify our understanding of this renewable energy innovation. The overarching conclusions I can infer from both chapters of this study are summarized below.

- Affordability is key. Survey respondents preferred community solar features that enhanced the affordability of projects, suggesting that the potential economic benefits are still more important than the social and environmental benefits of renewable energy programs. This may indicate that energy is still perceived as merely an economic commodity rather than a social and environmental good. For renewable energy projects to be successfully adopted by a broad segment of the population, the self-interest (financial utility) must be prioritized over the other-interest (social benefits). Therefore, economic advantages of community solar enrollment must be maximized, and subsequently marketed as such, for Portland residents (and energy consumers broadly) to become aware of this practice.

- Economy over community. Community engagement, peer influence, and other emphasis on communal features, such as local and visible projects, were not important to most of my survey respondents. Factors that enhanced affordability were most influential on willingness to participate in community solar. Thus, characteristics such as large size, sited far from Portland, and 
affordable upfront costs will have a stronger impact on the market acceptance of community solar than features that emphasize community and locality.

- Larger bill credit = larger probability of participation. The willingness to participate analysis of this study demonstrates that the economic benefit of community solar enrollment, i.e., the rate at which consumers are paid back for their investment, is the strongest predictor for participation in community solar. A large bill credit (reflecting a high RVOS) corresponding to monthly utility bill savings and a shorter payback period, in combination with a relatively affordable upfront fee, will likely see the broadest market penetration. A small bill credit rate, which causes minimal or no electricity bill savings, in combination with a steep enrollment fee, will likely see a very small market penetration.

- Environmental behaviors and attitudes are good indicators of community solar interest. Perceiving renewable energy as environmentally beneficial was significantly influential in predicting whether a respondent was interested in pursuing community solar. Having a negative perception of renewable energy, on the other hand, had a negative association with interest in community solar. Positive renewable energy attitudes are correlated with pro-environmental attitudes, as most renewable energy is considered environmentally advantageous compared to fossil fuel energy. Further, environmental behaviors such as voluntary enrollment in a green utility program and environmental organization membership were strong predictors of willingness 
to participate in community solar. This provides evidence that environmentally-minded individuals will be the initial market segment interested in community solar. The relationship between environmental attitudes, behaviors, and reported support for community solar supports other findings that pro-environmental attitudes will produce pro-environmental behavior.

- Demographic factors are most influential in expensive community solar projects. While income and political ideology had positive correlations with willingness to participate in all community solar projects scenarios, they had a stronger influence on WTP probability in the most expensive scenario. This indicates that if community solar programs require steep upfront fees, lowerincome and politically conservative residents will be less likely to join; politically-liberal and higher-income consumers will be the dominant market segment adopting community solar.

- Response neutrality is likely a result of low awareness. Many community solar preference questions in the survey were dominated by neutral answers. This is likely because awareness of community solar was dramatically low among survey respondents. The low level of familiarity relates to the fact that most Portland residents have likely never had market experience with community solar (or any consumer choice in renewable energy, for that matter), thus their preferences are neutral or somewhat uninformed. 
- Perceptions of solar energy barriers were mild, thus solar energy enablers may be necessary for growth. Most survey respondents either disagreed or were neutral about the listed barriers of solar energy utilization. This pattern suggests that an enabling mechanism, where information about the advantages of solar energy (and community solar) is readily available, might be the necessary nudge Portland needs to accelerate the adoption of this resource. A high level of support for community solar among survey respondents may indicate that these programs could be the enabling tool Portland requires to contribute towards its renewable energy and climate change mitigation goals.

- Attitude-behavior gap, willingness to participate, and barriers of enrollment cannot be truly measured until community solar projects have been implemented. Additional research should be conducted to examine the success of community solar after projects have been developed. Once the Portland market has encountered some experience with community solar, then perhaps preferences will be revealed and gaps between support and actual adoption will surface. 


\section{REFERENCES}

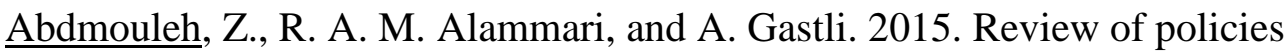
encouraging renewable energy integration \& best practices. Renewable and Sustainable Energy Reviews 45: 249-262.

Anderson, S., M. Armstrong, I. Fish, M. Crim, K. Diesner, T. Evans, D. Williams-Rajee, and T. Lynch. 2015 Climate Action Plan. City of Portland and Multnomah County, Portland Bureau of Planning and Sustainability, Portland, Oregon, USA.

Arts, J. W. C., R. T. Frambach, and T. H. A. Bijmolt. 2011. Generalizations on consumer innovation adoption: A meta-analysis on drivers of intention and behavior. International Journal of Research in Marketing 28:134-144.

Bin, S. and H. Dowlatabadi. 2005. Consumer lifestyle approach to US energy use and the related CO2 emissions. Energy Policy 33: 197-208.

Bird, L., and J. Sumner. 2011. Consumer attitudes about renewable energy: trends and regional differences. Subcontract Report NREL/SR-6A20-50988. U.S. Department of Energy, National Renewable Energy Laboratory, Golden, Colorado, USA.

Bollinger, B. and K. Gillingham. 2012. Peer effects in the diffusion of solar photovoltaic panels. Marketing Science 31: 900-912. 
Brehm, K., P. Bronski, K. Coleman, S. Doig, J. Goodman, T. K. Blank, and T. Palazzi. 2016. Community-scale solar: why developers and buyers should focus on this high potential market segment. Rocky Mountain Institute.

Claudy, M. C., M. Peterson, and A. O’Driscoll. 2013. Understanding the attitudebehavior gap for renewable energy systems using behavioral reasoning theory. Journal of Macromarketing 33:273-287

Coughlin, J., J. Grove, L. Irvine, J. F. Jacobs, S. J. Phillips, L. Moynihan, and J. Wiedman. 2010. A Guide to Community Solar: Utility, Private, and Non-profit Project Development. Department of Energy.

Devine-Wright, P. 2011. Place attachment and public acceptance of renewable energy: A tidal energy case study. Journal of Environmental Psychology 31: 336-343.

Dillman, D. 2000. Mail and Internet Surveys: the Tailored Design Method. John Wiley and Sons, Inc., New York, NY.

Edenhofer, O., R. Pichs-Madruga, Y. Sokana, and K. Seyboth. 2011. Special Report on Renewable Energy Sources and Climate Change Mitigation- Summary for Policy Makers. Intergovernmental Panel on Climate Change.

Ek, K. 2005. Public and private attitudes towards "green" electricity: the case of Swedish wind power. Energy Policy 33: 1677-1689.

Eleftheriadis, I. M. and E. G. Anagnostopoulou. 2015. Identifying barriers in the diffusion of renewable energy sources. Energy Policy 80: 153-164. 
Ellabban, O. and H. Abu-Rub. 2016. Smart grid customers' acceptance and engagement: An overview. Renewable and Sustainable Energy Reviews 65: 1285-1298

Etter, J. F., and T. V. Perneger. 1997. Analysis of non-response bias in a mailed health survey. Journal of Clinical Epidemiology 50: 1123-1128.

Faiers, A., and C. Neame. 2006. Consumer attitudes towards domestic solar power systems. Energy Policy 34:1797-1806.

Faiers, A., C. Neame, and M. Cook. 2007. The adoption of domestic solar-power systems: Do consumers assess product attributes in a stepwise process? Energy Policy 35:3418-3423.

Feldman, D., A. M. Brockway, E. Ulrich, R. Margolis. Shared solar: current landscape, market potential, and the impact of federal securities regulation. Technical Report NREL/TP-6A20-63892. U.S. Department of Energy, National Renewable Energy Laboratory, Golden, Colorado, USA

Gadenne, D., B. Sharma, D. Kerr, and T. Smith. 2011. The influence of consumers' environmental beliefs and attitudes on energy saving behaviors. Energy Policy 39:7684-7694.

Graziano, M. and K. Gillingham. 2014. Spatial patterns of solar photovoltaic system adoption: the influence of neighbors and the built environment J. Econ. Geogr. 15 $815-39$ 
Hamilton, L. C., J. Hartter, M. Lemcke-Stampone, D. W. Moore, and T. G. Safford. 2015. Tracking public beliefs about anthropogenic climate change. PLOS One 10:e0138208.

Heiskanen, E., K., Matschoss, and H. Kuusi. 2013. Report on specific features of public and social acceptance and perception of nearly zero-energy buildings and renewable heating and cooling in Europe with a specific focus on the target countries. D2.6. of the Entranze Project. Intelligent Energy Europe.

Jager, W. 2006. Stimulating the diffusion of photovoltaic systems: A behavioural perspective. Energy Policy 34:1935-1943.

Kollmuss, A. and J. Agyeman. 2002. Mind the Gap: Why do people act environmentally and what are the barriers to pro-environmental behavior? Environmental Education Research, 8: 239-260.

Langevin, J., P. L. Gurian, and J. Wen. 2013. Reducing energy consumption in low income public housing: Interviewing residents about energy behaviors. Applied Energy: 102: 1358-1370.

Maize, K. 2015. Solar gardens: a fast-growing approach to photovoltaic power. Power: $30-33$.

Mallett, A. 2007. Social acceptance of renewable energy innovations: the role of technology cooperation in urban Mexico. Energy Policy 35: 2790-2798. 
Margolis, R. and J. Zuboy. 2006. Nontechnical Barriers to Solar Energy Use: Review of Recent Literature. Technical Report NREL/TP-520-40116 U.S. Department of Energy, National Renewable Energy Laboratory, Golden, Colorado, USA.

Mideska, T. K. and S. Kallbekken. 2010. The impact of climate change on the electricity market: A review. Energy Policy 38: 3579-3585.

O’Shaughnessy, E., J. Heeter, L. Chang, E. Nobler. Status and trends in the U.S. voluntary green power market (2014 data). Technical Report NREL/TP-6A20-65252. U.S. Department of Energy, National Renewable Energy Laboratory, Golden, Colorado, USA.

Price, J. C., I. A. Walker, and F. Boschetti. 2014. Measuring cultural values and beliefs about environment to identify their role in climate change responses. Journal of Environmental Psychology 37:8-20.

Polis, H. J., S. J. Dreyer, and L. D. Jenkins. 2017. Public Willingness to Pay and Policy Preferences for Tidal Energy Research and Development: A Study of Households in Washington State. Ecological Economics 136: 213-225.

Sagoff, M. 1988. The Economy of the Earth. Cambridge University Press, New York.

Schelly, C. 2014. Residential solar electricity adoption: what motivates, and what matters? A case study of early adopters. Energy Research \& Social Science 2: 183-191. 
Segal, L. M. and D. G. Sullivan. 1998. Trends in home ownership: race, demographics, and income. Federal Reserve Bank of Chicago.

SEPA Report: Accelerating adoption of community solar. 2016. Pacific Consulting Group \& Solar Electric Power Association.

Steele, J., L. Bourke, A. E. Luloff, P. S. Liao, G. L. Theodori, and R. S. Krannich. 2001. The drop-off/pick-up method for household survey research. Journal of the Community Development Society 32: 238-250.

U.S. Census Bureau. 2010 Census.

Wejnert, B. 2002. Integrating models of diffusion of innovations: a conceptual framework. Annual Review of Sociology 28: 297-326.

Westaby, J. D. 2005. Behavioral reasoning theory: Identifying new linkages underlying intentions and behavior. Organizational Behavior and Human Decision Processes 98: 97-120.

Wolsink, M. 2000. Wind power and the NIMBY-myth: institutional capacity and the limited significance of public support. Renewable Energy 21: 49-64.

Wolsink, M. 2005. Wind power implementation: the nature of public attitudes: equity and fairness instead of 'backyard motives'. Renewable \& Sustainable Energy Reviews 11: 1188-1207. 
Wüstenhagen, R., M. Wolsink, and M. J. Bürer. 2007. Social acceptance of renewable energy innovation: An introduction to the concept. Energy Policy 35:26832691.

Yang, R. and R. Long. 2016. Analysis of the Influencing Factors of the Public Willingness to Participate in Public Bicycle Projects and Intervention Strategies-A Case Study of Jiangsu Province, China. Sustainability 8: 1-16. 


\section{APPENDIX A. SCALE DEFINTIONS FOR ATTITUDE MODEL VARIABLES}

Knowledge Items

Renewable energy in general \& solar energy

CODE DESCRIPTION

0 Not knowledgeable at all

1 Slightly knowledgeable

2 Moderately knowledgeable

3 Very knowledgeable

4 Extremely knowledgeable

PDX Renewable Energy Proportion

CODE DESCRIPTION

0 Not knowledgeable at all

1 Moderately knowledgeable

2 Knowledgeable

Climate Action Plan

CODE DESCRIPTION

0 Not at all informed

1 Not very informed

2 Somewhat informed

3 Well informed

4 Extremely informed

\section{Energy Conservation}

General Conscientiousness

CODE DESCRIPTION

0 1 Not at all energy conscious

1 Not very energy conscious

2 Somewhat energy conscious

3 Very energy conscious

4 Extremely energy conscious

Energy Attitudes, Climate Change Beliefs, \& Solar Energy Barriers CODE DESCRIPTION

-2 Strongly disagree

-1 Somewhat disagree

0 Neither agree nor disagree

1 Somewhat agree

2 Strongly agree 
$\underline{\text { Awareness Items }}$

Solar energy options

\section{CODE DESCRIPTION}

0 Not at all familiar

1 Not very familiar

2 Somewhat familiar

3 Familiar

4 Very familiar

Prior knowledge about community solar

\section{CODE DESCRIPTION}

0 None at all

1 A little

2 A moderate amount

3 A lot

4 A great deal

\section{Community Items}

Peer Influence

CODE DESCRIPTION

0 Not at all more likely

1 Not much more likely

2 Somewhat more likely

3 Much more likely

4 Very much more likely

Community involvement (number of days each year spent on a community activity)

\begin{tabular}{r|l} 
CODE & DESCRIPTION \\
\hline 0 & 0 days \\
1 & 1 to 5 days \\
2 & 6 to 12 days \\
3 & 13 to 24 days \\
4 & 25 to 50 days \\
5 & 51 to 100 days \\
6 & 101 to 150 days \\
7 & 151 or more days
\end{tabular}


$\underline{\text { Interest Items }}$

Interest in solar energy

CODE DESCRIPTION

0 Not at all interested

1 Not very interested

2 Somewhat interested

3 Very interested

4 Extremely interested

Interest in community solar

CODE DESCRIPTION

0 Not at all interested

1 Not very interested

2 Unsure

3 Somewhat interested

4 Very interested

Timing of community solar adoption

\section{CODE DESCRIPTION}

0 I would never enroll in a community solar program

1 I'm interested, but I can't really see myself doing it in the next few years

2 I'd wait a year or two till more people have done it to see how it works out

3 I'd do some research over the next few months and then maybe I'd enroll

4 Now-within a month 


\section{Appendix B. Renewable Energy \& Community Solar Questionnaire}

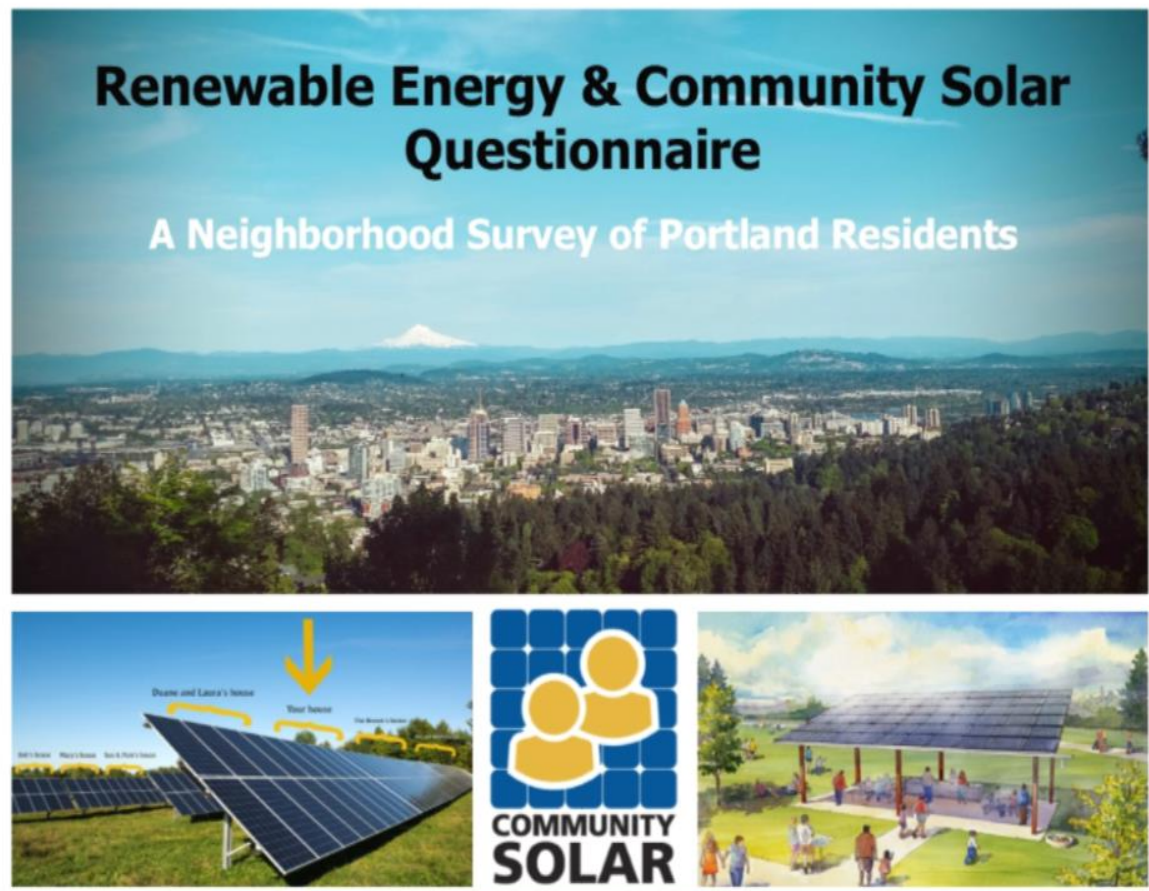

Your help with this effort is greatly appreciated! Thank you!

Community solar allows you to participate in local solar projects when rooftop solar is not possible or desired. At a time when demand for renewable energy, and solar energy in particular, is growing rapidly across the United States, community solar provides an alternative or an addition to your utility's existing renewable energy programs. Recent changes in Oregon law mean that community solar is coming soon to Portland.

This survey is part of my Portland State University (PSU) graduate thesis project designed to understand Portland residents' attitudes towards and interest in community solar. If you have any questions, please call me, Anne Weaver, at 503-608-2730, or email me at weav4@pdx.edu.

\section{Instructions}

- Please carefully read each question and make your responses clear.

- Feel free to write any additional comments anywhere on the survey.

- Put the completed questionnaire in the bag and place it at your door for us to pick up.

- Your responses are completely confidential.

\section{Portland State}




\section{General Energy Questions}

1

Who is your electricity provider?

$\bigcirc$ Portland General Electric (PGE) O Pacific Power $\bigcirc$ I don't know

2

Are you currently enrolled in a voluntary or opt-in renewable energy utility program?
Yes
No
I'm not sure

If yes, please write the name of the program if you know it?

3 What proportion of Portland's energy is generated from renewable energy sources other than hydroelectric (e.g., solar or wind energy)?

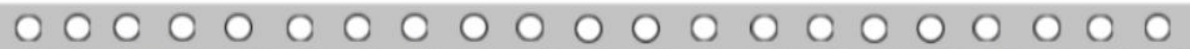

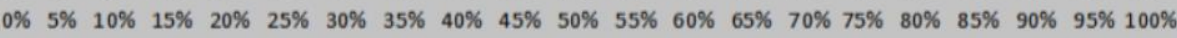

4

To meet future energy demands, what are the top three energy sources that you believe PGE or Pacific Power should invest in for the future? (Select one 5st, one 6nd, and one $7 \mathrm{rd}$ )

\begin{tabular}{|c|c|c|c|}
\hline & 1st & 2nd & 3rd \\
\hline Biofuels & 0 & 0 & 0 \\
\hline Coal & 0 & 0 & 0 \\
\hline Geothermal & 0 & 0 & $\mathrm{O}$ \\
\hline Hydropower & 0 & 0 & 0 \\
\hline Natural Gas & 0 & 0 & 0 \\
\hline Nuclear & 0 & $\mathrm{O}$ & 0 \\
\hline Oil & 0 & 0 & 0 \\
\hline Solar & $\mathrm{O}$ & $\mathrm{O}$ & 0 \\
\hline Wind & 0 & 0 & 0 \\
\hline
\end{tabular}

5

How knowledgeable are you about renewable energy in general? (Select one)
$\bigcirc$ Extremely knowledgeable
$\bigcirc$ very knowledgeable
$\bigcirc$ Somewhat knowledgeable
$\bigcirc$ Not very knowledgeable
$\bigcirc$ Not at all knowledgeable


6 How energy conscious do you consider yourself? (Select one)

$\bigcirc$ Extremely energy conscious

Very energy conscious

$\bigcirc$ Somewhat energy conscious

Not very energy conscious

Not at all energy conscious

7 How much do you agree or disagree with the following statements about energy?

\begin{tabular}{|c|c|c|c|c|c|}
\hline $\begin{array}{l}\text { For each statement, select } \\
\text { one response }\end{array}$ & $\begin{array}{l}\text { Strongly } \\
\text { Agree }\end{array}$ & $\begin{array}{l}\text { Somewhat } \\
\text { Agree }\end{array}$ & Neutral & $\begin{array}{l}\text { Somewhat } \\
\text { Disagree }\end{array}$ & $\begin{array}{l}\text { Strongly } \\
\text { Disagree }\end{array}$ \\
\hline $\begin{array}{l}\text { We should continue using coal, oil, and other } \\
\text { fossil fuels because they are more affordable to } \\
\text { produce }\end{array}$ & $\mathrm{O}$ & $\mathrm{O}$ & 0 & $\mathrm{O}$ & $\mathrm{O}$ \\
\hline $\begin{array}{l}\text { I'm too busy to ever think about renewable } \\
\text { energy }\end{array}$ & O & $\bigcirc$ & $\bigcirc$ & $\bigcirc$ & $\bigcirc$ \\
\hline $\begin{array}{l}\text { We can't produce enough renewable energy to } \\
\text { make a difference for climate change }\end{array}$ & $\mathrm{O}$ & O & O & $\mathrm{O}$ & O \\
\hline $\begin{array}{l}\text { Renewable energy helps prevent climate } \\
\text { change }\end{array}$ & 0 & O & O & O & O \\
\hline Large-scale wind or solar farms would be costly & y $\bigcirc$ & O & O & O & O \\
\hline $\begin{array}{l}\text { Renewable energy will help us transition away } \\
\text { from foreign fossil fuels }\end{array}$ & $\mathrm{O}$ & O & O & O & $\bigcirc$ \\
\hline $\begin{array}{l}\text { I don't really think much about where my } \\
\text { energy comes from }\end{array}$ & $\mathrm{O}$ & O & O & O & O \\
\hline $\begin{array}{l}\text { We aren't going to run out of oil, gas, or coal } \\
\text { reserves anytime soon }\end{array}$ & O & O & O & O & ○ \\
\hline $\begin{array}{l}\text { As long as it's affordable I don't care where my } \\
\text { energy comes from }\end{array}$ & $\mathrm{O}$ & O & $\mathrm{O}$ & O & O \\
\hline The need for renewable energy is overrated & $\bigcirc$ & $\bigcirc$ & $\bigcirc$ & $\bigcirc$ & O \\
\hline $\begin{array}{l}\text { Renewable energy will help reduce our impact } \\
\text { on the planet }\end{array}$ & $\mathrm{O}$ & $\bigcirc$ & $\mathrm{O}$ & O & O \\
\hline $\begin{array}{l}\text { Installation and maintenance costs for } \\
\text { renewable energy technologies are expensive }\end{array}$ & $\bigcirc$ & O & O & O & O \\
\hline
\end{tabular}

\section{Solar Energy \& You}

8 How knowledgeable are you about solar electricity? (Select one)

$\bigcirc$ Extremely knowledgeable

$\bigcirc$ Very knowledgeable

Somewhat knowledgeable

Not very knowledgeable

$\bigcirc$ Not at all knowledgeable 

residence? (Select one)

Extremely interested

Very interested

Somewhat interested

Not very interested

Not at all interested

10 How much do you agree or disagree that the following are barriers for you to pursue a home solar electricity system?

\begin{tabular}{|c|c|c|c|c|c|}
\hline $\begin{array}{l}\text { For each statement, select one } \\
\text { response }\end{array}$ & $\begin{array}{l}\text { Strongly } \\
\text { Agree }\end{array}$ & $\begin{array}{l}\text { Somewhat } \\
\text { Agree }\end{array}$ & Unsure & $\begin{array}{l}\text { Somewhat } \\
\text { Disagree }\end{array}$ & $\begin{array}{l}\text { Strongly } \\
\text { Disagree }\end{array}$ \\
\hline My roof is not suited for a solar array & 0 & 0 & $\mathrm{O}$ & 0 & 0 \\
\hline I don't have the time & & O & O & & \\
\hline I'm not interested in home solar & & $\bigcirc$ & 0 & & \\
\hline The costs are too high & & $\mathrm{O}$ & 0 & & \\
\hline It would be too much hassle & & ○ & $\bigcirc$ & & \\
\hline I don't know enough about home solar & & & & & \\
\hline $\begin{array}{l}\text { I don't plan to live in my place of residence } \\
\text { long enough for it to pay off }\end{array}$ & $\bigcirc$ & $\bigcirc$ & $\bigcirc$ & O & $\bigcirc$ \\
\hline Home solar is too new to the market & 0 & 0 & 0 & 0 & 0 \\
\hline $\begin{array}{l}\text { I'd be concerned about reliability and } \\
\text { maintenance }\end{array}$ & $\bigcirc$ & $\bigcirc$ & $\bigcirc$ & $\Omega$ & $\bigcirc$ \\
\hline
\end{tabular}

11

There are a number of ways to access solar electricity in your home. Please rate your level of familiarity for each of the following options for solar electricity.

\begin{tabular}{|c|c|c|c|c|c|}
\hline $\begin{array}{c}\text { For each statement, select one } \\
\text { response }\end{array}$ & $\begin{array}{l}\text { Very } \\
\text { Familiar }\end{array}$ & Familiar & $\begin{array}{l}\text { Somewhat } \\
\text { Familiar }\end{array}$ & $\begin{array}{l}\text { Not Very } \\
\text { Familiar }\end{array}$ & $\begin{array}{l}\text { Not At All } \\
\text { Familiar }\end{array}$ \\
\hline $\begin{array}{l}\text { Green power program through your } \\
\text { utility, such as PGE's Green Future } \\
\text { Solar voluntary opt-in program }\end{array}$ & $\mathrm{O}$ & O & $\mathrm{O}$ & $\mathrm{O}$ & $\mathrm{O}$ \\
\hline Community or shared solar programs & $\bigcirc$ & $\mathrm{O}$ & $\mathrm{O}$ & $\mathrm{O}$ & 0 \\
\hline Leasing a home solar electricity system & O & O & $\mathrm{O}$ & $\mathrm{O}$ & $\mathrm{O}$ \\
\hline Owning a home solar electricity system & ○ & $\bigcirc$ & $\mathrm{O}$ & $\bigcirc$ & $\mathrm{O}$ \\
\hline
\end{tabular}




\section{How it works:}

1. The solar array captures energy from the sunlight.

2. The electricity generated from the sun energy flows to the electricity grid.

3. The utility calculates the electricity produced and credits the value of that electricity to the members of the community solar program (residents, businesses).

4. The value of the solar electricity produced from the array is applied to each member's utility bill as a monthly credit.

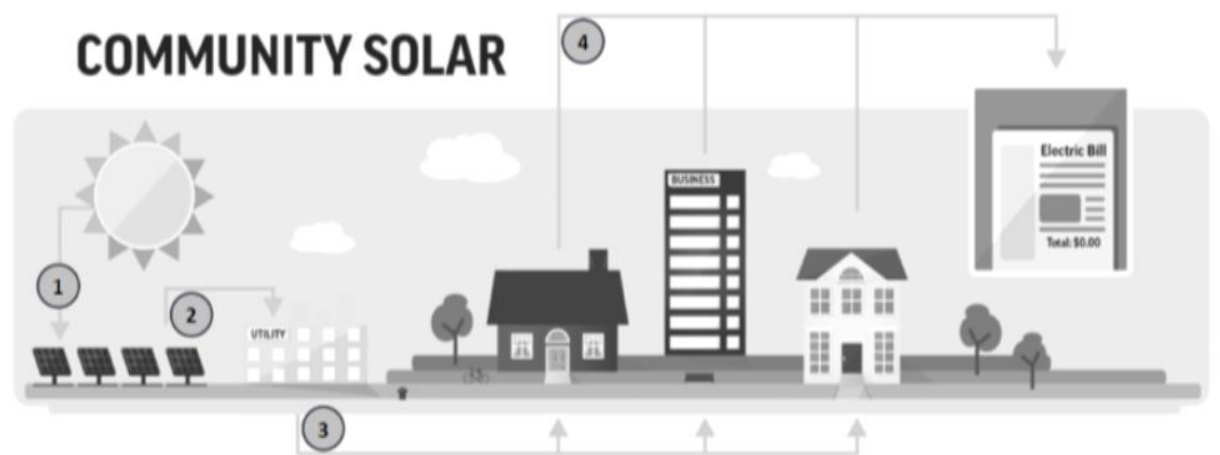

\section{Why Community Solar?}

Oregon's "Clean Electricity and Coal Transition Plan" was passed in 2016 and directs the Oregon Public Utility Commission to establish a community solar program through Investor -Owned Utilities (PGE and Pacific Power) by the summer of 2017.

What is a Community Solar Project?

Community solar projects are solar-electric systems that provide power and financial benefits to multiple people and businesses (as opposed to rooftop solar, which typically only benefits the owner of the roof).

What else is there to know about Community Solar?

Where? Community solar arrays can be developed anywhere in the state. How Big? Projects must be at least $25 \mathrm{KW}$ or enough to power about 3 to 5 homes. Enrollment? Common options: monthly subscription or an upfront payment. Other benefits? Participants will own the Renewable Energy Certificates (RECs) and may be eligible for federal tax credits as well as state solar incentives.

\section{STOP! Please read this page before going on to the next page...}


12 Prior to reading the information on the facing page, how much did you know about community solar (also referred to as shared solar or solar gardens)? (Select one)

I know a great deal

I know quite a bit

I know a little

Heard of, but I know very little

Never heard of them

13

In general, how interested would you be in joining a community solar project? (Select one)

$\bigcirc$ Very interested

Somewhat interested

Unsure

Not very interested

Not at all interested

14 From what you know so far, how much do you agree or disagree with the following statements about community solar?

\begin{tabular}{|c|c|c|c|c|c|}
\hline Select one response for each statement & $\begin{array}{l}\text { Strongly } \\
\text { Agree }\end{array}$ & Agree & $\begin{array}{l}\text { Neither Agree } \\
\text { nor Disagree }\end{array}$ & Disagree & $\begin{array}{l}\text { Strongly } \\
\text { Disagree }\end{array}$ \\
\hline \multicolumn{6}{|c|}{$\begin{array}{l}\text { Community solar sounds too complex to work in } \\
\text { my neighborhood }\end{array}$} \\
\hline \multicolumn{6}{|l|}{$\begin{array}{l}\text { I would prefer to use a monthly subscription } \\
\text { enrollment plan in a community solar project }\end{array}$} \\
\hline \multicolumn{6}{|l|}{$\begin{array}{l}\text { I would prefer a community solar project man- } \\
\text { aged by my electric utility company }\end{array}$} \\
\hline \multicolumn{6}{|l|}{$\begin{array}{l}\text { I would prefer a community solar project man- } \\
\text { aged by a private firm or a nonprofit organization } \\
\text { that is not my utility company }\end{array}$} \\
\hline \multicolumn{6}{|l|}{$\begin{array}{l}\text { Community solar projects should be located } \\
\text { wherever it is most affordable, even if that means } \\
\text { they are out of sight }\end{array}$} \\
\hline \multicolumn{6}{|l|}{$\begin{array}{l}\text { Community solar projects should be located on } \\
\text { the ground where they are visible to the commu- } \\
\text { nity, for example on a vacant lot }\end{array}$} \\
\hline \multicolumn{6}{|l|}{$\begin{array}{l}\text { Community solar projects should be relatively } \\
\text { small; less than } 1 \mathrm{MW} \text {, which would provide } \\
\text { electricity to about } 100 \text { homes in Oregon }\end{array}$} \\
\hline $\begin{array}{l}\text { Community solar projects should emphasize } \\
\text { affordability, even if it means industrial scaled } \\
\text { projects sited far from the recipients }\end{array}$ & & & & & \\
\hline
\end{tabular}

15 If a community solar project was available to you right now, how soon do you think you would enroll? (Select one)

Now- within a month

I'd do some research over the next few months and then maybe l'd enroll

I'd wait a year or two till more people have done it to see how it works out

I'm interested, but I can't really see myself doing it in the next few years

I would never enroll in a community solar program 
There are three other important factors that will affect the cost of a community solar program: location, size, and upfront cost to enroll in a project. These elements are not independent of each other, as all three influence the viability of a project. Please read the following project descriptions and indicate your willingness to enroll in each project given the overall impact on your monthly electricity cost.

Project 1: A community solar project located in your Portland neighborhood. This $500 \mathrm{KW}$ project would provide power for about 40-60 households. The one-time cost to enroll in this project would be a payment of $\$ 1,200$. Please rate your willingness to enroll in this program if it meant your overall monthly cost for electricity would be:

\begin{tabular}{|c|c|c|c|c|c|}
\hline $\begin{array}{l}\text { Select one response for } \\
\text { each electricity cost }\end{array}$ & $\begin{array}{l}\text { Definitely } \\
\text { Yes }\end{array}$ & $\begin{array}{c}\text { Probably } \\
\text { Yes }\end{array}$ & Unsure & $\begin{array}{l}\text { Probably } \\
\text { No }\end{array}$ & $\begin{array}{l}\text { Definitely } \\
\quad \text { No }\end{array}$ \\
\hline $10 \%$ lower & 0 & 0 & $\mathrm{O}$ & 0 & $\mathrm{O}$ \\
\hline $5 \%$ lower & $\mathrm{O}$ & $\mathrm{O}$ & $\mathrm{O}$ & $\mathrm{O}$ & $\mathrm{O}$ \\
\hline $2.5 \%$ lower & $\mathrm{O}$ & 0 & 0 & $\mathrm{O}$ & 0 \\
\hline Unchanged & 0 & 0 & 0 & 0 & 0 \\
\hline $2.5 \%$ higher & $\bigcirc$ & 0 & $\mathrm{O}$ & $\bigcirc$ & $\mathrm{O}$ \\
\hline $5 \%$ higher & 0 & 0 & $\mathrm{O}$ & 0 & 0 \\
\hline $10 \%$ higher & 0 & 0 & $\mathrm{O}$ & $\mathrm{O}$ & $\mathrm{O}$ \\
\hline
\end{tabular}

Project 2: A community solar project located in rural Washington County. This $5 \mathrm{MW}$ project would be located on open land and provide power to around 500 Portland households. The one-time cost to enroll in this project would be a payment of $\$ 600$. Please rate your willingness to enroll in this program if it meant your overall monthly cost for electricity would be:

\begin{tabular}{|c|c|c|c|c|c|}
\hline $\begin{array}{l}\text { Select one response for } \\
\text { each electricity cost }\end{array}$ & $\begin{array}{l}\text { Definitely } \\
\text { Yes }\end{array}$ & $\begin{array}{l}\text { Probably } \\
\text { Yes }\end{array}$ & Unsure & $\begin{array}{c}\text { Probably } \\
\text { No }\end{array}$ & $\begin{array}{l}\text { Definitely } \\
\text { No }\end{array}$ \\
\hline $10 \%$ lower & $\mathrm{O}$ & 0 & $\mathrm{O}$ & 0 & 0 \\
\hline $5 \%$ lower & $\mathrm{O}$ & 0 & 0 & 0 & 0 \\
\hline $2.5 \%$ lower & 0 & 0 & 0 & 0 & 0 \\
\hline Unchanged & 0 & 0 & 0 & 0 & 0 \\
\hline $2.5 \%$ higher & 0 & 0 & 0 & 0 & 0 \\
\hline $5 \%$ higher & $\mathrm{O}$ & $\mathrm{O}$ & 0 & $\mathrm{O}$ & $\mathrm{O}$ \\
\hline $10 \%$ higher & 0 & 0 & 0 & 0 & 0 \\
\hline
\end{tabular}

Project 3: A community solar project located in Eastern Oregon with more sunshine and less expensive land. This $30 \mathrm{MW}$ project would provide power to about 3,000 households. The one-time cost to enroll in this project would be $\$ 300$. Please rate your willingness to enroll in this program if it meant your overall monthly cost for electricity would be:

\begin{tabular}{|c|c|c|c|c|c|}
\hline $\begin{array}{l}\text { Select one response for } \\
\text { each electricity cost }\end{array}$ & $\begin{array}{l}\text { Definitely } \\
\text { Yes }\end{array}$ & $\begin{array}{l}\text { Probably } \\
\text { Yes }\end{array}$ & Unsure & $\begin{array}{l}\text { Probably } \\
\text { No }\end{array}$ & $\begin{array}{l}\text { Definitely } \\
\text { No }\end{array}$ \\
\hline $10 \%$ lower & $\mathrm{O}$ & $\mathrm{O}$ & $\mathrm{O}$ & 0 & 0 \\
\hline $5 \%$ lower & 0 & 0 & 0 & 0 & 0 \\
\hline $2.5 \%$ lower & 0 & 0 & 0 & 0 & 0 \\
\hline Unchanged & 0 & 0 & 0 & 0 & 0 \\
\hline $2.5 \%$ higher & 0 & 0 & 0 & 0 & 0 \\
\hline $5 \%$ higher & 0 & 0 & 0 & 0 & 0 \\
\hline $10 \%$ higher & 0 & 0 & 0 & $\mathrm{O}$ & 0 \\
\hline
\end{tabular}



that your neighbors, friends, or family were participating too?
Very much more likely
Much more likely
Somewhat more likely
Not much more likely
Not at all more likely

\section{Climate Change Your views on climate change and its impacts on Portland}

18

\begin{tabular}{|c|c|c|c|c|c|}
\hline Select one response for each statement & $\begin{array}{c}\text { Strongly } \\
\text { Agree }\end{array}$ & $\begin{array}{l}\text { Somewhat } \\
\text { Agree }\end{array}$ & $\begin{array}{l}\text { Neither Agree } \\
\text { nor Disagree }\end{array}$ & $\begin{array}{l}\text { Somewhat } \\
\text { Disagree }\end{array}$ & $\begin{array}{l}\text { Strongly } \\
\text { Disagree }\end{array}$ \\
\hline $\begin{array}{l}\text { If we do nothing, climate change will have dire } \\
\text { consequences for all life, including humans }\end{array}$ & $\mathrm{O}$ & $\mathrm{O}$ & $\mathrm{O}$ & O & O \\
\hline $\begin{array}{l}\text { Climate might be changing, but it is not as bad as } \\
\text { it is being portrayed }\end{array}$ & $\mathrm{O}$ & $\mathrm{O}$ & $\mathrm{O}$ & O & $\mathrm{O}$ \\
\hline $\begin{array}{l}\text { There is probably nothing we can do to stop cli- } \\
\text { mate change because it is out of our control }\end{array}$ & $\mathrm{O}$ & O & O & O & O \\
\hline Climate change is a natural phenomenon & O & $\mathrm{O}$ & O & $\mathrm{O}$ & $\mathrm{O}$ \\
\hline Climate change is primarily caused by humans & $\mathrm{O}$ & $\mathrm{O}$ & ○ & $\mathrm{O}$ & $\mathrm{O}$ \\
\hline Climate change is a hoax and conspiracy & 0 & 0 & O & 0 & 0 \\
\hline
\end{tabular}

19

How much do you agree or disagree with the following statements about the impacts of climate change on Portland? (Select one response for each statement)

\begin{tabular}{|c|c|c|c|c|c|}
\hline Climate change will... & $\begin{array}{c}\text { Strongly } \\
\text { Agree }\end{array}$ & $\begin{array}{c}\text { Somewhat } \\
\text { Agree }\end{array}$ & $\begin{array}{l}\text { Neither Agree } \\
\text { nor Disagree }\end{array}$ & $\begin{array}{l}\text { Somewhat } \\
\text { Disagree }\end{array}$ & $\begin{array}{l}\text { Strongly } \\
\text { Disagree }\end{array}$ \\
\hline Cause summers in Portland to be hotter & O & O & $\mathrm{O}$ & 0 & O \\
\hline Cause winters in Portland to be wetter & 0 & O & O & 0 & \\
\hline Not impact Portland & $\mathrm{O}$ & O & $\mathrm{O}$ & ○ & \\
\hline Cause people to move to Portland & $\mathrm{O}$ & $\mathrm{O}$ & $\mathrm{O}$ & O & $\mathrm{O}$ \\
\hline Cause people to leave Portland & $\mathrm{O}$ & $\mathrm{O}$ & $\mathrm{O}$ & O & 0 \\
\hline Threaten the way I make a living & $\mathrm{O}$ & $\mathrm{O}$ & $\mathrm{O}$ & 0 & 0 \\
\hline Improve the way I make a living & O & $\mathrm{O}$ & & & \\
\hline Threaten my quality of life & Q & O & O & O & \\
\hline Improve my quality of life & $\mathrm{O}$ & $\mathrm{O}$ & $\mathrm{O}$ & $\mathrm{O}$ & $\mathrm{O}$ \\
\hline
\end{tabular}

20 The City of Portland and Multnomah County partnered to develop strategies that Portland and the region can take to address climate change. How informed are you about the Portland Climate Action Plan? (Select one)

$\begin{array}{ccccc}\begin{array}{c}\text { Not at all } \\ \text { informed }\end{array} & \begin{array}{c}\text { Not very } \\ \text { informed }\end{array} & \begin{array}{c}\text { Somewhat } \\ \text { informed }\end{array} & \begin{array}{c}\text { Well } \\ \text { informed }\end{array} & \begin{array}{c}\text { Extremely } \\ \text { informed }\end{array} \\ \bigcirc & 0 & 0 & \bigcirc & \bigcirc\end{array}$




\section{Your Energy Use}

21

Does your home use natural gas for either home heating or hot water? (Select one)
$\bigcirc$ Yes
$\bigcirc$ No
I don't know

22 When heating your home on a cold evening which of the following statements best applies?

I don't control the heating in my home.

I generally set the heat at $65^{\circ} \mathrm{F}$ or below.

$\mathrm{I}$ I generally set the heat between $65^{\circ} \mathrm{F}$ and $67^{\circ} \mathrm{F}$.

I generally set the heat between $68^{\circ} \mathrm{F}$ and $70^{\circ} \mathrm{F}$.

I generally set the heat at $71^{\circ} \mathrm{F}$ or above.

23 When cooling your home on a hot evening which of the following statements best applies?

I don't use an air conditioner to cool my home

I have a window based air conditioner that I use to cool specific rooms in my home

I have a central air conditioner that I typically set above $75^{\circ} \mathrm{F}$

I have a central air conditioner that I typically set between $71^{\circ} \mathrm{F}$ and $75^{\circ} \mathrm{F}$

I have a central air conditioner that I typically set between $66^{\circ} \mathrm{F}$ and $70^{\circ} \mathrm{F}$

I have a central air conditioner that I typically set at or below $65^{\circ} \mathrm{F}$

24 When purchasing goods that are quickly consumed (for example: paper products, cleaning supplies, or coffee), how important are the following to you?

\begin{tabular}{|c|c|c|c|c|c|}
\hline $\begin{array}{l}\text { Select one response } \\
\text { for each factor }\end{array}$ & $\begin{array}{c}\text { Very } \\
\text { important }\end{array}$ & Important & $\begin{array}{l}\text { Somewhat } \\
\text { Important }\end{array}$ & $\begin{array}{l}\text { Not very } \\
\text { important }\end{array}$ & $\begin{array}{l}\text { Not at all } \\
\text { important }\end{array}$ \\
\hline Cost & 0 & 0 & 0 & 0 & 0 \\
\hline Ease of Access & 0 & 0 & ○ & ○ & ○ \\
\hline Efficiency & $\bigcirc$ & 0 & 0 & 0 & 0 \\
\hline Environmental Impact & 0 & 0 & O & O & 0 \\
\hline Innovation & 0 & 0 & O & O & 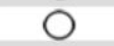 \\
\hline Reliability & 0 & 0 & 0 & 0 & 0 \\
\hline
\end{tabular}

25

When purchasing goods and services that last a long time and that are relatively more costly (for example: a car, an appliance, or furniture), how important are the following to you?

\begin{tabular}{|c|c|c|c|c|c|}
\hline $\begin{array}{l}\text { Select one response } \\
\text { for each factor }\end{array}$ & $\begin{array}{c}\text { Very } \\
\text { important }\end{array}$ & Important & $\begin{array}{l}\text { Somewhat } \\
\text { Important }\end{array}$ & $\begin{array}{l}\text { Not very } \\
\text { important }\end{array}$ & $\begin{array}{l}\text { Not at all } \\
\text { important }\end{array}$ \\
\hline Cost & $\bigcirc$ & $\bigcirc$ & $\bigcirc$ & 0 & $\bigcirc$ \\
\hline Ease of Access & O & $\bigcirc$ & 0 & 0 & 0 \\
\hline Efficiency & $\bigcirc$ & $\bigcirc$ & $\bigcirc$ & $\bigcirc$ & $\bigcirc$ \\
\hline Environmental Impact & 0 & 0 & 0 & 0 & 0 \\
\hline Innovation & $\bigcirc$ & $\bigcirc$ & 0 & 0 & 0 \\
\hline Reliability & 0 & 0 & 0 & 0 & 0 \\
\hline
\end{tabular}




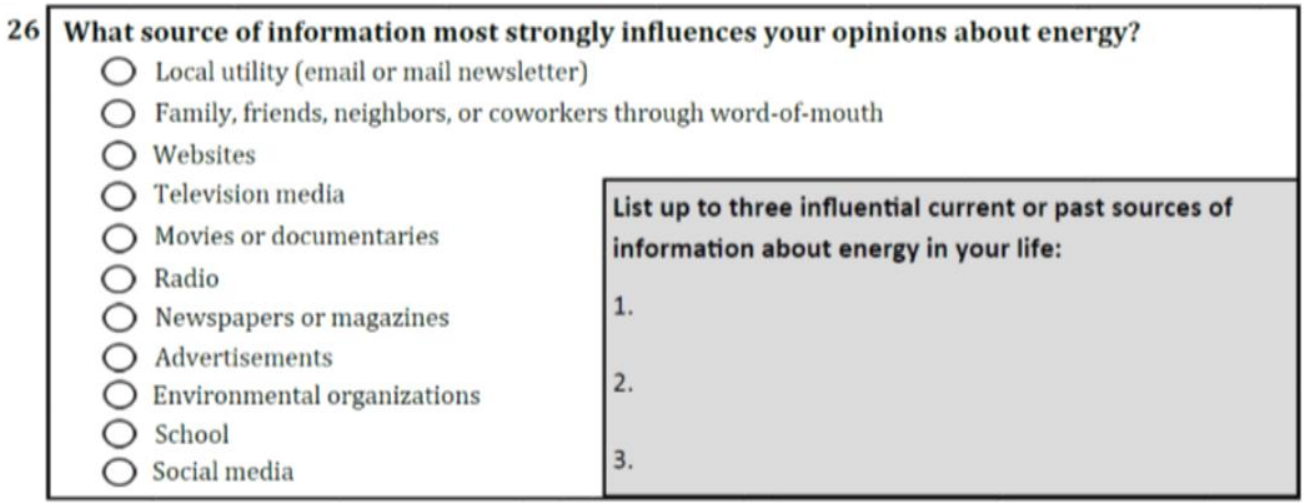

27 In the past year, approximately how often have you engaged in the following activities?

\begin{tabular}{|c|c|c|c|c|c|c|c|c|}
\hline $\begin{array}{l}\text { Select one response } \\
\text { for each statement }\end{array}$ & Never & $\begin{array}{c}\text { About } \\
\text { once a } \\
\text { year }\end{array}$ & $\begin{array}{c}\text { About } \\
\text { twice a } \\
\text { year }\end{array}$ & $\begin{array}{l}\text { 3-4 times } \\
\text { a year }\end{array}$ & $\begin{array}{l}\text { About } \\
\text { once a } \\
\text { month }\end{array}$ & $\begin{array}{l}2-3 \text { times } \\
\text { a month }\end{array}$ & Weekly & Daily \\
\hline Attended neighborhood meetings & $\bigcirc$ & ○ & $\mathrm{O}$ & $\bigcirc$ & $\bigcirc$ & ○ & $\bigcirc$ & $\bigcirc$ \\
\hline Volunteered for the local library & 0 & O & 0 & O & O & O & O & 0 \\
\hline Volunteered at the local school & $\mathrm{O}$ & $\bigcirc$ & $\mathrm{O}$ & ○ & $\bigcirc$ & ○ & $\bigcirc$ & $\mathrm{O}$ \\
\hline $\begin{array}{l}\text { Volunteered at a local nonprofit } \\
\text { organization }\end{array}$ & ○ & 0 & 0 & O & 0 & 0 & 0 & 0 \\
\hline Volunteered at a community center & $\bigcirc$ & $\bigcirc$ & O & $\bigcirc$ & $\bigcirc$ & ○ & ○ & O \\
\hline Attended church & $\mathrm{O}$ & O & O & $\mathrm{O}$ & $\mathrm{O}$ & $\mathrm{O}$ & O & $\mathrm{O}$ \\
\hline
\end{tabular}

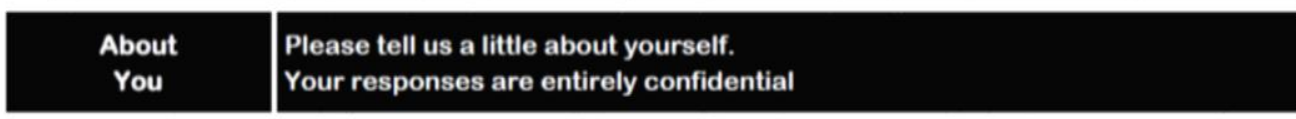

28 What is your gender? $\bigcirc$ Male $\bigcirc$ Female $\bigcirc$ Prefer not to answer

29 What year were you born?

30 Do you rent or own the home you live in? $\bigcirc$ Rent $\bigcirc$ own

31 Approximately what is the square footage of your home?

32 How many people live in your household including yourself? Adults Children (under 18)

33 Are you a member of an environmental organization? Yes $\bigcirc$ No $\bigcirc$

34 Which of the following best describes your home?
Single family detached house
Single family attached house (townhouse)
Duplex, triplex, or fourplex
$\bigcirc$ Apartment or condominium
other 
35 How long do you plan to live in your current home? (Select One)

Less than 1 year

At least 1 more year

At least 5 more years
At least 10 more years

I don't know

36 What is the highest level of education that you have completed? (Select one)
$\bigcirc$ Less than high school
Associate's degree (2-year)
High school or equivalent
Bachelor's degree (4-year)
Some college, no degree
Graduate or professional degree

37 Please rate whether you consider your political views to be more liberal or more conservative (Select one)
O

\section{$\mathrm{O}$}
Very
Somewhat
Conservative

\section{Neither Conservative} nor Liberal

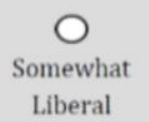
O
Very Liberal

38 Which of the following best describes your household's 2015 pre-tax annual income?
Less than $\$ 25,000$
\$ $\$ 75,000-\$ 99,999$
$\$ 150,000-\$ 174,999$
O $\$ 25,000-\$ 49,000$
\$100,000-\$124,999
\$175,000-\$199,999
O $\$ 50,000-\$ 74,999$
○125,000-\$149,999
Greater than $\$ 200,000$

Thank you for completing the questionnaire. Please feel free to write below or on the following page any additional information you would like to share with us. Your responses are confidential and

cannot be attributed back to you. 
Please use the space below to write any additional comments you have about renewable energy, community solar, or climate change.

\section{Don't forget to put your questionnaire in the bag and leave it for us at your front door!}

Thank you for your participation in this study! If you have any questions, please contact:

Anne Weaver, M.S. Student

Max Nielsen-Pincus, Assistant Professor

503-608-2730/weav4@pdx.edu

503-725-2827 / maxnp@pdx.edu

\& Portland State 
Appendix C: Summary Report
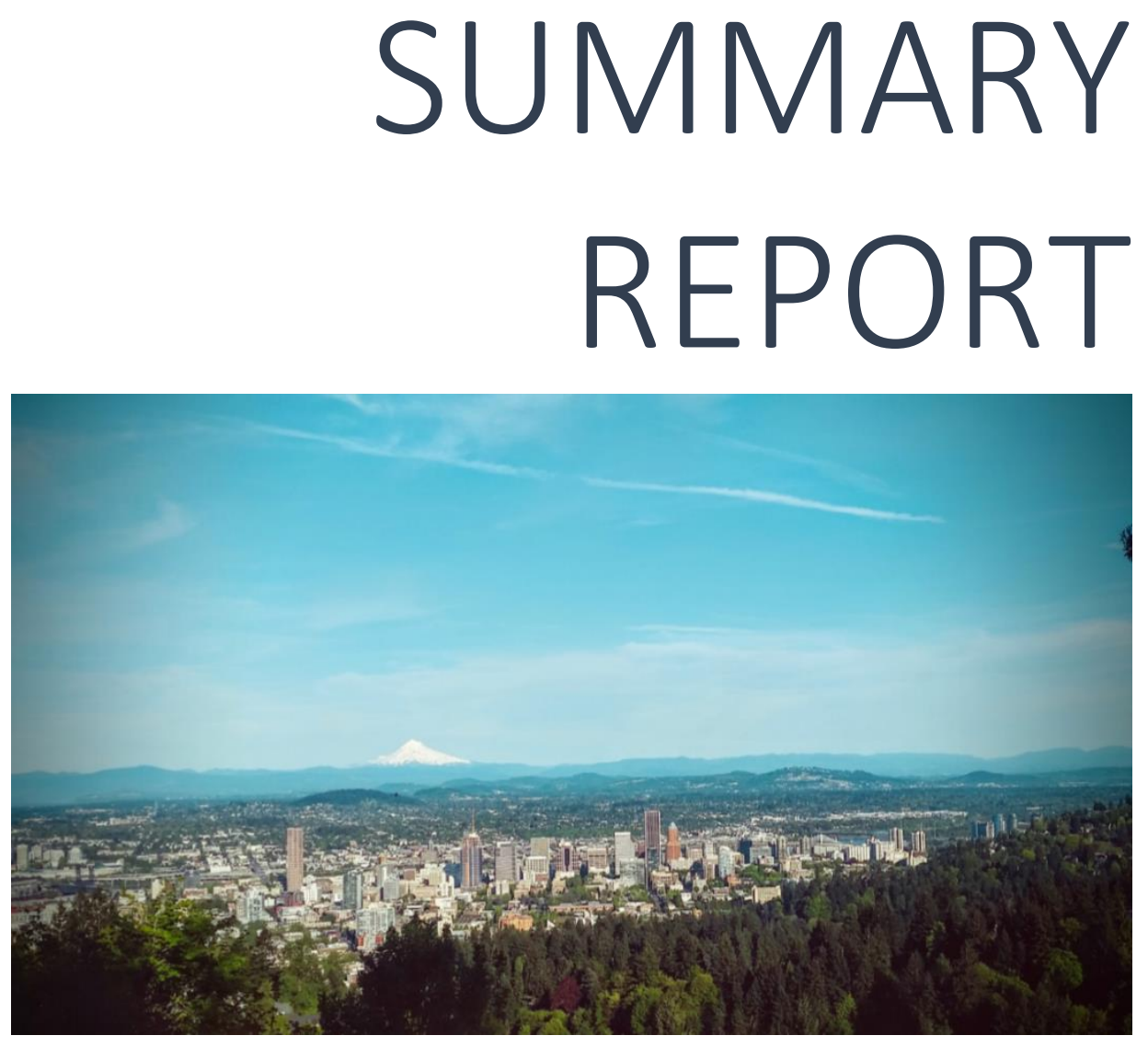

\section{April 2017}

\section{Renewable Energy \& Community Solar Questionnaire}

Report by Anne Weaver Environmental Science \& Management Department Portland State University Portland State 


\section{Acknowledgements}

This summary report was created by Anne Weaver, M.S. student in the Environmental Science \& Management Department at Portland State University, advised by Dr. Max Nielsen-Pincus, Assistant Professor.

Funding for the survey was provided by the Edward D. and Olive C. Bushby Scholarship fund, Portland General Electric, and the Nielsen-Pincus Natural Resources Policy and Management Lab. I'm very grateful for their support in this project.

I'm also very thankful for everyone involved in the design and implementation of this survey; this project wouldn't be complete without their advice, guidance, and support.

Additionally, l'd like to thank the 330 Portland residents who were kind enough to devote their time and patience in completing this questionnaire. This study could not have taken place without their participation.

Cover photo taken by Anne Weaver 


\section{Table of Contents}

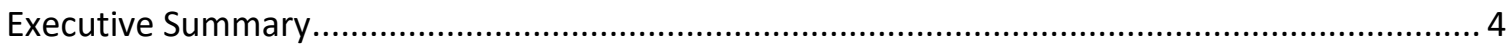

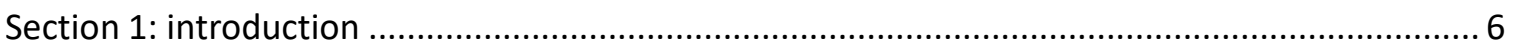

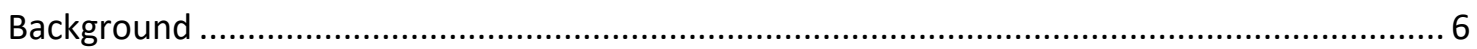

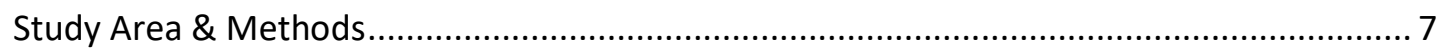

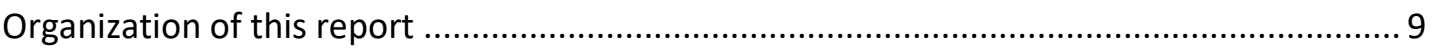

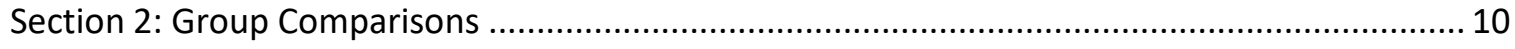

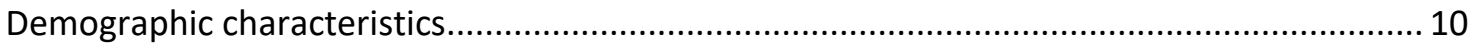

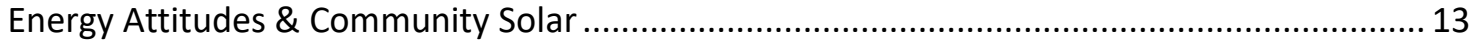

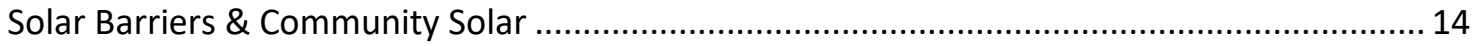

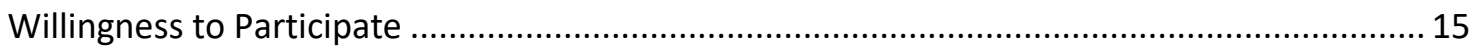

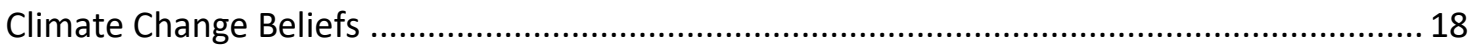

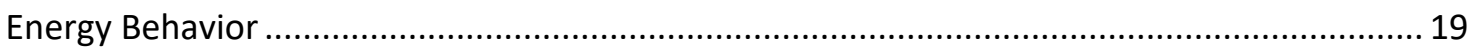

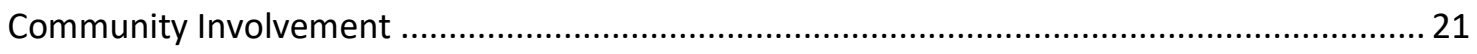

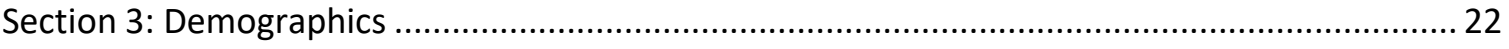

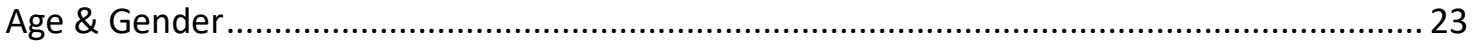

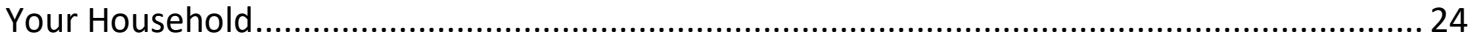

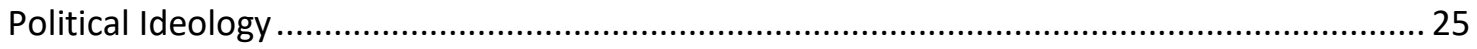

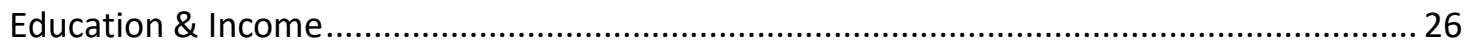

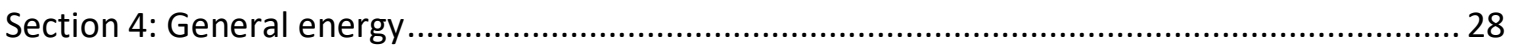

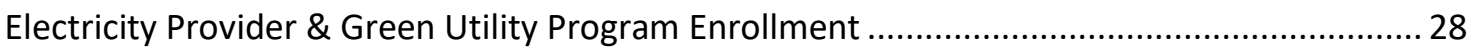

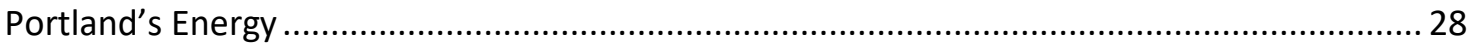

Knowledge

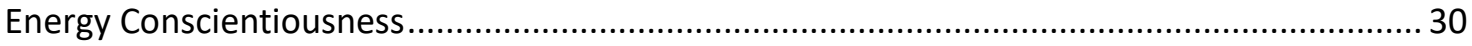

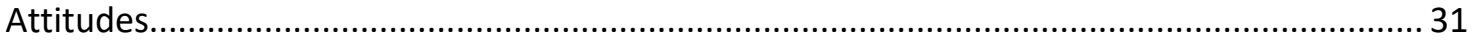

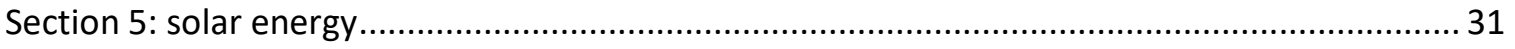

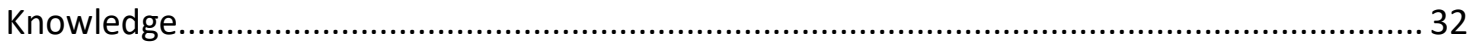

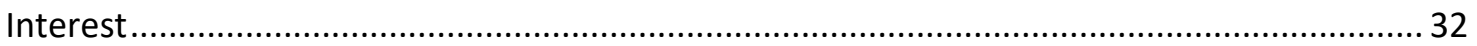

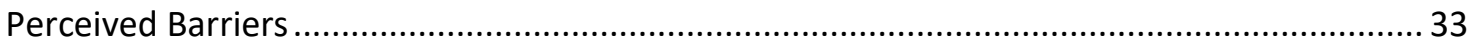

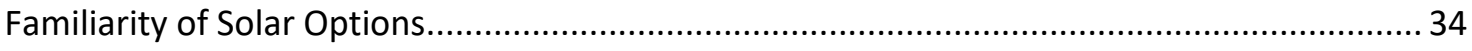

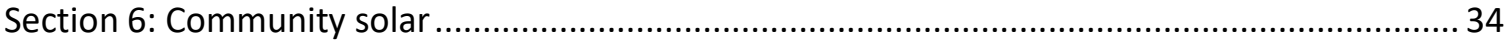




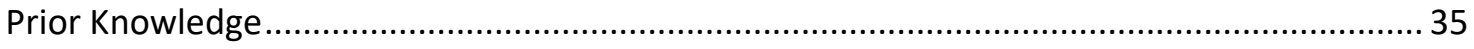

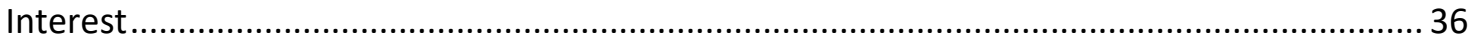

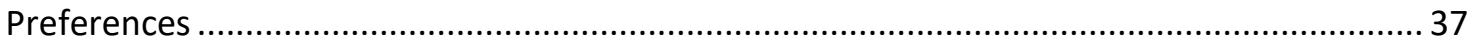

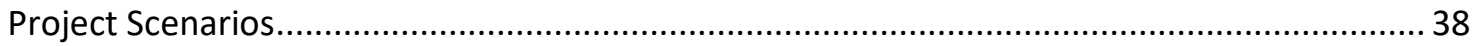

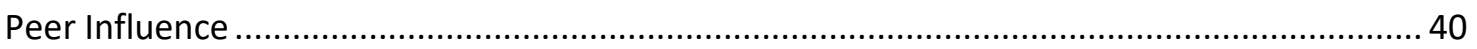

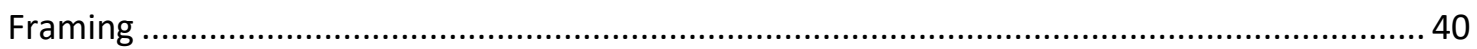

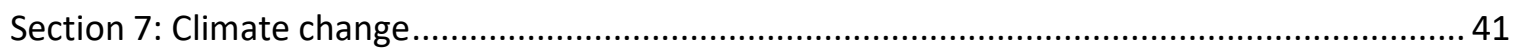

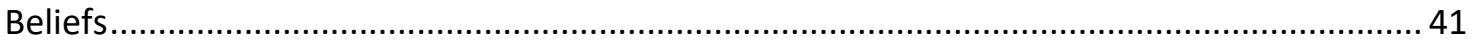

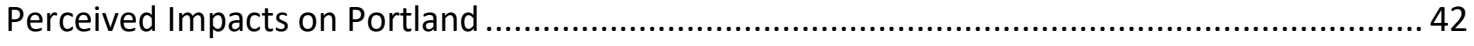

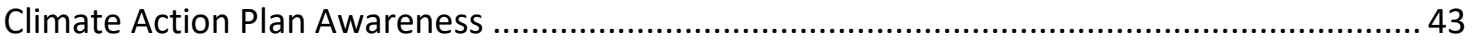

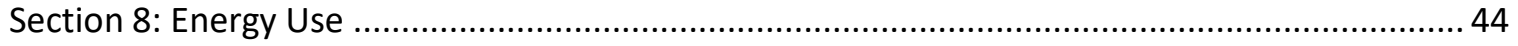

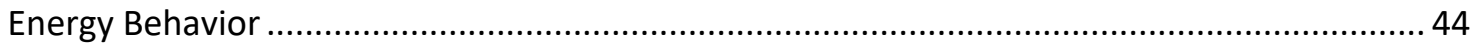

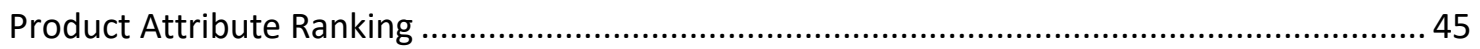

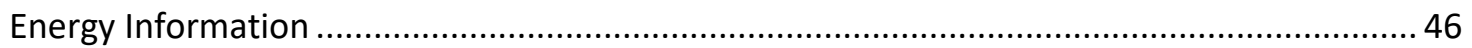

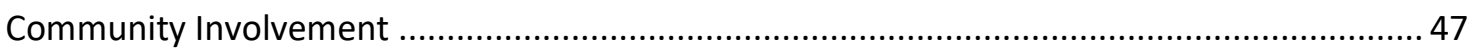

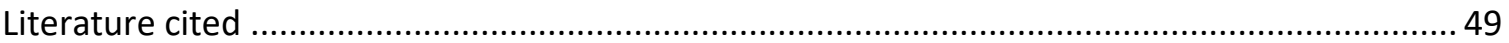




\section{Executive Summary}

Climate change mitigation cannot be successful without the adoption of innovative clean energy and energy efficient practices among the residential electricity sector, a large contributor of greenhouse gas emissions in the U.S. (EPA, 2014). The proportion of renewable energy sources (e.g. wind and solar) in the electricity mix nationally, as well as in Oregon and Portland, is small yet growing. One way to accelerate the growth of this proportion is through the development of community solar programs. Oregon's "Clean Electricity and Coal Transition Plan" enables community solar beginning in 2017 and is a direct response to the need to increase production of renewable electricity. This 2016 bill will increase the state Renewable Portfolio Standards (RPS) to $50 \%$ by 2040 , phase out coal by 2035 , and establish a community solar program for customers of Investor-Owned Utilities including Portland General Electric and Pacific Power.

My thesis research at Portland State University explores the attitudes, awareness, willingness to enroll, and other variables that may influence interest in community solar among Portland residents; a market that has little experience with this new energy practice. My research objectives are to understand what internal and external factors will help the diffusion of this innovation throughout the Portland population. Internal factors are individual consumers (demographic variables, environmental beliefs, knowledge of energy, awareness, community involvement, etc.), while external factors are the features of the community solar project controlled by project developers and the state (costs, benefits, location, size, management, etc.). Additionally, I'm investigating consumer preferences for project scenarios in order to conduct market research for future community solar programs in Oregon.

To achieve my research objectives, I developed a survey, "Renewable Energy \& Community Solar Questionnaire", for Portland residents to capture attitudes about energy and community solar. The survey contained six sections of questions: general energy, solar energy, community solar, climate change, energy use, and demographics. I distributed this questionnaire in the fall and winter of 2016, using a hybrid survey distribution methodology; the Drop-off/Pick-Up method for the first two rounds of contact and the Tailored Design method for the last two rounds of contact. I sampled from 14 Portland neighborhoods: 2 neighborhoods in each of Portland's seven districts.

I received a total of 330 completed surveys, resulting in a $34.2 \%$ response rate. Sample size from each neighborhood ranged from 12 to 35 survey participants; average neighborhood sample size was 23 residents. My survey respondents were mostly middle aged (median age $=50$ ), highly educated, middle-class homeowners who reported liberal political leaning. About three-quarters of survey participants were PGE customers, while the other quarter were Pacific Power customers. A high proportion of my respondents (36\%) were already enrolled in a voluntary green utility program, such as Green Source or Blue Sky. My respondents may be thought of as potential early adopters of community solar projects.

This report summarizes the responses from each section of my questionnaire. In addition, Section Two explores the differences between three groups. These groups were created based 
on respondents' interest in community solar; my variable of interest. If a respondent had selected "somewhat" or "very" interested in enrolling in community solar, they would be placed in the Interested group. If a respondent was unsure about their interest, then they were categorized as Unsure. And if a respondent had stated they were "not very" or "not at all" interested in community solar, then they were placed in the Not Interested group. Comparisons between these categories are described in Section Two.

\section{Key Findings}

\section{Interest in Community Solar}

- Almost $60 \%$ of survey respondents were somewhat or very interested in joining a community solar project; $11 \%$ were uninterested and $29 \%$ were unsure.

- Most survey respondents stated they would join a community solar project after a few months of additional research ( $58 \%$ ) if one was available right now. Roughly $22 \%$ would wait a few years to see how the projects turn out, while $\sim 7 \%$ would enroll immediately. The remainder stated they would likely never enroll.

- There was considerable variation among respondents in terms of interest in pursuing home solar arrays: less than $30 \%$ of respondents from Madison South were interested in having access to solar energy, while almost $70 \%$ of Sullivan's Gulch respondents stated they were very or extremely interested in solar access.

- The graph below displays the proportion of respondents stating they would probably or definitely be willing to join a community solar project based on changes in their electricity bill each month. The three lines represent three project scenarios: Project 1 is a small expensive project located in Portland, Project 2 is a moderately priced, mid-sized project located in rural Washington County, and Project 3 is an affordable industrialscale project located in Eastern Oregon. As bill savings move from high to low, the proportion of respondents willing to participate changes from $70 \%(+/-10 \%$ depending on the project) to roughly $10 \%$. 


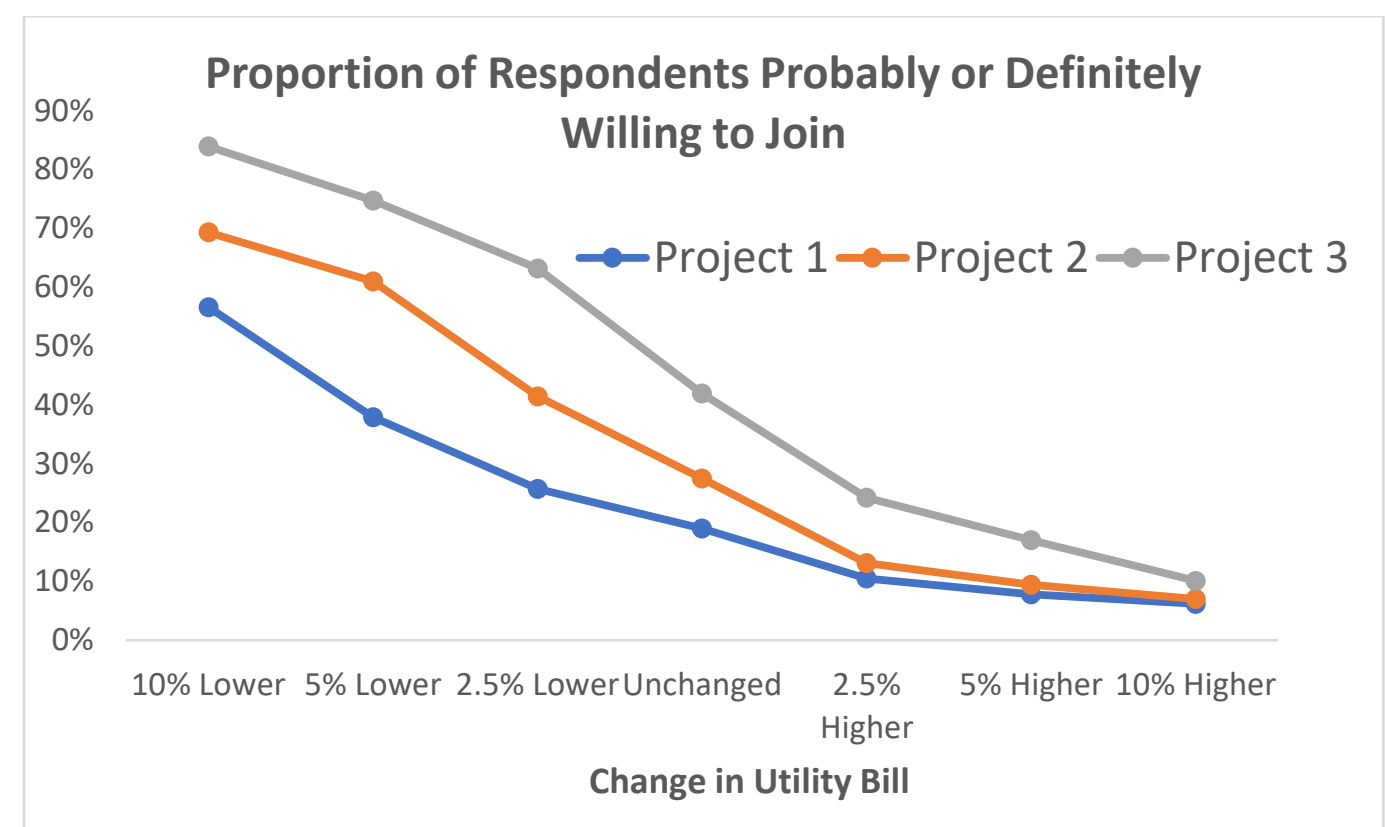

\section{Project Preferences}

- Most respondents were neutral about project features, such as size or location. However, there was a stronger preference for projects emphasizing affordability, rather than location.

- Preference for project management was insignificant, though more respondents preferred utility management over third-party management.

- Upfront cost was a strong predictor variable for willingness to participate; a project requiring a $\$ 1,200$ upfront fee saw $\sim 20 \%$ of respondents willing to join, while a project with a $\$ 300$ upfront fee saw over $40 \%$ of respondents willing to enroll (with an unchanged monthly utility bill). Those proportions changed significantly when utility bill savings were increased or decreased.

\section{Awareness}

- Survey respondents were very unfamiliar with community solar: most participants rated themselves as "unfamiliar" as well as having no prior knowledge about community solar.

- There was also very low familiarity among survey respondents in regards to other solar options, but participants felt somewhat familiar with voluntary green utility programs

\section{Attitudes towards Energy}

- Most respondents agreed with the positive statements about renewable energy and disagreed with negative statements about renewable energy.

- The Interested group exhibited positive perceptions of renewable energy, while the Not Interested group seemed to express the attitude that renewable energy is still too expensive.

\section{Barriers for Solar Adoption}


- Most solar barriers were not perceived as significant among respondents, though the more prominent barriers were lack of knowledge, concerns about reliability and maintenance, and high costs.

- The Not Interested group perceived cost as more of a solar adoption barrier than the Interested group; suggesting that cost may be a barrier for community solar adoption as well.

\section{Demographic Factors}

- A younger demographic seemed to express more interest in community solar: median age of Interested group was 46, while the median age for the Not Interested group was 60.

- Differences in political ideology between interest groups were observed: the Interested group was very politically liberal, while the Not Interested group had a higher proportion of politically conservative respondents.

- Middle-income (middle-class) respondents were mostly categorized as Interested, while the Not Interested group had higher proportions of respondents at either end of the income spectrum.

- $45.5 \%$ of the Interested respondents were enrolled in a voluntary green utility program, while less than $10 \%$ of Not Interested respondents were.

\section{Section 1: Introduction}

The transition to renewable electricity generation is at the forefront of the climate change mitigation movement (IPCC, 2011). Energy from wind, solar, geothermal, and other renewable sources still comprise a small proportion of the overall electricity mix in the United States, yet these sources are beginning to be cost-competitive with fossil fuels if all costs and benefits are considered. States and cities throughout the U.S. are increasing renewable portfolio standards (RPS) and developing climate action plans to address climate change and achieve carbon emission reductions in all sectors. One mechanism, out of many, that supplants fossil fuel generated energy in the utility grid with a renewable source is community solar (also called "shared solar").

Community solar is an energy practice that's been adopted by a number of U.S. states and is being considered by many more. A versatile innovation that includes a variety of designs, structures, and scenarios, community solar is expected to grow substantially in the upcoming years (NREL, 2015). Policy and legislation enable the growth of community solar, due to its inherent nature of being a form of electricity generation, which is a commodity that's regulated to ensure cost compliance. This is evident in the recent growth trends of community solar programs throughout the U.S.; without a legislative authorization to utilities, community solar likely couldn't succeed among energy markets. 
What's unique about community solar is that it's essentially the middle ground between individual rooftop PV systems and premium renewable energy programs offered through utilities to support the development of industrial-scale solar farms. Community solar projects are shared solar electric systems where community members can buy or subscribe to the energy generated from the solar array; allowing the "owners" or "leasers" to share both the costs and the benefits of the solar energy (Maize, 2015). Projects can be of any size, mounted either on a large rooftop or on the ground, and usually located anywhere in the utility's service territory. Community solar projects address the traditional barriers of solar energy: they offer renewable energy at an affordable price and they allow renters or home owners who don't have adequate roofs for a photovoltaic (PV) system the opportunity to still obtain the benefits of solar energy (Maize, 2015). Further, community solar programs often have low-income provisions that require a certain proportion of generating capacity to be made available to lowincome residents; advancing energy equity.

Oregon passed a senate bill (SB 1547) in 2016 called the "Clean Electricity and Coal Transition Plan" that increases the state RPS to $50 \%$ by 2040 and phases out coal-fired generation by 2035. A mechanism that will help the state achieve these goals is community solar, which was also a provision in SB 1547. Under this rule, the Oregon Public Utility Commission (OPUC) must establish a community solar program for Investor-Owned Utilities (Portland General Electric and Pacific Power) by July $1^{\text {st }}, 2017$. Community solar projects in Oregon must be larger than $25 \mathrm{~kW}$ (no maximum size), located anywhere within the state, and they have an inclusionary $10 \%$ low-income goal, among other rules currently being established in the rulemaking process.

This project explores the possible diffusion of community solar in a market that's historically not utilized much solar energy. I developed a survey for Portland residents to address my research objectives. My research questions are outlined below:

- What factors are likely to influence the social acceptance of community solar among the Portland market?

- What are the attitudes of Portland residents that drive intent to participate in community solar projects?

- What framing methods or other project designs will help the diffusion of community solar in Portland?

My survey instrument helped answer these questions in addition to outlining consumer preferences for community solar projects. The questionnaire, titled "Renewable Energy \& Community Solar Questionnaire", was designed for Portland residents who are customers of PGE and Pacific Power and who are essentially eligible participants of 
future community solar projects. This report summarizes the responses to the questionnaire.

\section{Study Area \& Methods}

Portland is the largest city in Oregon and therefore has the largest population of residents eligible for community solar projects (the two utilities located within Portland are the Investor-Owned Utilities establishing community solar projects for their customers). For these reasons, I deemed it as a suitable study area for my research. Additionally, Portland's overall electricity mix uses a very small proportion of solar energy, therefore I thought it would be interesting to investigate perceptions of solar energy among Portland residents, including perceived barriers and general familiarity with solar energy options. PGE and Pacific Power are also national leaders in voluntary green utility program enrollment rates. This demonstrates that the customers of these utilities (residents of Portland) are generally interested in participating in renewable energy projects and perhaps this green trend will be reflected in future community solar enrollment rates.

Beyond these reasons, the City of Portland is a pioneer when it comes to developing climate action plans. The most recent Portland Climate Action Plan included a small section on community solar, outlining it as a potential tool to help Portland achieve its carbon emission reductions, demonstrating that the City of Portland is thinking about community solar. I felt it was appropriate to conduct market research in a city that's unfamiliar with this energy practice, but is interested in utilizing it in both commercial and residential sectors to achieve emission reduction goals.

I utilized a stratified random sampling approach to divide the City of Portland by neighborhood. To ensure that I would gather a gradient of Portland's demographics in my survey, I chose to randomly select two neighborhoods in each of Portland's seven districts, totaling fourteen neighborhoods. The neighborhoods selected were Hillside and Linnton (Northwest), Kenton and Overlook (North), Sabin and Sullivan's Gulch (inner Northeast), Rose City Park and Madison South (central Northeast), Hazelwood and Russell (East), North Tabor and Foster-Powell (Southeast), and West Portland Park and Multnomah (Southwest). Figure 1.1 shows the neighborhoods where the surveys were distributed. Once the neighborhoods were chosen, I numbered every street in each neighborhood (using Google Maps) and randomly selected five streets. On every selected street, I numbered each house and randomly selected fifteen homes, building the per-neighborhood sample size to 75 homes. Thus, my total survey sample size was 1,050 homes. 
This sampling strategy was used because my survey recruitment method was a hybrid between the Tailored Design Method (Dillman 2000) and the Drop-off/Pick-up Method (Steele et al., 2016). Surveys were initially distributed door-to-door (in-person) and retrieved via the mail or pick-up. After this method was used, I transitioned into a mail survey, where surveys and postcards were mailed to participants in the third and fourth rounds of contact. Two different survey modes were offered: paper or web-based, where a link was provided on the cover letter. The door-to-door delivery of surveys was administered between September and November 2016, and the mail surveys were distributed in December of 2016. Eligible survey participants were residents above the age of 18 who were responsible for paying the monthly utility bill. As of March 1, 2017, I received 330 completed questionnaires, yielding a response rate of $34.2 \%$ (after subtracting vacant homes or ineligible residents).

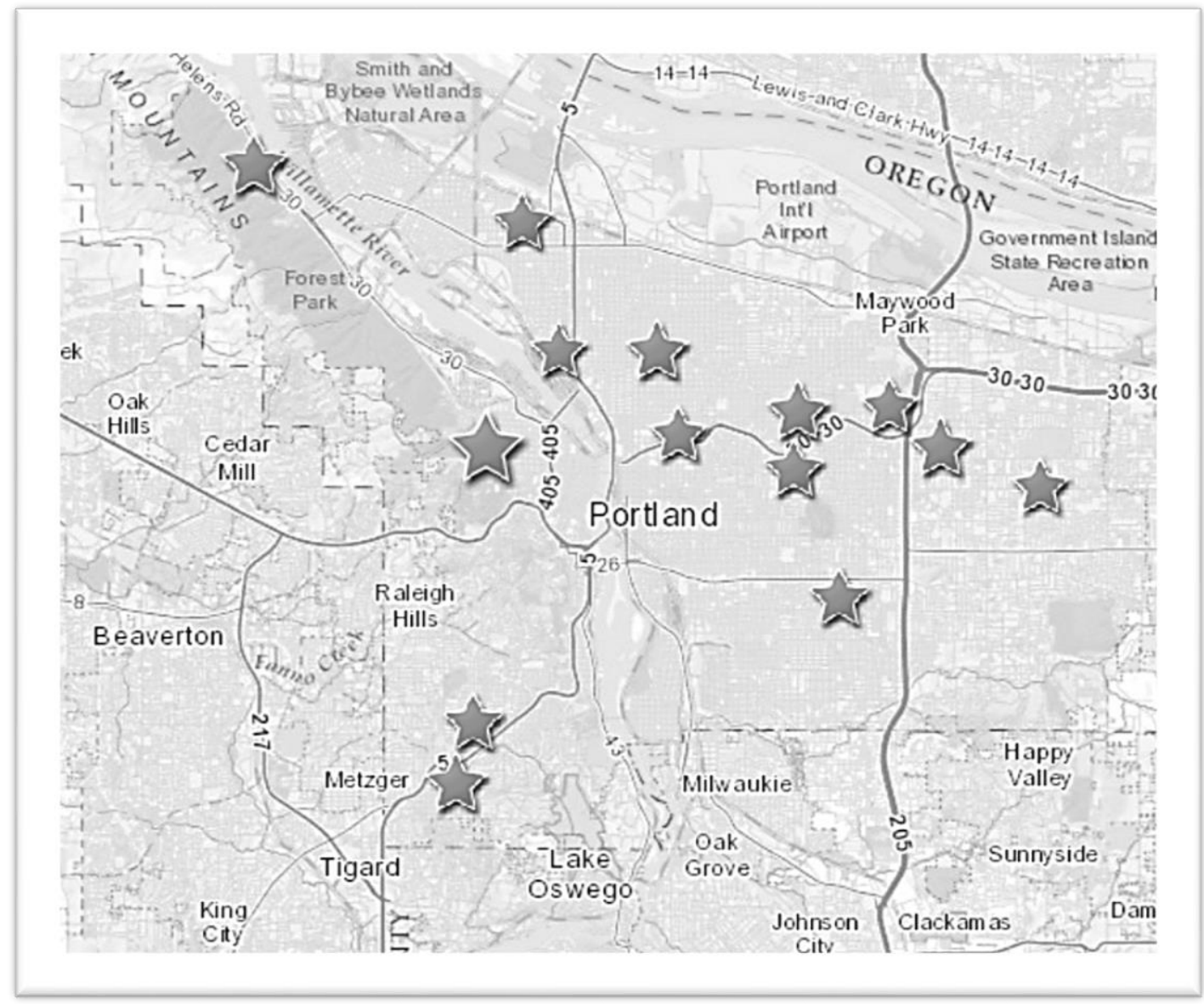

Figure 1.1 Map of 14 Portland neighborhoods in sample. Stars represent each selected neighborhood. 


\section{Organization of this Report}

The remaining seven sections of this report summarize the key findings and responses of the 330 completed surveys. The organization of the report reflects the structure of the survey questions, where each section includes an overall summary and then any relevant figures and tables demonstrating the distribution of responses. Each section is outlined below:

- Section Two includes an in-depth comparison between group responses, which are the key findings from this analysis. These groups were developed based on respondents' general interest in joining a community solar project. Groups categorize respondents as either Interested, Unsure, or Not Interested in community solar.

- Section Three includes a summary of the respondent demographics. While the demographic section of my survey was at the end, I decided to put this section towards the beginning of this report so that readers can get a clear understanding of who my survey participants were. Demographics included age, gender, household information, political ideology, education, and income. I compare my survey demographics to the census data of each neighborhood.

- Section Four provides a summary of the responses to the first section of the questionnaire. These questions were designed to get an understanding of how knowledgeable the participant was in regards to renewable energy as well as their attitudes towards energy. In addition, this section gathered information about the participant's electricity provider and their participation in a voluntary green utility program.

- Section Five summarizes the responses to questions about solar energy. These questions asked respondents about how knowledgeable they were in regards to solar energy, how interested they were in pursuing a home solar system, what they perceived as barriers to utilizing solar, and how familiar they were with different solar energy options.

- Section Six includes response distributions of the community solar section of my survey. These questions asked participants if they had any prior knowledge about community solar, general interest in joining a community solar project and the timing of adoption, preferences for various project designs, willingness to participate in different project scenarios, and if peer influence impacted intent to enroll. A framing component is also included.

- Section Seven is devoted to summarizing survey participants' beliefs about climate change. Other questions in this section inquired about respondents' 
perceptions of climate change impacts on Portland as well as general familiarity with the Portland Climate Action Plan.

- Section Eight includes distributions of responses to questions about energy usage. These questions looked at energy behavior; if respondents were conservative with their AC or heating. Additionally, I asked participants to rank their perceived importance of product attributes for daily and durable goods. This section also included a question looking at how involved survey respondents were with their community.

\section{Section two: Group Comparisons \& Key Findings}

To assess differences among survey participants, I separated my sample into three groups based on their answers to the variable of interest: (Q13) in general, how interested would you be in joining a community solar project? If respondents chose "very" or "somewhat" interested in joining a project, I put them in the Interested group. If a respondent was unsure about their interest, I placed them in the Unsure group. And finally, if a respondent selected "not very" or "not at all" interested, then I categorized them as Not Interested. There were 192 respondents in the Interested group, 96 in the Unsure group, and 36 in the Not Interested group.

The following section includes an assessment of response differences among these three groups for each section of my survey: demographic characteristics of each group, energy attitudes, perceived solar barriers, willingness to participate, climate change beliefs, energy behavior and community involvement. Each subsection starts with a summary about the variable and then describes the key findings from the group comparisons. Sections three through eight provide additional information about the response distributions of each question in my survey.

\section{Demographic Characteristics}

I wanted to investigate if there were differences in demographic variables among the three groups, specifically looking at variations in age, education, income, and political ideology. These differences may suggest what sort of demographic is more likely to adopt community solar first and what marketing strategies should be developed to reach the different market segments.

From these group comparisons, it can be concluded that survey respondents who were more interested in community solar tended to be liberal, middle-class homeowners, who were between the age of 35 and 55 and who were also highly educated. Politically conservative survey participants reported an overall lower interest in joining a community solar project. 


\section{Key Findings}

Figures 2.1, 2.2, and $\mathbf{2 . 3}$ demonstrate the differences in education, political views, and income (respectively) among the three groups. Overall, most respondents had a Bachelor's degree or higher. The Unsure group had the highest proportion of respondents with high school diplomas (or less) or some college completed. The Not Interested group had the highest percentage of respondents with a Bachelor's degree or higher (almost 80\%).

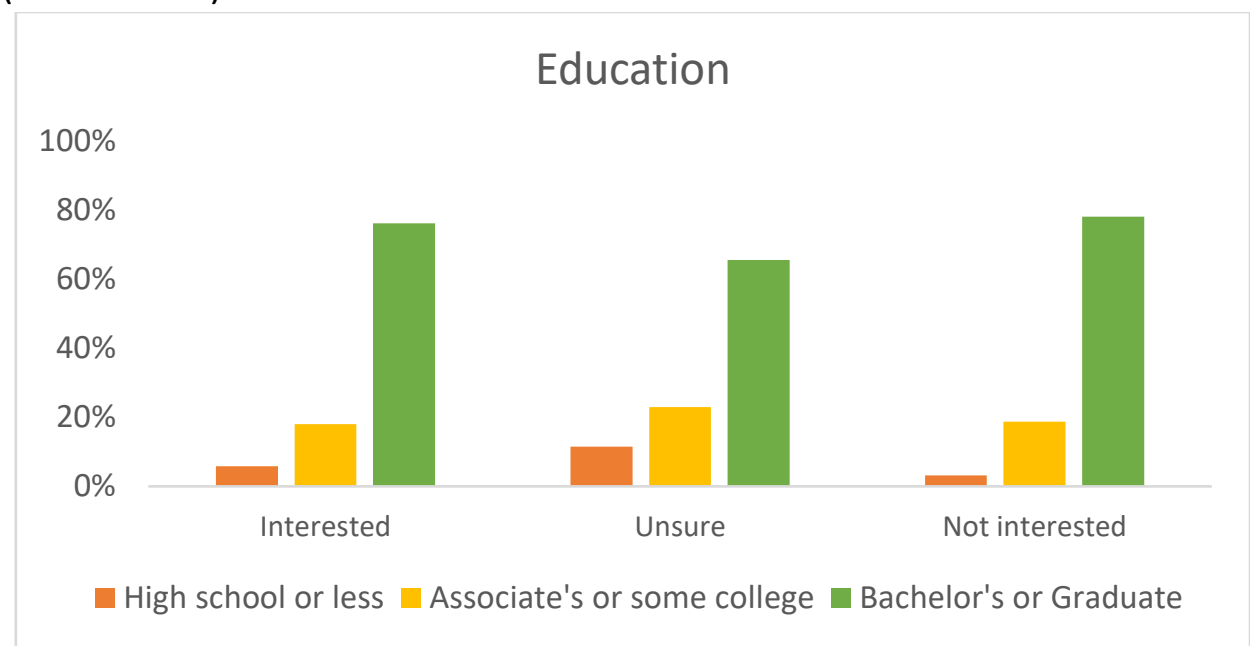

Figure 2.1 Education levels of respondents between each group. Most respondents in every group had a Bachelor's degree or higher.

In terms of political views, there were significant differences among the groups. The Not Interested group had the most respondents rating themselves as somewhat or very conservative ( $\sim 40 \%)$. The Interested group, on the other hand, was $86 \%$ liberal and $3 \%$ conservative. The Unsure group also had a high proportion of liberal respondents but also the largest percentage of "neither conservative nor liberal" respondents. The distribution of liberal and conservative respondents in the Interested and Unsure groups mirrors the distribution of political ideologies among my whole survey sample, while the Not Interested group has a very dissimilar proportion of conservative respondents. This trend suggests that conservative residents are more likely to be uninterested in community solar, while liberal residents are more likely to be interested. 


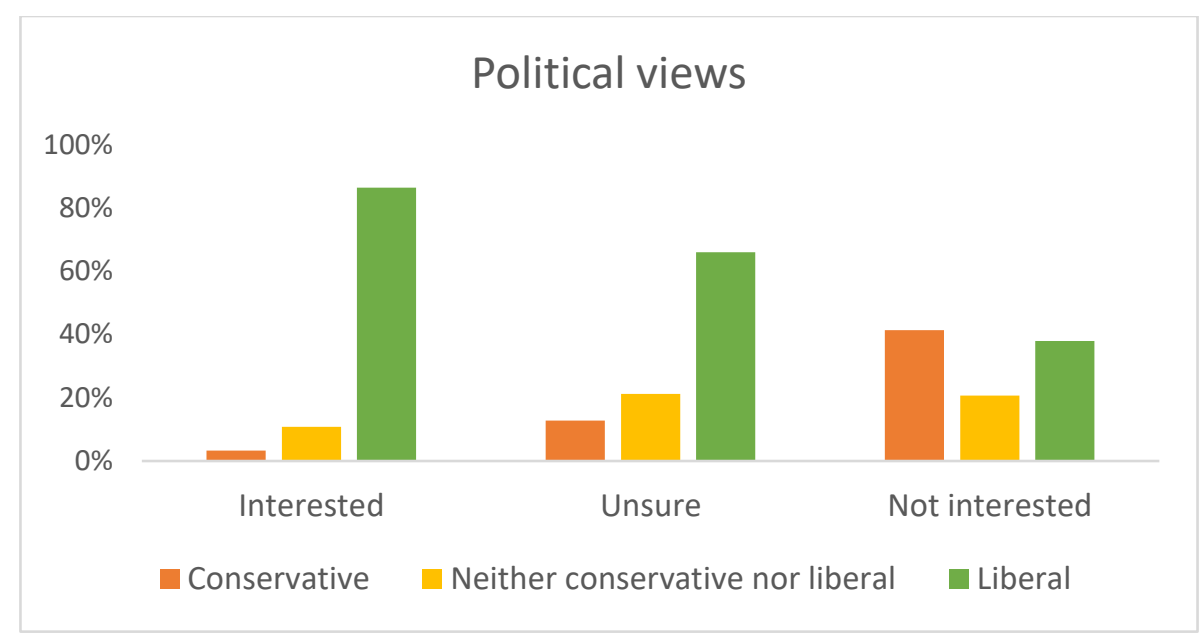

Figure 2.2 Comparison of political ideologies between groups. Interested and Unsure groups were highly liberal, while Not Interested group had a higher proportion of conservative respondents.

Income was another demographic variable that I compared among groups (Figure 2.3). The Not Interested group had the highest proportion of respondents in the $\$ 25$ to $\$ 74 \mathrm{~K}$ category, as well as in the $\$ 150$ to $\$ 200 \mathrm{~K}$ and greater than $\$ 200 \mathrm{~K}$ categories (most respondents were at either end of the income spectrum, rather than the middle). The Unsure and Interested groups had lower proportions of respondents with incomes greater than \$150K; most fell between \$25 and \$150K (middle class).

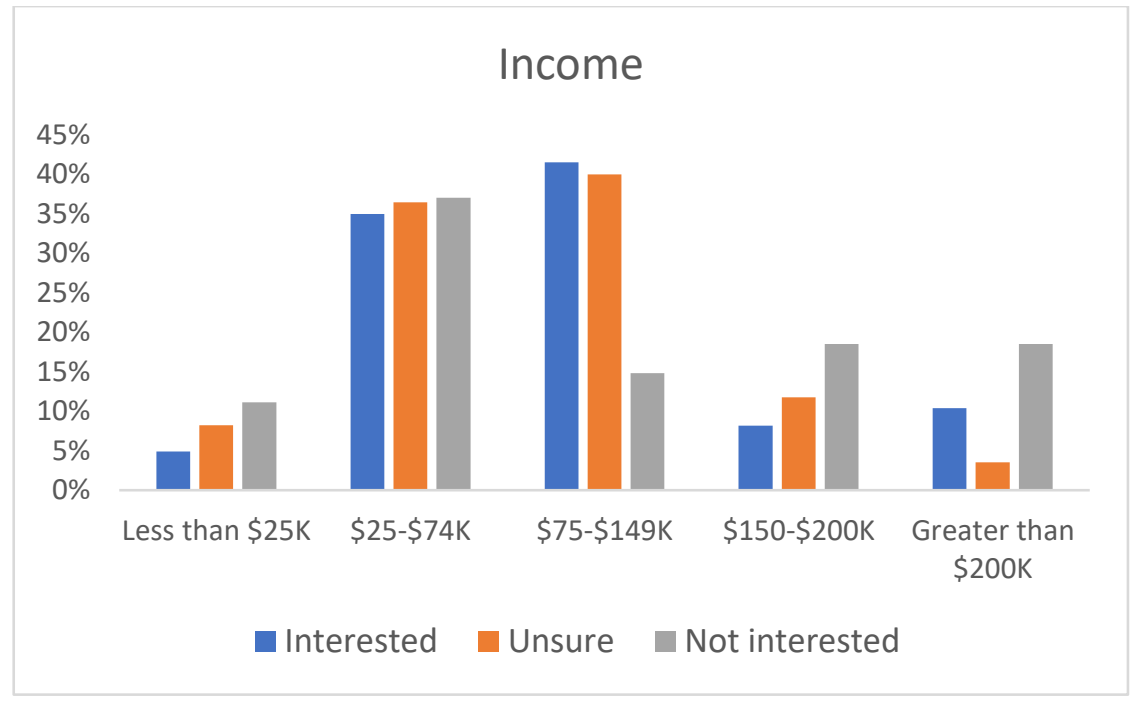

Figure 2.3 Distribution of income levels among the three groups. Most respondents for all groups had household incomes between $\$ 25$ and $\$ 149 \mathrm{~K}$. Not Interested group had a larger proportion of respondents earning $\$ 150 \mathrm{~K}$ or greater, as well as $\$ 25 \mathrm{~K}$ or less. 
I also looked at the median age of each group. The median age for the Not Interested group was $\mathbf{6 0}$ years old; $\mathbf{5 7}$ for the Unsure group; $\mathbf{4 6}$ for the Interested group. This data suggests that a younger demographic is potentially more interested in community solar than an older segment of the market.

\section{Attitudes towards energy \& community Solar}

Attitudes and beliefs can often dictate intent and behavior (Gadenne et al., 2011), thus I wanted to explore the connection between attitudes towards renewable energy and interest in joining a community solar project. This subsection provides analysis on the differences in respondents' attitudes towards energy based on their group. Figure $\mathbf{2 . 4}$ illustrates these differences for four different statements about energy.

\section{Key Findings}

The Not Interested group overall had more negative perceptions of renewable energy. This pattern is evident in all four charts within Figure 2.4 The Interested group had the highest proportion of respondents with positive perceptions of renewable energy. For the statement, "we should continue using fossil fuels because they're cheaper to produce" the Not Interested group had the same proportion of residents agreeing as disagreeing, while the Interested group had almost $90 \%$ of its respondents disagreeing (Unsure group was in the middle, but still had high proportion of disagreement). A positive statement about renewable energy, "renewable energy will help prevent climate change" saw significant agreement from all groups, yet still saw the lowest among the Not Interested group (almost 30\% disagreed). The other two statements captured a negative attitude towards renewable energy ("renewable energy is overrated") and indifference towards energy ("I don't really think about where my energy comes from"). Again, these statements saw high levels of disagreement among all groups, but with decreasing proportions moving from the Interested to Not Interested group; $\sim 30 \%$ and $\sim 33 \%$ of Not Interested respondents agree that renewable energy is overrated and that they don't think about where their energy comes from, respectively. 


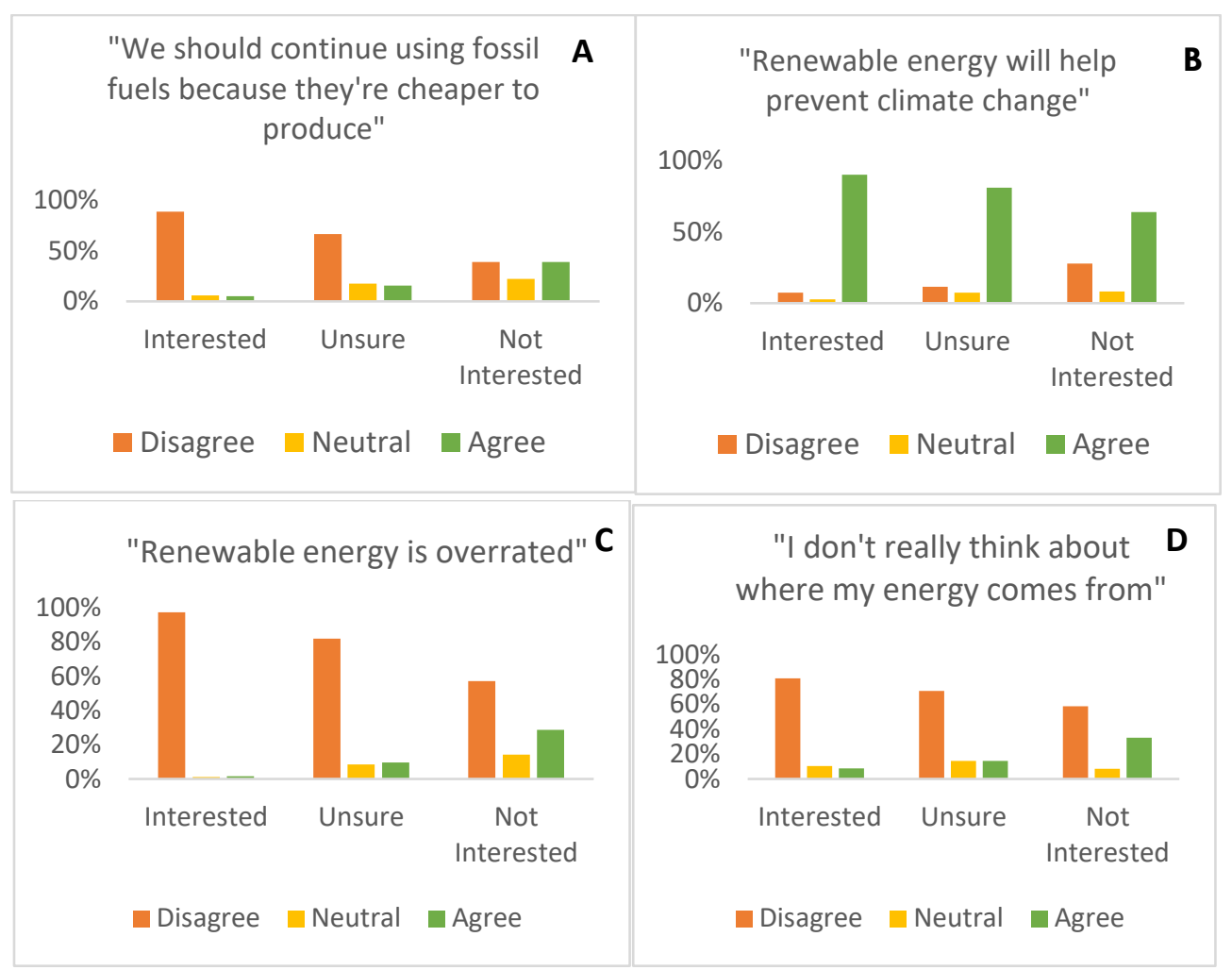

Figure 2.4 Differences in attitudes towards energy among the three groups. Figure A illustrates response distributions for a statement relating to the belief that renewable energy is too expensive. Figure B shows response distributions for a positive statement about renewable energy. Figure $\boldsymbol{C}$ displays response differences for a negative attitude about renewable energy and Figure $\boldsymbol{D}$ shows response distributions for a statement that relates to indifference towards energy.

\section{Barriers of Solar Energy \& Community solar}

I was interested in exploring how the different groups perceived barriers to utilizing solar energy. Perhaps these barriers correlate to the reasons why some respondents feel unsure about community solar or are not interested (see Section Six). The two significant barriers among all respondents were high costs and lack of knowledge, thus I compared responses for those barriers between the three groups. Distributions of responses for both barriers are displayed in Figure $\mathbf{2 . 5}$

\section{Key Findings}

The Not Interested group perceived high costs as a barrier more than the Interested or Unsure groups; almost 70\% of Not Interested respondents agreed that solar costs are too high. There's a possibility that the cost of community solar enrollment is also a barrier for these respondents. The Interested group had the most respondents who 
disagreed or were neutral about cost as a barrier. Figure A within Figure 8.6 demonstrates the response differences.

For the lack of knowledge barrier (Figure B below), the groups had mostly the same distribution of responses: about $50 \%$ of all respondents in each group felt that lack of solar information was a barrier for adoption. The Not Interested group had the highest proportion of disagreement among the groups, but the differences were not significant.

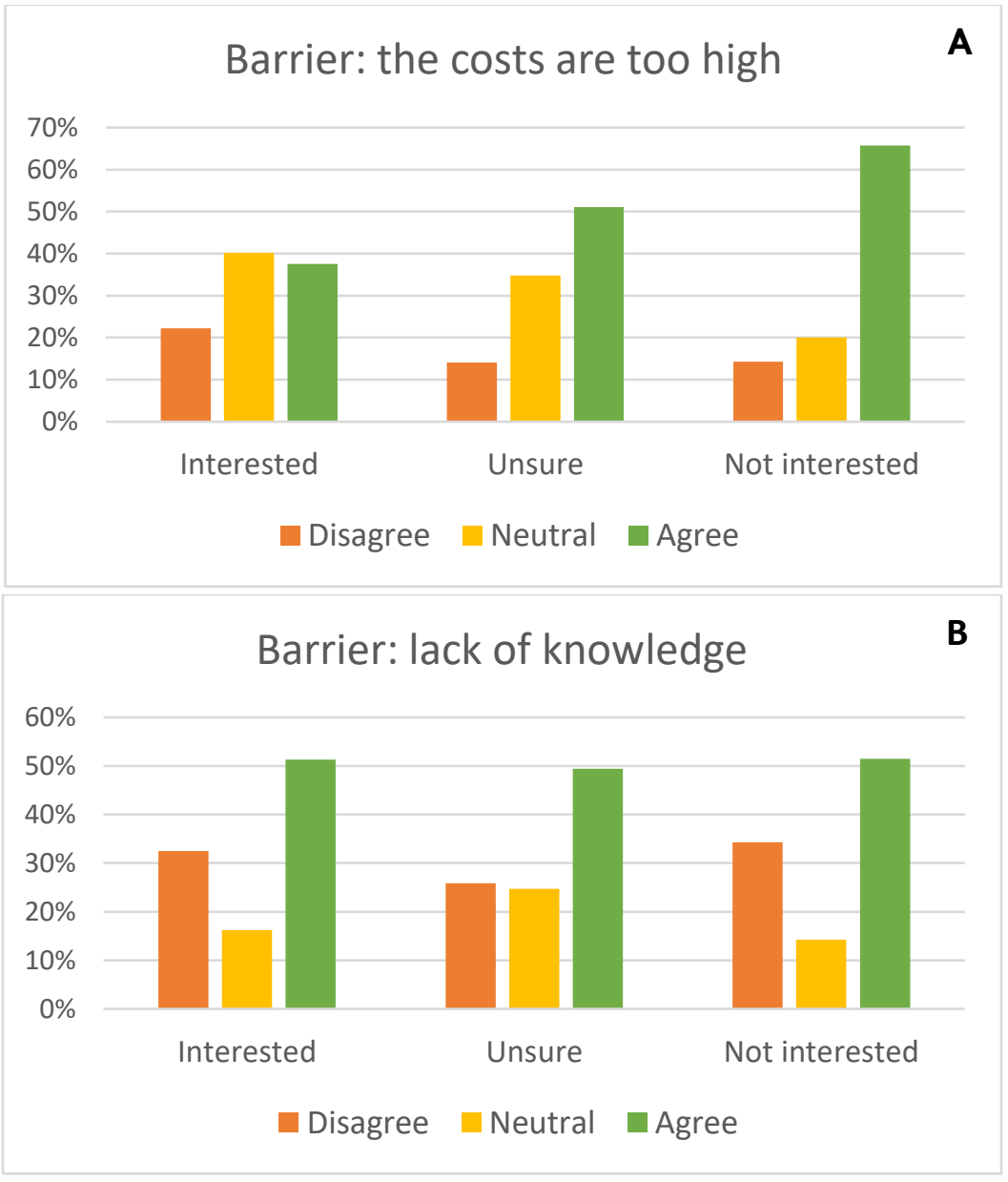

Figure 2.5 Illustration of the response differences between the three groups for two solar barriers: high costs (Figure A) and lack of knowledge (Figure B).

\section{Group Comparison: Willingness to participate}

Another comparison made was between the groups in terms of willingness to participate in different project scenarios, based on utility bill changes. This is because community solar projects come with a balance of tradeoffs. Larger projects are typically cheaper than small-scale projects due to economies of scale. But industrial-scale projects require substantial acreage, which Portland proper doesn't have a lot of. Thus, 
larger community solar projects would be cheaper to develop and more affordable for participants, but they would be outside of the community, possibly located in Eastern Oregon where land is cheaper and sunshine is more abundant. The distance of these projects would lower the communal aspect of community solar projects. On the other hand, a local community solar project within Portland would localize the energy production and allow it to be an integral part of the community. But small and local arrays would likely require steep upfront costs to join.

To get a sense of what types of projects Portland residents would prefer, I provided survey respondents with three different project scenarios and asked them to rate their willingness to enroll based on changes in their monthly utility bill. Project descriptions are outlined below:

Project 1: $500 \mathrm{~kW}$ community solar project located in a Portland neighborhood. It would require a one-time upfront cost of $\$ 1,200$ to join and would provide power for about 4060 households.

Project 2: $5 \mathrm{MW}$ community solar project located on open land in rural Washington County. The one-time cost to enroll in this project would be a payment of $\$ 600$ and would power around 500 Portland households.

Project 3: 30MW project located in Eastern Oregon (more sunshine and less expensive land). It would provide power to about 3,000 households and cost $\$ 300$ to enroll.

Changes in their bill would either be three different increments of savings (electricity bill would be $10 \%, 5 \%$, or $2.5 \%$ lower if they enrolled in the project), unchanged, or three different increments of increased costs (electricity bill would be $10 \%, 5 \%$, or $2.5 \%$ higher as a result of joining a community solar project). These bill savings or costs correspond with the bill credit that will be applied to the electricity bills of members of community solar projects. The bill credit rate is currently an unknown value, but it could potentially be higher, lower, or equivalent to the current retail rate of power. A high bill credit rate reflects a high resource value of solar (RVOS), meaning the true cost of solar- when all costs and benefits are considered and it's weighed against other fuel sources- is valuable. If the bill credit rate is the same as the retail rate of power, the RVOS is worth the same as the default energy source and community solar participants will see an unchanged utility bill. If the bill credit is low, meaning a low RVOS, participants won't be getting paid back for their investment in the long term and will be seeing a higher utility bill. The value of the bill credit is currently under investigation in an RVOS study in Oregon. 
For the group comparisons, I specifically looked at willingness to enroll in Project 1 and Project 3 if the bill was $10 \%$ higher or $10 \%$ lower each month. I chose to compare Projects 1 and 3 with each other because they're at either ends of the spectrum in terms of cost, size, and location. The differences between the groups are illustrated in Figure 2.6. For overall response distributions for all saving increments and project scenarios, refer to Section Six.

\section{Key Findings}

Not surprisingly, the Interested group was more willing to enroll in all project scenarios and bill changes than the Not Interested group. In Project 1, almost $70 \%$ of Interested respondents said they were willing to join if it meant their electricity bill was $10 \%$ lower, but less than $30 \%$ of Not Interested respondents said they were willing.

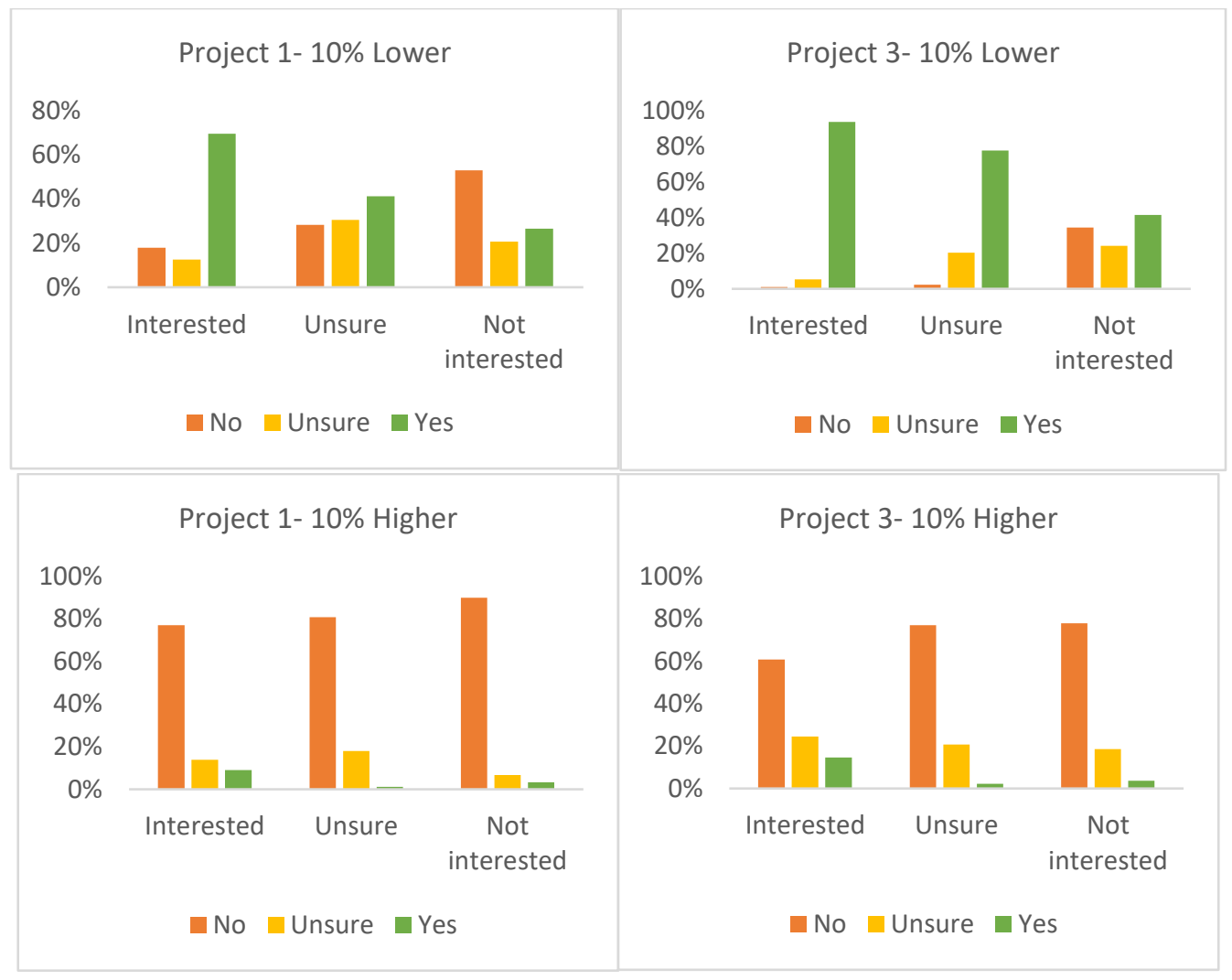

Figure 2.6 Distribution of responses for each project scenario, organized by group. Top two charts are scenarios with a 10\% lower utility bill for Project 1 and Project 3, while the bottom two charts are 10\% higher utility bill scenarios for each project. "No" responses reflect unwillingness to join (respondents who chose definitely or probably no), "unsure" responses are respondents undecided about their willingness to participate, and "yes" responses are respondents who chose definitely or probably willing to join. 
Looking at Project 3 (cheaper to enroll, large in size, located in Eastern Oregon), over $90 \%$ of Interested respondents, $\sim 40 \%$ of Not Interested respondents, and $\sim 80 \%$ of Unsure respondents expressed interest in enrolling if it meant their utility bill was $10 \%$ lower. The distribution is reversed for both projects when the change in electricity bill is $10 \%$ higher: most respondents are not willing to enroll. However, a lower proportion of Interested respondents said they were unwilling to enroll than the Not Interested respondents. There was the highest percentage of unsure responses in the Project 1$10 \%$ lower and Project 3-10\% higher scenarios. This is likely due to the varying tradeoffs within each project: Project 1 is expensive to join upfront, but an electricity bill $10 \%$ lower is still an attractive proposition for customers. Project 3 , on the other hand, is fairly affordable to join in, but a $10 \%$ higher utility bill takes away from the upfront affordability appeal.

The comparisons made between project scenarios and changes in bill savings tell us that the bill credit rate (the amount participants are getting paid back for their share in a community solar project) is the strongest factor influencing willingness to enroll. This is evident when you compare the four graphs in Figure 2.6. We see the biggest drop in willingness to enroll when bill savings change from $10 \%$ lower to $10 \%$ higher in both projects, rather than changing from 10\% lower in Project 1 to 10\% lower in Project 3 (as well as $10 \%$ higher). The proportion of Interested respondents willing to join in Project 1- $10 \%$ lower is almost $70 \%$, while it's less than $10 \%$ in Project $1-10 \%$ higher. This pattern suggests that the long-term savings (or costs) of a bill credit have a stronger effect on willingness to participate than upfront costs, location, or project size.

\section{Climate Change Beliefs \& Community Solar}

Beliefs about climate change fall under the environmental attitude blanket; someone who believes that climate change is happening now, threatening livelihoods, and is caused primarily by human activities generally has somewhat of an environmental ethic (Hamilton et al., 2015). Thus, beliefs and attitudes about an environmental issue such as climate change can be used to influence one's behaviors and actions impacting that issue (Price et al., 2014). This relationship can be applied to the connection between community solar participation and beliefs about climate change. I hypothesize that someone who holds more of an alarmist attitude about climate change would be more likely to be interested in community solar, because it's a mitigatory mechanism for climate change. On the other hand, someone who regards climate change as a hoax or who believes it doesn't pose a serious threat to mankind may be less inclined to join a community solar project. To understand how the perceptions of climate change differed among the groups, I compared the responses to two different statements about climate change. 


\section{Key Findings}

I provided several different statements about climate change that pertain to either acceptance that climate change is real and primarily caused by human activity, or the "denial" notion that climate change is either a natural phenomenon or is a hoax (Hamilton et al., 2015). These statements captured a "climate change acceptance" attitude or a "climate change denial" attitude. Figure $\mathbf{2 . 7}$ illustrates the response differences among the groups for these two climate change attitudes.

Most respondents in each group agreed that climate change will have dire effects for all life if we do nothing (Figure A). The Not Interested group, however, had a lower proportion of agreement (over $20 \%$ disagreed with the statement). We see an inverse pattern when looking at the response distributions for the statement "climate change is a hoax" (Figure B). Almost $100 \%$ of the Interested group disagreed, while $~ 70 \%$ of the Not Interested group disagreed.

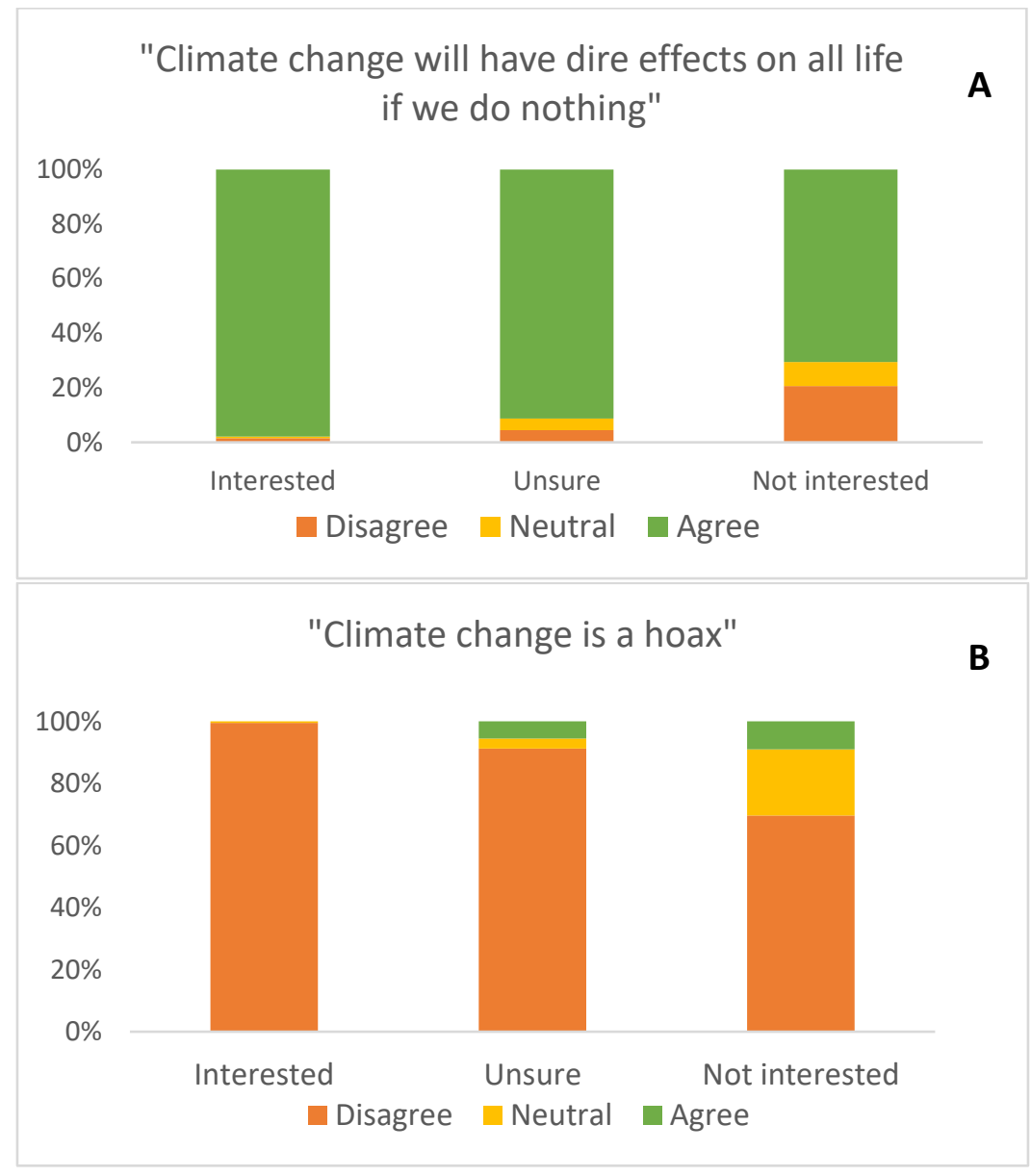

Figure 2.7 Response differences among groups for two statements about climate change. Figure A illustrates group response distributions for an "acceptance" attitude 
towards climate change. Figure B illustrates group response distributions for a "denial" climate change attitude.

The trend illustrated in both graphs of Figure $\mathbf{2 . 7}$ suggests that the Not Interested group holds less of a "climate change acceptance" attitude than the other two groups (and more of a "denial" belief). Perhaps this sentiment ties in with the disinterest in participating in community solar for this group. It should still be noted, however, that the majority of the Not Interested still believe that climate change will have dire effects on all life and disagree that climate change is a hoax.

\section{Energy Behavior \& Community Solar}

One of the primary ways in which people interact with energy is through the utilization of heating or air conditioning $(\mathrm{AC})$ in their home. These two energy uses, heat and $\mathrm{AC}$, comprise significant proportions of residential electricity emissions. Conservative usage of these two activities may correspond with environmental attitudes and behaviors, both factors that may influence a resident's interest in community solar. For example, someone who uses $\mathrm{AC}$ and heating in a conservative, energy-conscious manner may be more inclined to join a community solar project because they're already exhibiting environmental behavior through energy conservation.

\section{Key Findings}

The heating and air conditioning scales displayed in Figure $\mathbf{2 . 8}$ show three different settings that correspond with energy conscious, moderately energy conscious, or not energy conscious behaviors, in addition to other likely settings, such as not having an air conditioning or using a window-based AC. In terms of heating, the Interested group had the highest proportion of respondents reporting that they set their heat below 67 degrees, which is congruent with conservative energy behavior. The Not Interested group had the highest proportion of respondents among all groups setting their heat between 68 and 70 degrees ( $\sim 50 \%)$, and 71 degrees or above ( $15 \%)$, but the lowest proportion of respondents setting their heat at 67 degrees or below ( 35\%). This trend is in line with the hypothesis that the Interested group would be more conservative with energy (in terms of heating usage) than the Not Interested group.

Energy behavior in terms of AC use tells a different story, which is illustrated in Figure 2.9. Most respondents did not own an $A C$ unit, which is unsurprising as Portland has a relatively mild climate. Second to "no AC", the Interested and Unsure groups also had high proportions of respondents using a window-based AC rather than a central system. But the Not Interested group had the second highest proportion of respondents stating 
they set the $A C$ between 71 and 75 degrees. A very low proportion of respondents from all groups stated they set the AC below 70 degrees. The patterns observed in the AC figure don't strongly correspond with the belief that residents not interested in community solar would be more likely unconservative with $A C$ use. This is most likely due to the fact that $A C$ use is not a prominent energy activity in Portland.

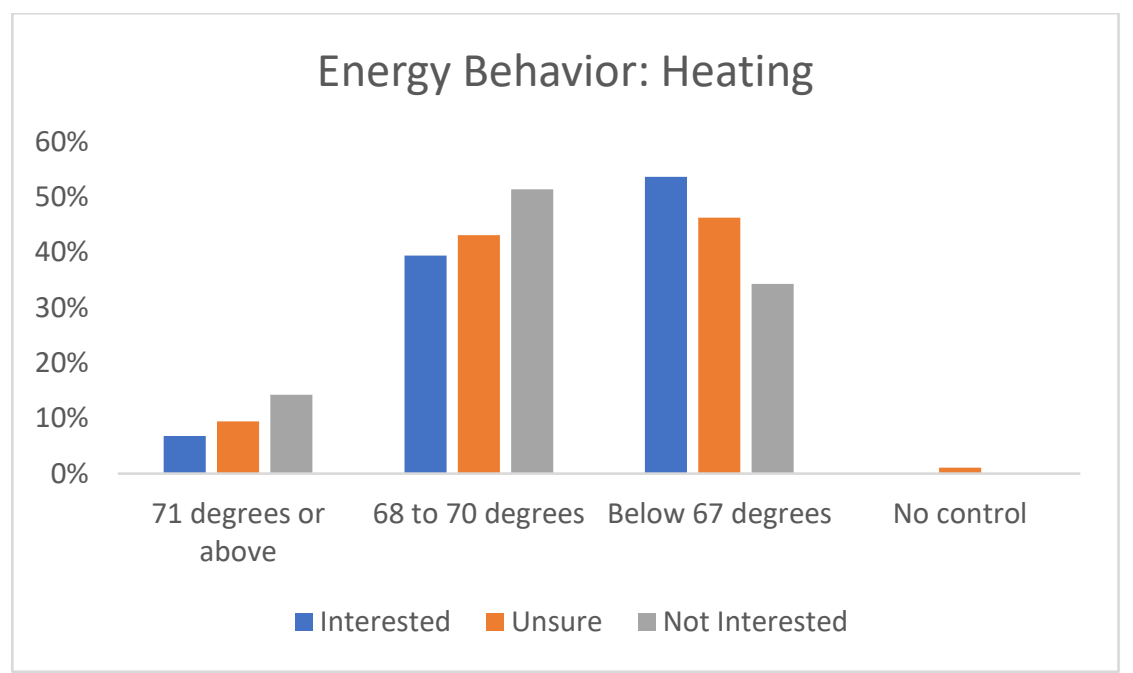

Figure 2.8 Response differences among groups for heating behavior. The $x$-axis displays the heat setting: 71 degrees or above corresponds with unconservative behavior, 68 to 70 degrees is moderately conservative, and below 67 degrees is considered conservative energy behavior. The $y$-axis is the distribution of respondents.

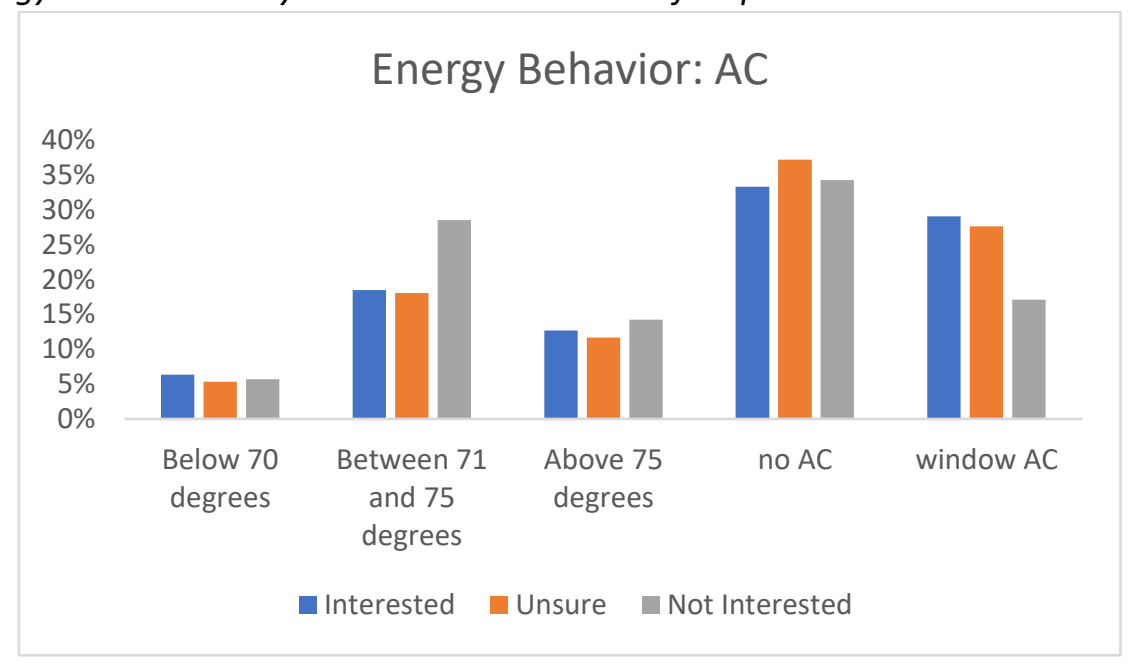

Figure 2.9 Distribution of responses for each group for $A C$ use. Most respondents either used no AC or had a window-based AC. Setting the AC at 70 degrees or below corresponds with unconservative energy behavior, setting it between 71 and 75 correlates with moderately conservative behavior, and setting the AC above 75 would be considered conservative. 


\section{Community Involvement \& Community Solar}

One of the defining features of community solar is the notion that energy from such a project will be relatively local and possibly a facet of the community. Community members can enroll in a project knowing that their neighbors or friends also have the opportunity to participate. Because community solar is often an inherently communityoriented feature, it could be assumed that residents who are more involved with their community, such as volunteering at a local community center or frequently attending a church, would be more inclined to show interest in community solar. To assess how community-oriented my respondents were, I asked them to report how often they engaged in a number of community activities over the past year (see Section Seven for a list of activities). I then scored each respondent by adding up the frequency of participation in each activity, which was measured in days (scores can be seen in table below Figure 2.10).

\section{Key Findings}

While most respondents reported only engaging in a community activity 0 to 2 days last year, the Not Interested group had the highest proportion of respondents in the "37 to 104 days" and "Greater than 105 days" bins compared to the other groups. The Interested group had the most respondents in the " 0 to 2 days" and the " 3 to 36 days" bins. The Unsure group had the highest proportion of respondents in the " 0 to 2 days" category. Figure $\mathbf{2 . 1 0}$ illustrates a pattern where the respondents who were less interested in community solar were actually more involved in their community, while the respondents who were undecided about community solar were the least community-oriented.

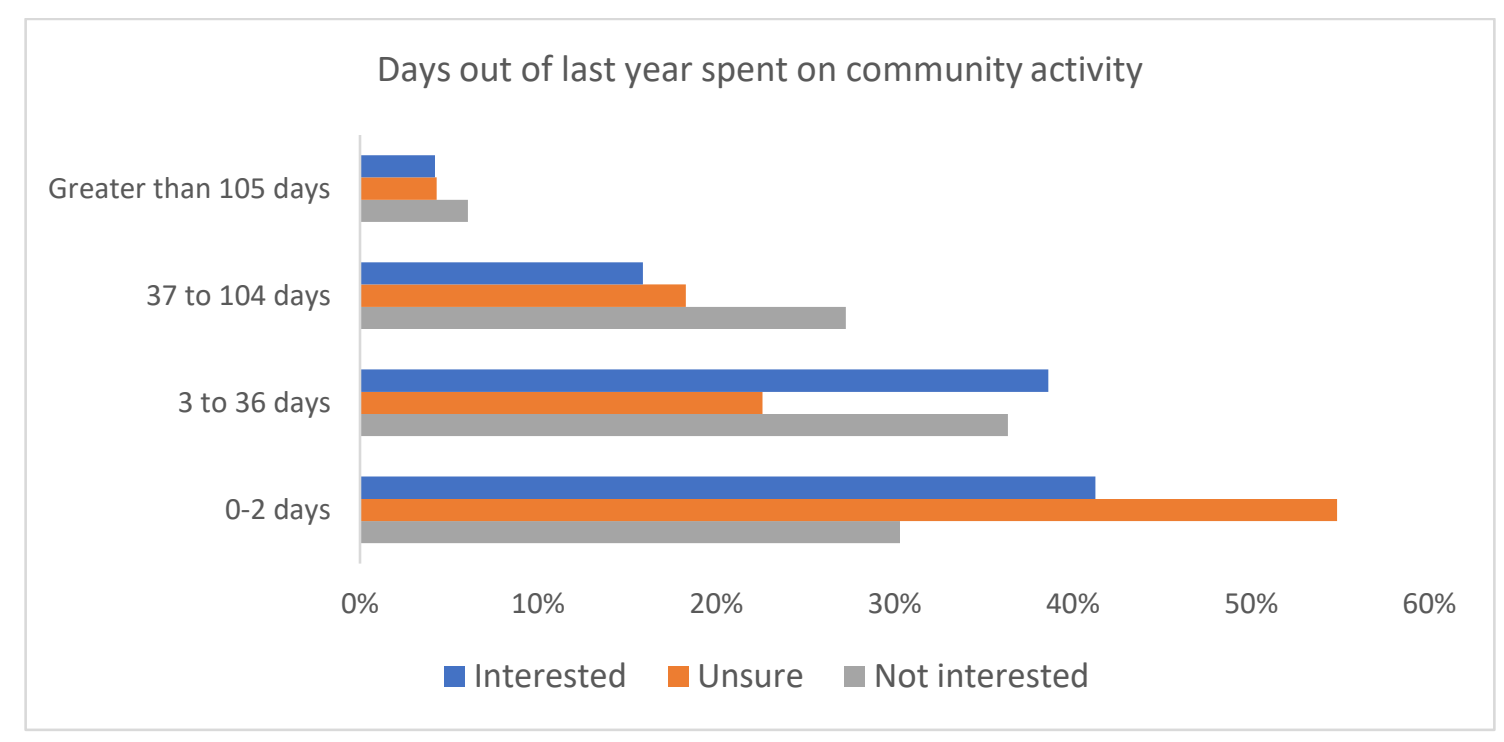




\begin{tabular}{|c|c|c|c|c|c|c|c|c|}
\hline $\begin{array}{c}\text { Participa- } \\
\text { tion } \\
\text { Frequency }\end{array}$ & Never & $\begin{array}{c}\text { Once } \\
\text { a } \\
\text { year }\end{array}$ & $\begin{array}{c}\text { Twic } \\
\text { e a } \\
\text { year }\end{array}$ & $\begin{array}{c}\text { Quarter- } \\
\text { ly }\end{array}$ & $\begin{array}{c}\text { Mon- } \\
\text { thly }\end{array}$ & $\begin{array}{c}\text { Several } \\
\text { times a } \\
\text { month }\end{array}$ & Weekly & $\begin{array}{c}\text { More than } \\
\text { once a } \\
\text { week }\end{array}$ \\
\hline $\begin{array}{c}\text { Score (in } \\
\text { days) }\end{array}$ & 0 & 1 & 2 & 4 & 12 & 36 & 52 & 104 \\
\hline
\end{tabular}

Figure 2.10 The table below the chart shows the scoring methodology used to assess how community-oriented a respondent was. The scores from all the activities were summed and a total community involvement score was calculated for each respondent. Then, the total scores of the respondents from each group were compared and displayed in the figure above.

\section{Section three: Demographic information}

This section summarizes the demographic characteristics of the respondents who completed the "Renewable Energy \& Community Solar Questionnaire". I include the number of the survey question next to the question summary.

Where available, I made a comparison between the demographic information of my survey respondents and the census data of the Portland neighborhoods I sampled from. I used data from the 2010 Census Data for Portland Neighborhoods. I expected to see differences between the census data and my survey participants, as older and more educated citizens are more prone to complete questionnaires (Etter and Perneger 1997). I made these comparisons to understand if there were areas of bias or over/underrepresentation. I expected to see differences between census data and survey respondents because it's possible that utility bill payers (my survey participants) are not representative of the entire Portland population.

Most of my survey respondents were homeowners residing in single family homes. While Portland has a diversity of renters and homeowners living in all types of households (attached or detached homes, duplexes, condominiums, and apartments), the nature of my survey methodology allowed me to sample primarily from the singlefamily household demographic. While renters and multi-family unit dwellers comprised a small proportion of my overall sample, I believe my survey did a good job at representing the single-family household segment of the market.

\section{Age \& Gender}

Q29. The median age of my survey respondents was 50, while the median age for Portland overall is 36.4. Thus, younger residents were not as represented in my survey as older participants were. Again, this is unsurprising as survey-takers are more likely to be older and educated. It should also be noted that survey participants were the utility 
bill-payers of their household, which is also a segment not representative of the overall population of Portland in terms of age.

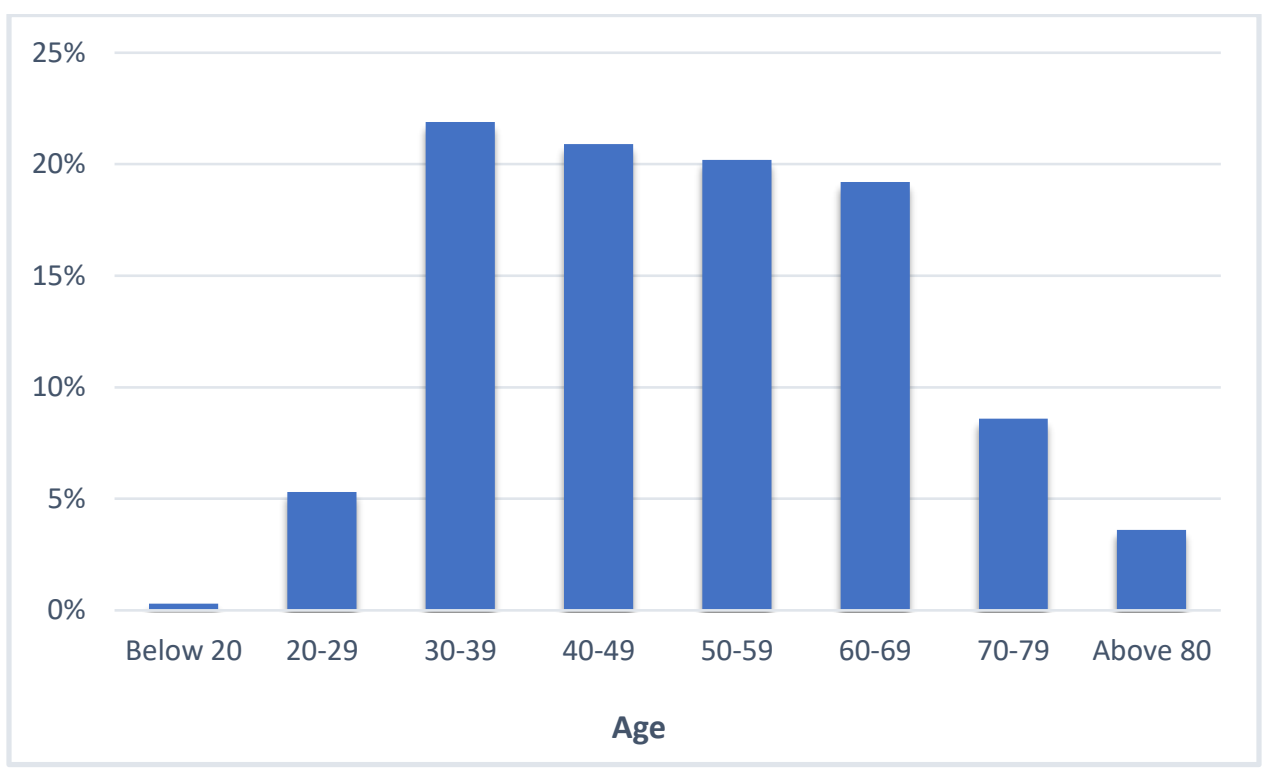

Figure 3.1 [Q29] Age distribution of survey participants ( $N=302)$.

I also found the median age of my survey respondents from each neighborhood and compared it to the neighborhood census median ages (Figure 3.2). While none of the median ages were the same between survey and census, there were a few similar trends. For example, Hillside has the highest median age among the neighborhoods and the median age of my Hillside respondents was also among the highest. Kenton and Linnton were also neighborhoods that had relatively similar median ages between survey and census. 


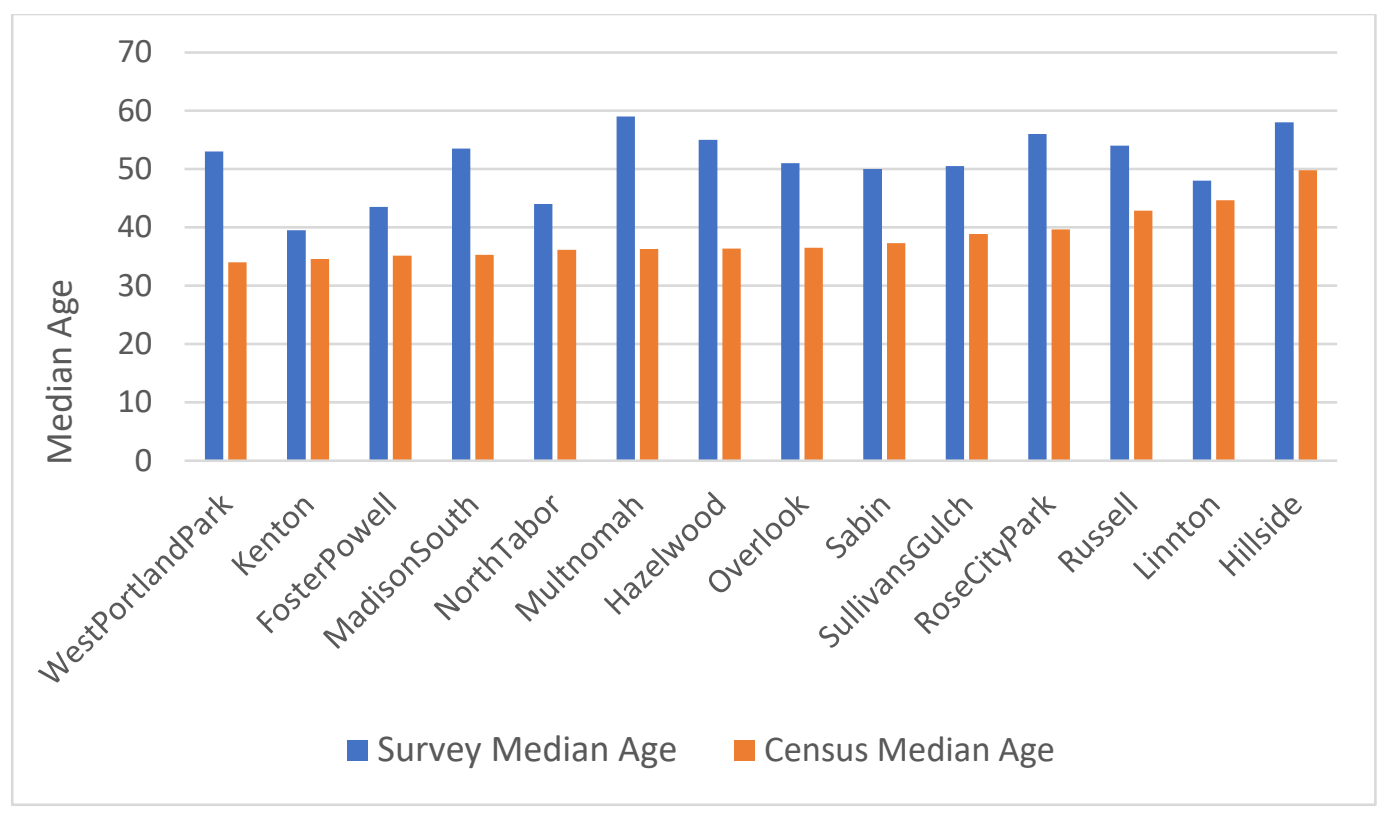

Figure 3.2 [Q29] Comparison of median ages by neighborhood between census data and survey data. Overall, survey respondents were older than the census population data.

Q28. 53\% of survey participants were male, while $43.9 \%$ were female (3.4\% preferred not to say). According to census data for the City of Portland, $50.5 \%$ of the population is female. Therefore, females were underrepresented in my survey.

\section{Your Household}

Q30.19.1\% of my survey respondents rented their home, while $80.9 \%$ were homeowners $(\mathrm{N}=314)$. Owners were overrepresented in my survey, as Portland's overall owner-occupied housing rate is $52.9 \%$. The Drop-Off/Pick-Up methodology that I used to distribute surveys prohibited me from reaching multi-family unit apartment buildings, as most of those complexes have locked front entrances. Because of this, I was likely unable to reach a representative sample of the Portland renter population.

Q31. House square footage was another piece of information I collected to get a better understanding about my sample households. Figure $\mathbf{3 . 3}$ demonstrates the distribution of household sizes in my sample.

Q32. The most common household size was 2 occupants (38\%), while $18.8 \%$ of respondents lived alone, $22.4 \%$ of homes had 3 residents, $16.3 \%$ had 4 occupants, and $4.5 \%$ of homes had 5 or more occupants $(N=313)$.

Q34. Most homes sampled were single-family detached homes (90.2\%). Another $4.4 \%$ were duplexes, triplexes, or quadplexes, $2.5 \%$ were apartments, and $2.8 \%$ were either townhomes or "other" ( $\mathrm{N}=317)$. 
Q35. I also inquired about the planned length of residence that the participant believed he or she would stay at their current home. Figure $\mathbf{3 . 4}$ reflects the response distribution of planned length of residence. Many respondents reported their planned length of residence is at least 5 or 10 years, which would work well with the length of contract for community solar participation. Additionally, if respondents plan to move from their house in a few years or less, but within PGE or Pacific Power territory, community solar contracts could be portable for such participants.

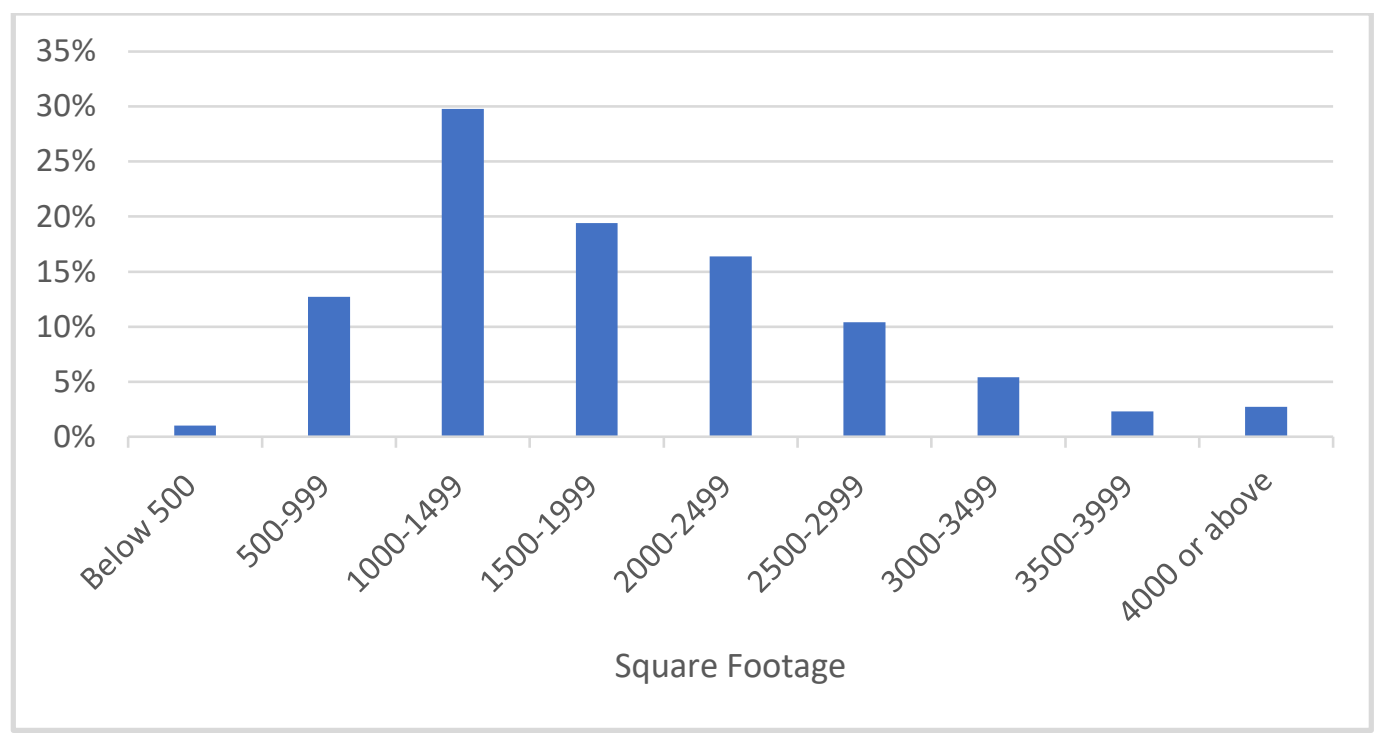

Figure 3.3 [Q31] Distribution of house size of survey participants. Most of the homes were between 1,000 and 2,500 square feet $(N=301)$.

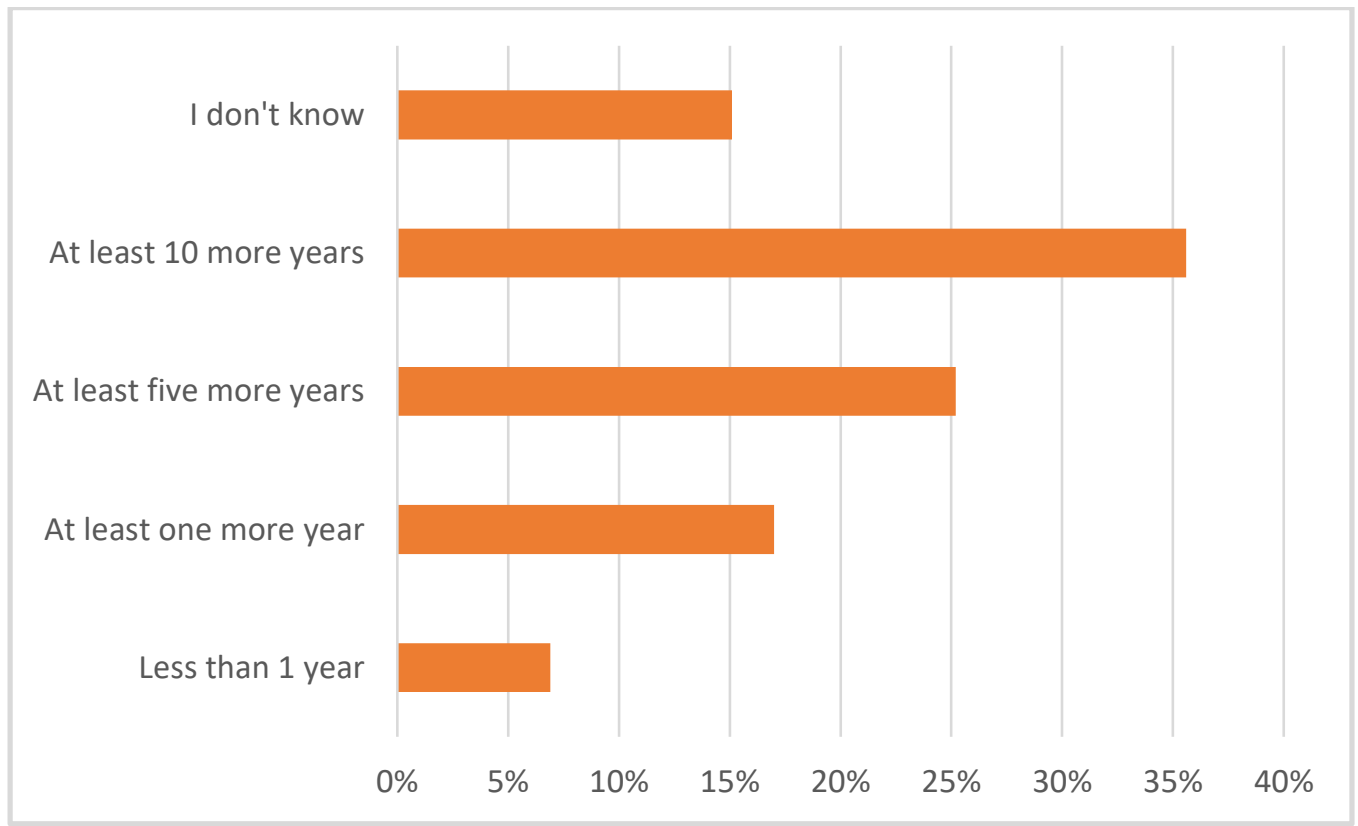


Figure 3.4 [Q35] Distribution of survey respondents' planned length of residence at their current home. Over $60 \%$ of participants said they are planning to live at their Portland home for at least 5 or 10 years $(N=317)$.

\section{Political views}

Q37. Political ideology may play a role in someone's attitude towards renewable energy or community solar, thus I felt it was appropriate to ask my survey respondents to rate their political views on a conservative-liberal scale. Figure $\mathbf{3 . 5}$ shows the distribution of political ideologies of my survey respondents.

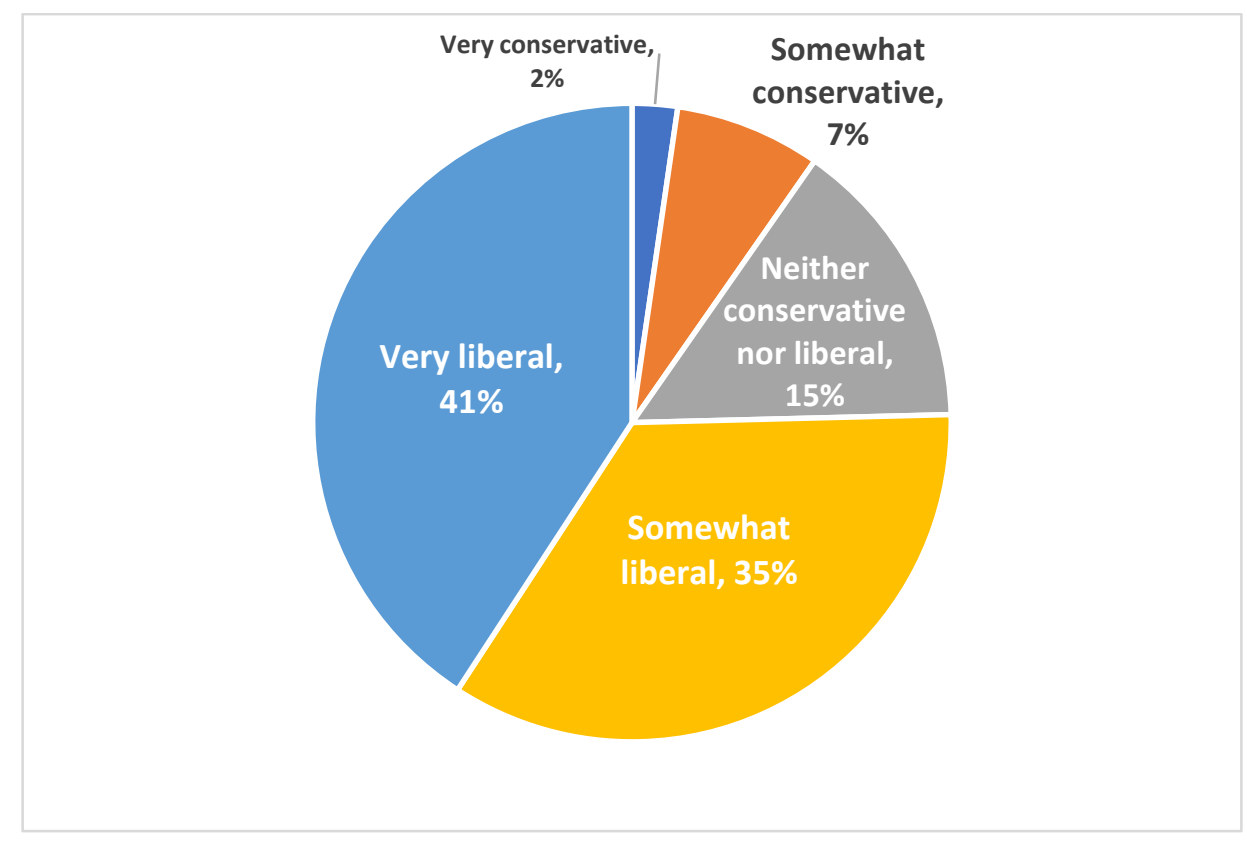

Figure 3.5 [Q37] Pie chart showing the distribution of political views among survey participants. Over $75 \%$ of respondents were either somewhat or very liberal ( $N=309)$.

\section{Education \& Income}

Q36. Educational attainment is a known demographic variable that influences proenvironmental behavior. I wanted to capture the education levels of my survey respondents to assess whether there was a relationship between interest in community solar and education. Figure $\mathbf{3 . 6}$ demonstrates the distribution of educational attainment of my survey participants. Overall census data for education tells us that $45.5 \%$ of Portland citizens 25 years or older have Bachelor's degrees or higher. My survey respondents are evidently more educated than the general population of Portland, ( $73 \%$ of survey participants have a Bachelor's degree or higher) which brings me back to the notion that educated citizens are more prone to complete questionnaires than uneducated residents. 
Q38. Because income has historically been a barrier to the adoption of solar PV systems (due to high upfront costs), and community solar could potentially break down that barrier, I collected income information about my survey participants. I compared the survey median income bin and the census median income of each of my selected neighborhoods (Figure 3.7, $\mathrm{N}=295$ ). Overall, $6.4 \%$ of my survey participants had incomes less than $\$ 25,000 ; 35.6 \%$ had incomes between $\$ 25,000$ and $\$ 74,999 ; 38.6 \%$ had incomes between $\$ 75,000$ and \$149,999; 10.2\% had incomes between \$150,000 and $\$ 199,999$, and $9.2 \%$ had a household income greater than $\$ 200,000$.

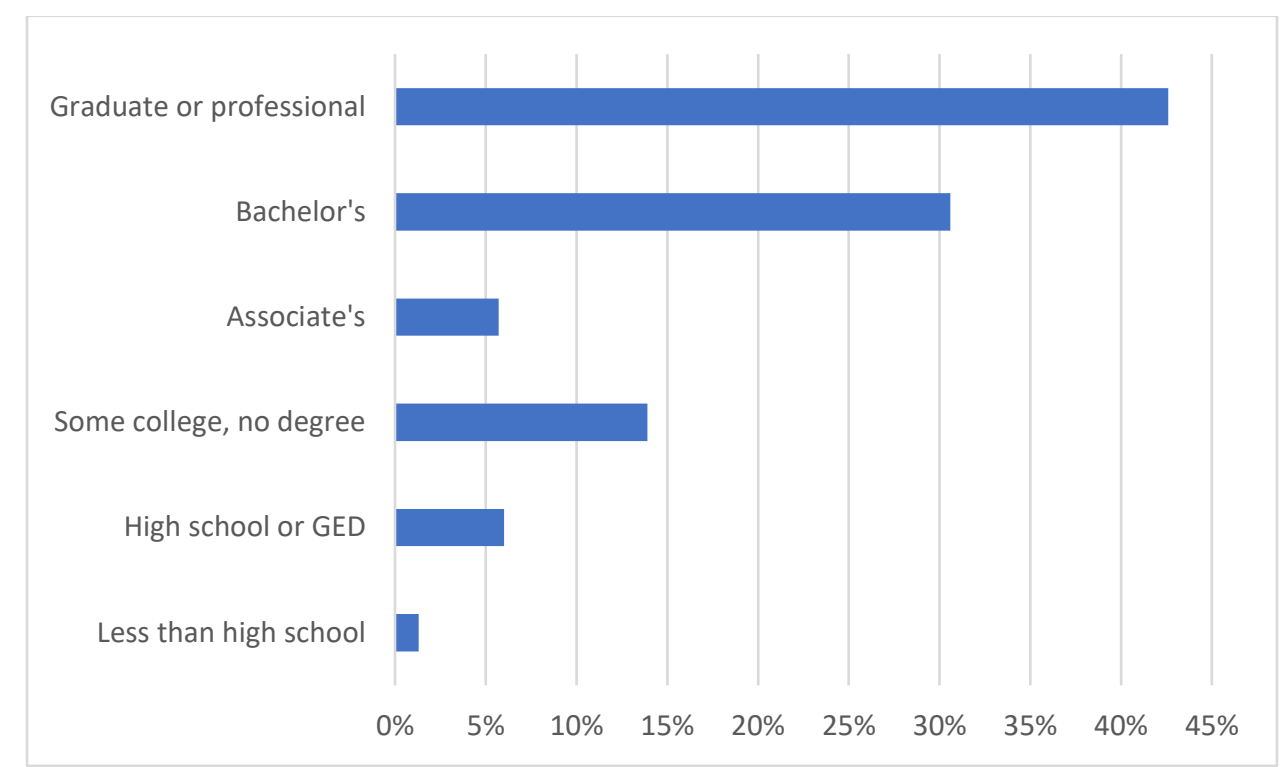

Figure 3.6 [Q36] Distribution of education levels of survey respondents ( $N=317)$. Almost three-quarters of participants had either a Bachelor's degree or a professional degree. 


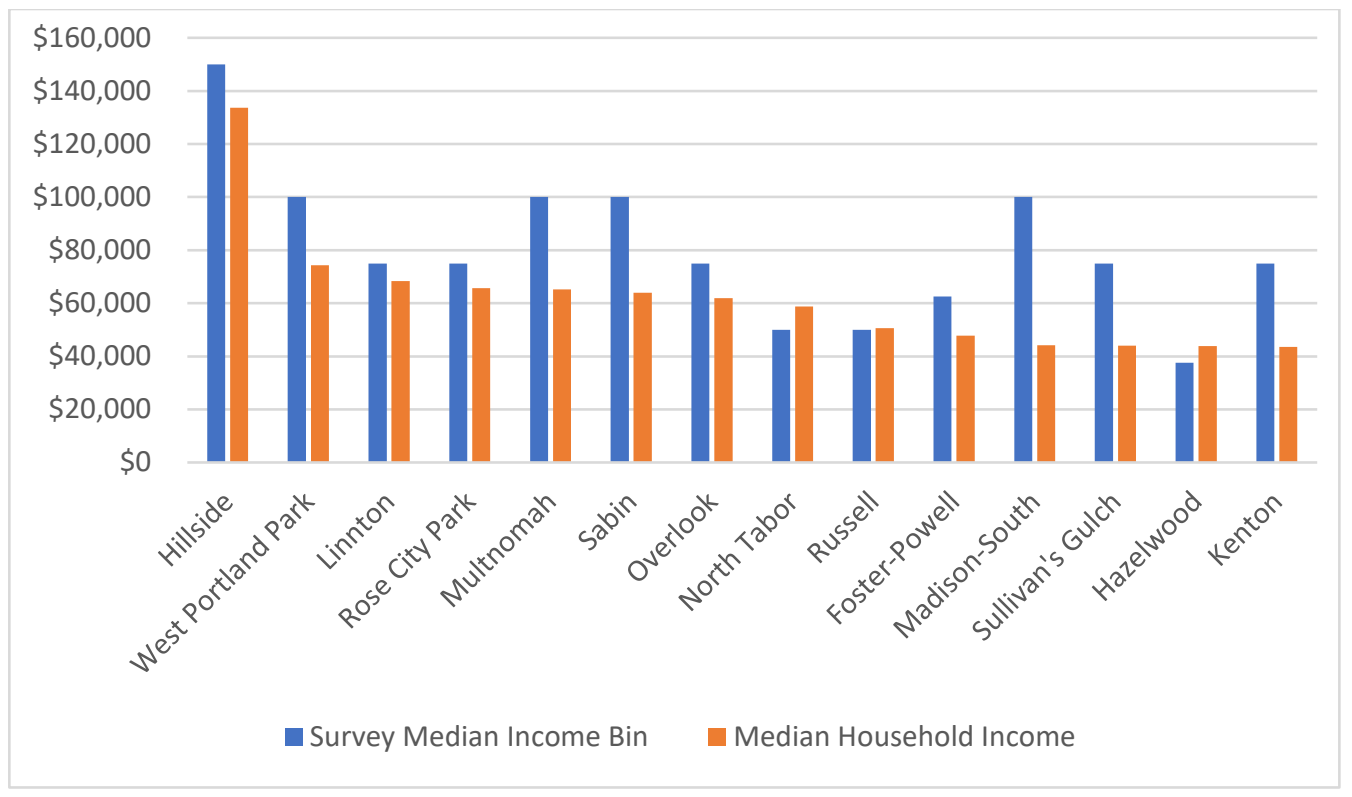

Figure 3.7 [Q38] Comparison between census median household income for each neighborhood in sample (orange bars) and median income bin chosen by survey participants in each neighborhood (blue bars). Higher income residents were overrepresented in my survey. Largest disparities were between the neighborhoods of Madison-South, Multnomah, and Sabin, which may be due to the omission of multi-unit apartment buildings in these neighborhoods (which correspond with younger residents and lower incomes).

\section{Section four: General Energy}

This section summarizes the responses to the first section of the "Renewable Energy and Community Solar Questionnaire". These questions inquired about general attitudes towards renewable energy; using a Likert-scale to rate agreement or disagreement with multiple energy statements. Additionally, energy knowledge, conscientiousness, electricity provider, and voluntary green utility program enrollment were other questions included in this section.

\section{Electricity provider \& green utility program enrollment}

Q1. 73\% of my participants had PGE as their utility, while $26 \%$ were Pacific Power customers. These statistics were to be expected as most neighborhoods in my sample were located within PGE territory rather than Pacific Power.

Q2. Figure 4.1 shows the proportion of residents enrolled in a voluntary green utility program and those who are not. Green utility program participants were overrepresented in my survey (10-15\% of Portland residents are enrolled in such a program). This may suggest that green utility program participants would be more 
inclined to join a community solar project (and more interested in completing this questionnaire) since they're already paying a premium to bring more renewables online.

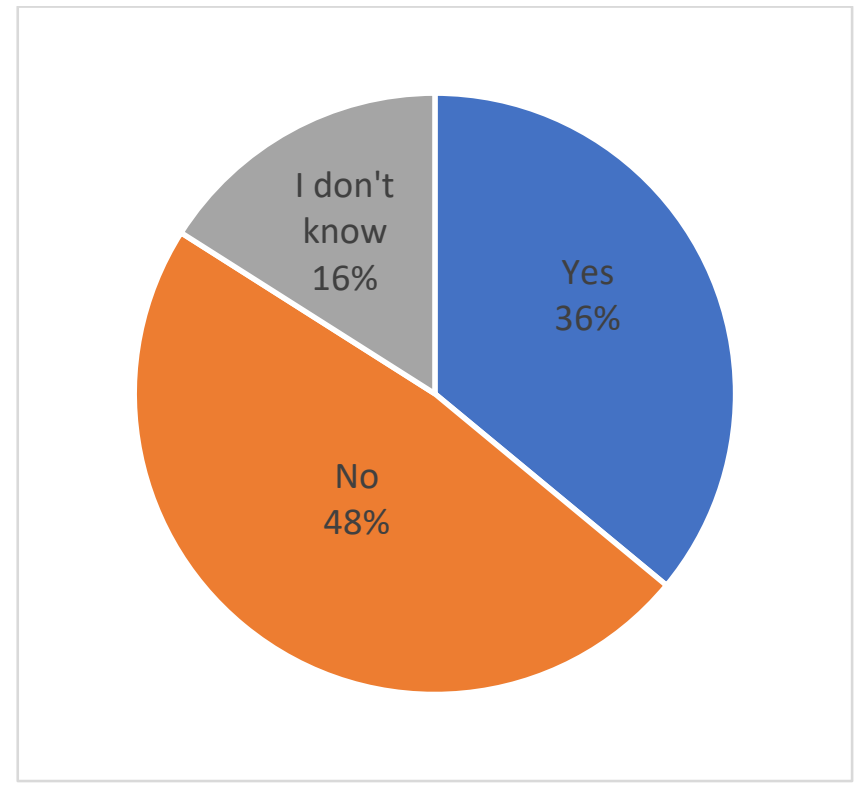

Figure 4.1 [Q2] Pie chart showing the distribution of responses from the question: "Are you currently enrolled in a voluntary green utility option?" ( $N=329)$

\section{Portland's Energy}

Q4. I asked about respondents' preferred source of energy that PGE or Pacific Power should invest in. This question used a ranking scale; I asked them to rank their top three energy choices. Figure $\mathbf{4 . 2}$ includes the response distributions of each energy source I provided. Solar and wind were the top choices among survey respondents, with hydropower, biofuels, and geothermal being the most frequently chosen third choices. 


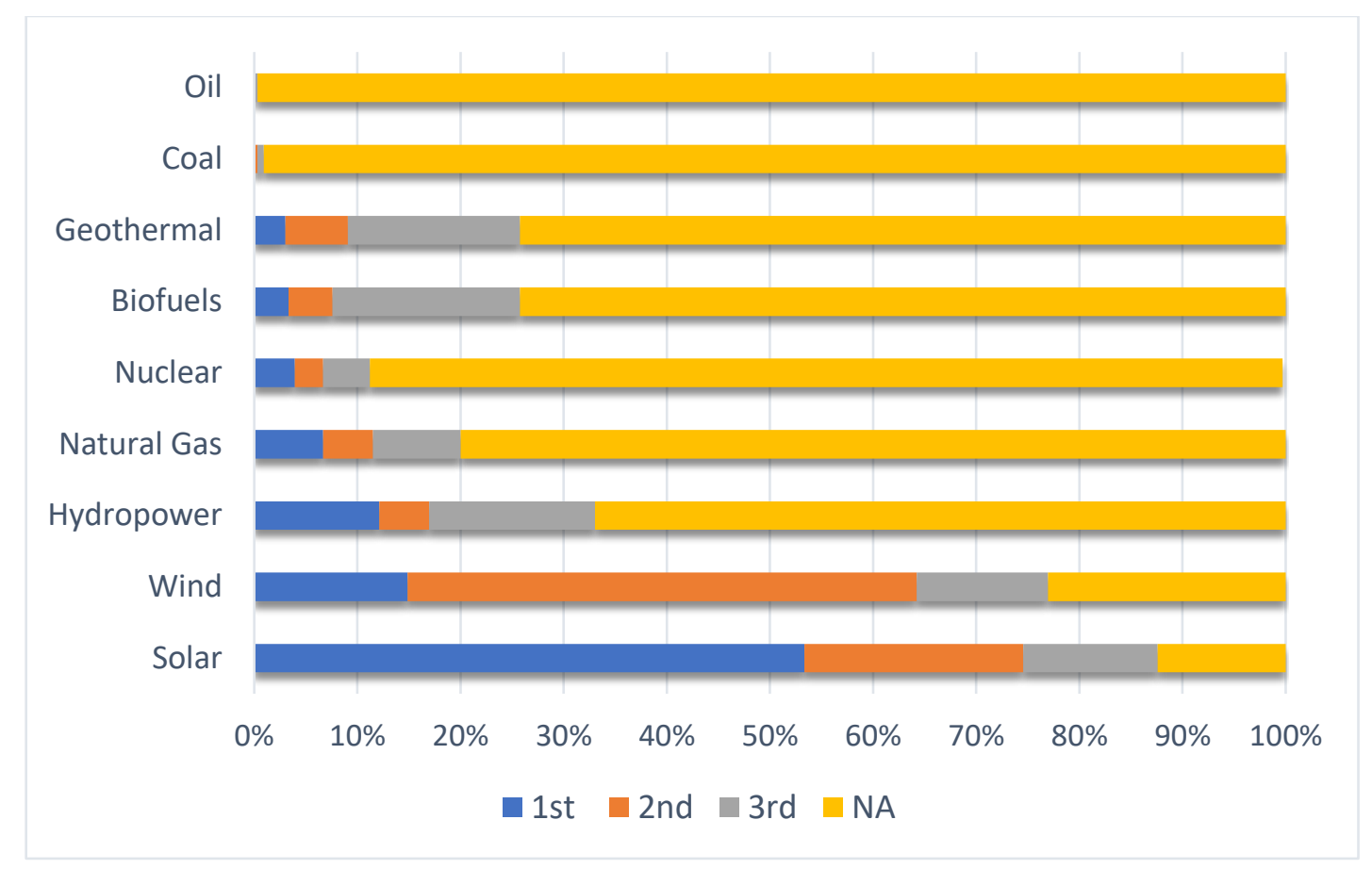

Figure 4.2 [Q4] Breakdown of responses for each energy source. Blue represents preferred energy source, orange and green represent second and third choices (respectively), and yellow reflects the proportion of no answers (not within top three energy sources). Almost $100 \%$ of survey respondents did not pick oil or coal within their preferred energy sources ( $N=330$ including $N A s)$.

\section{Energy knowledge}

Q3. To get a sense of how knowledgeable my survey participants were about Portland's electricity mix I asked the question, "What proportion of Portland's energy is generated from renewable energy sources other than hydroelectric (e.g., solar or wind energy)?" PGE and Pacific Power currently generate between 5 and $10 \%$ of Portland's electricity from renewable sources. Figure $\mathbf{4 . 3}$ shows the distribution of responses for this question. Most respondents were somewhat knowledgeable; however, the mean proportion of renewable energy was $18.8 \%$; roughly double the actual proportion.

Q5. This question directly asked the respondent to rate themselves on how knowledgeable they were about renewable energy in general. Mirroring the previous results from Q3, most participants felt moderately knowledgeable about renewable energy: 9.5\% were felt unknowledgeable, $37.1 \%$ were slightly knowledgeable, $45.7 \%$ were moderately knowledge, and $6.4 \%$ rated themselves as either knowledgeable or extremely knowledgeable ( $\mathrm{N}=327)$. 


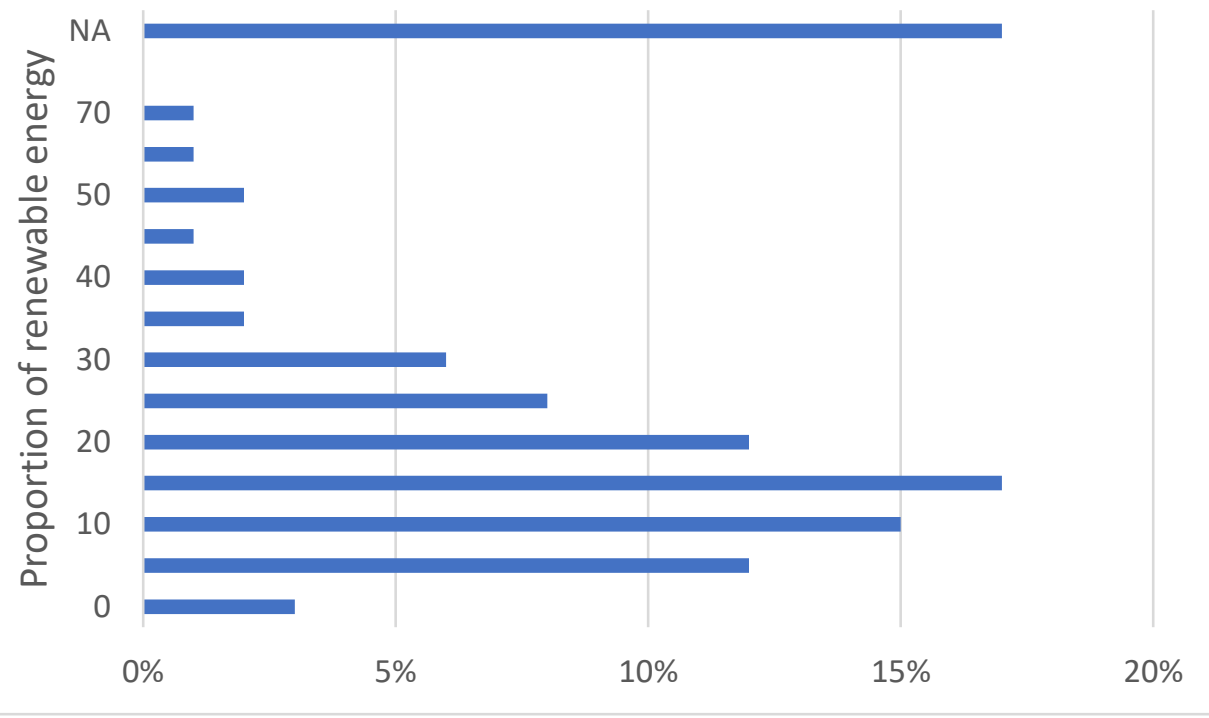

Figure 4.3 [Q3] Distribution of responses for the question asking about the renewable proportion of Portland's energy mix. Many respondents left this question blank, perhaps signifying a lack of knowledge ( $N=275$, excluding $N A s)$.

\section{Energy Conscientiousness}

Q6. Exhibiting conservative usage of energy and self-reporting energy conscientiousness may tie in with environmental behaviors and attitudes, which are factors that may influence intent to participate in community solar. Most respondents rated themselves as somewhat or very energy conscious (Figure 3.4, N=329).

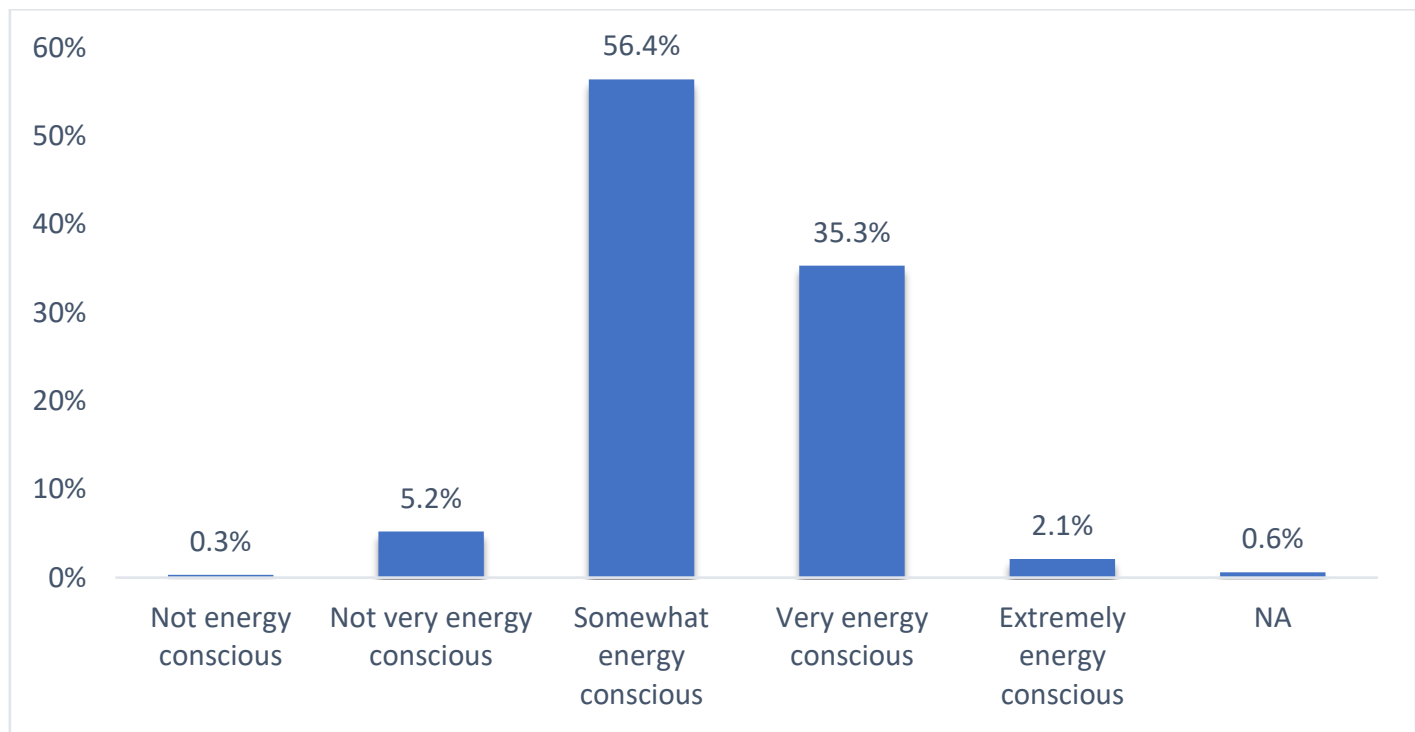

Figure 4.4 [Q6] Distribution of the responses for the question: "How energy conscious do you consider yourself?' 


\section{Attitudes}

Q7. The response distributions for various statements about renewable energy are given below in Table 4.1. The first three statements are positive; they have the highest proportion of respondents agreeing with them. The other nine statements reflect indifference, negativity, or costliness in relation to renewable energy. Most survey respondents disagreed with these negative or indifferent statements, while the statements about renewable energy being costly had a higher proportion of neutral or positive responses.

Table 4.1[Q7] Summarizes the response distributions for the question: "How much do you agree or disagree with the following statements about renewable energy?". It should be noted that I loaded "strongly agree" and "somewhat agree", as well as "strongly disagree" and "somewhat disagree" into two broader response categories: Agree and Disagree.

\begin{tabular}{|c|c|c|c|c|}
\hline Attitudes towards energy & Agree & Neutral & Disagree & $\mathbf{N}$ \\
\hline Renewable Energy helps prevent climate change & $84.7 \%$ & $4.6 \%$ & $10.7 \%$ & 326 \\
\hline $\begin{array}{l}\text { Renewable energy helps us transition away from fossil } \\
\text { fuels }\end{array}$ & $88.3 \%$ & $4.6 \%$ & $7.1 \%$ & 325 \\
\hline Renewable energy reduces our impact on the planet & $87.2 \%$ & $4.6 \%$ & $8.2 \%$ & 327 \\
\hline $\begin{array}{l}\text { We should continue to use fossil fuels because they're } \\
\text { cheaper }\end{array}$ & $12.5 \%$ & $11.3 \%$ & $76.2 \%$ & 327 \\
\hline $\begin{array}{l}\text { Renewable energy will make no difference for climate } \\
\text { change }\end{array}$ & $13.9 \%$ & $11.4 \%$ & $74.7 \%$ & 324 \\
\hline Solar \& wind are costly & $39.3 \%$ & $37.7 \%$ & $23.0 \%$ & 326 \\
\hline We aren't going to run out of fossil fuels anytime soon & $25.4 \%$ & $15.0 \%$ & $59.6 \%$ & 327 \\
\hline Renewable energy is overrated & $6.8 \%$ & $4.6 \%$ & $88.6 \%$ & 323 \\
\hline $\begin{array}{l}\text { Maintenance \& installation of renewable energy } \\
\text { technologies are costly }\end{array}$ & $52.1 \%$ & $34.4 \%$ & $13.5 \%$ & 326 \\
\hline I'm too busy to ever think about renewable energy & $9.8 \%$ & $14.5 \%$ & $75.7 \%$ & 325 \\
\hline I don't think about where my energy comes from & $13.8 \%$ & $11.6 \%$ & $74.6 \%$ & 327 \\
\hline $\begin{array}{l}\text { I don't care where my energy comes from as long as it's } \\
\text { affordable }\end{array}$ & $8.9 \%$ & $9.8 \%$ & $81.2 \%$ & 325 \\
\hline
\end{tabular}




\section{Section five: Solar Energy}

This section summarizes the responses from the second section in my survey. These survey questions were designed to capture information about residential interest in utilizing solar energy, knowledge about solar power, perceived barriers of home solar PV systems, and familiarity with different solar energy options. This section is a precursor to the community solar section because it builds an understanding about the respondents' awareness of solar and whether solar is perceived as an energy practice infeasible for the Portland market.

The key take-away from section four is that more survey respondents than not report interest in pursuing solar power. Perceived barriers of solar energy are insignificant (lack of knowledge is the largest barrier, however), while familiarity with most solar energy options is low; most respondents were not very familiar with community solar or leasing solar panels. This trend suggests that offering information or additional knowledge to residents regarding community solar may enable intent to adopt (Jager, 2006).

\section{Solar knowledge}

Q8. This question narrows the knowledge variable from general understanding about renewable energy to specific knowledge regarding solar electricity. Almost $85 \%$ of survey respondents felt slightly or moderately knowledgeable about solar electricity. Very few ( $6 \%$ ) felt confident enough to rate themselves as very or extremely knowledgeable. This suggests that a lack of knowledge is a plausible reason for hindering the adoption of solar in the Portland market. See Figure $\mathbf{5 . 1}$ for the distribution of survey responses.

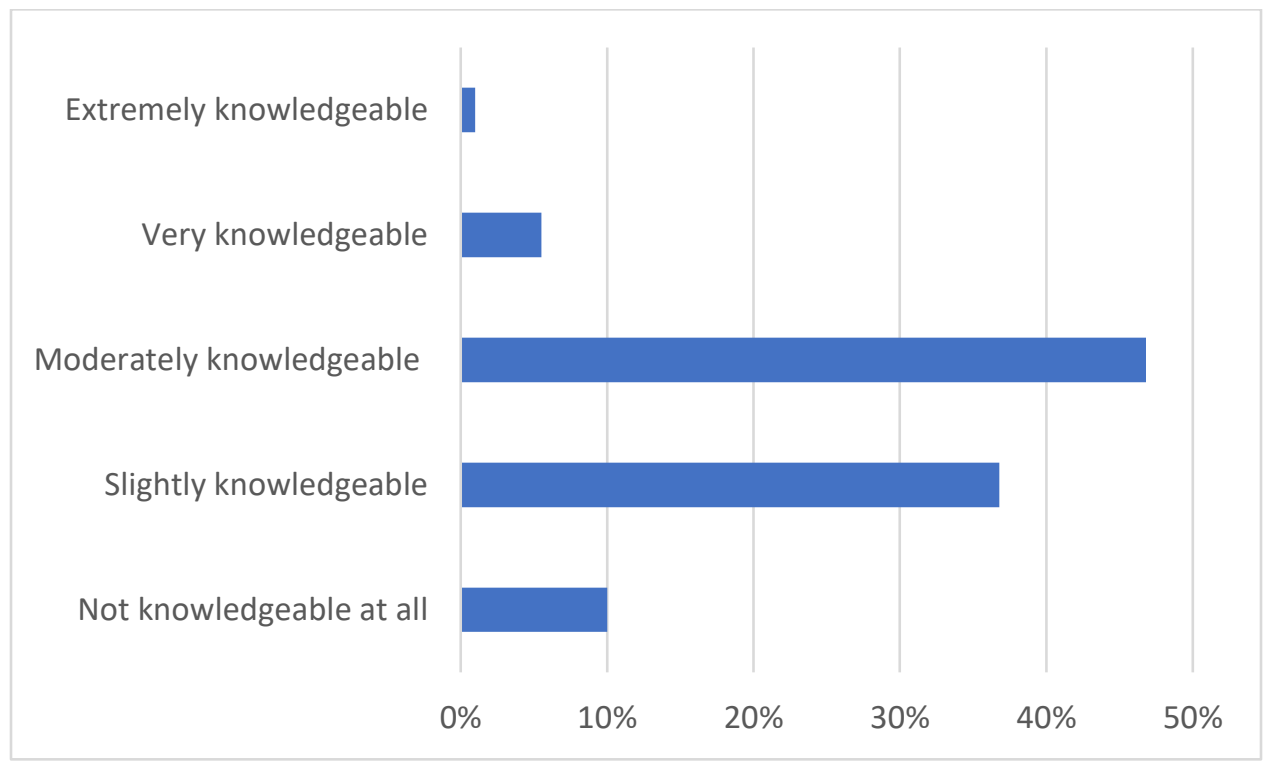


Figure 5.1 [Q8] asked survey respondents, "how knowledgeable are you about solar electricity?". This figure demonstrates the response distributions; most survey respondents felt slightly or moderately knowledgeable about solar electricity $(N=329)$.

\section{Interest in Solar}

Q9. I asked, "How interested or uninterested are you in having access to solar electricity at your place of residence?" to get a sense of how Portland residents feel about using solar power at their home. $1.5 \%$ and $9.5 \%$ of survey respondents stated they were not at all or not very interested in solar, respectively. Another $39.8 \%$ felt unsure about it, $29.9 \%$ stated they were very interested, and $19.3 \%$ stated they were extremely interested ( $\mathrm{N}=327)$. Additionally, I organized percent of respondents who were very or extremely interested in solar by neighborhood and displayed it in Figure 5.2.

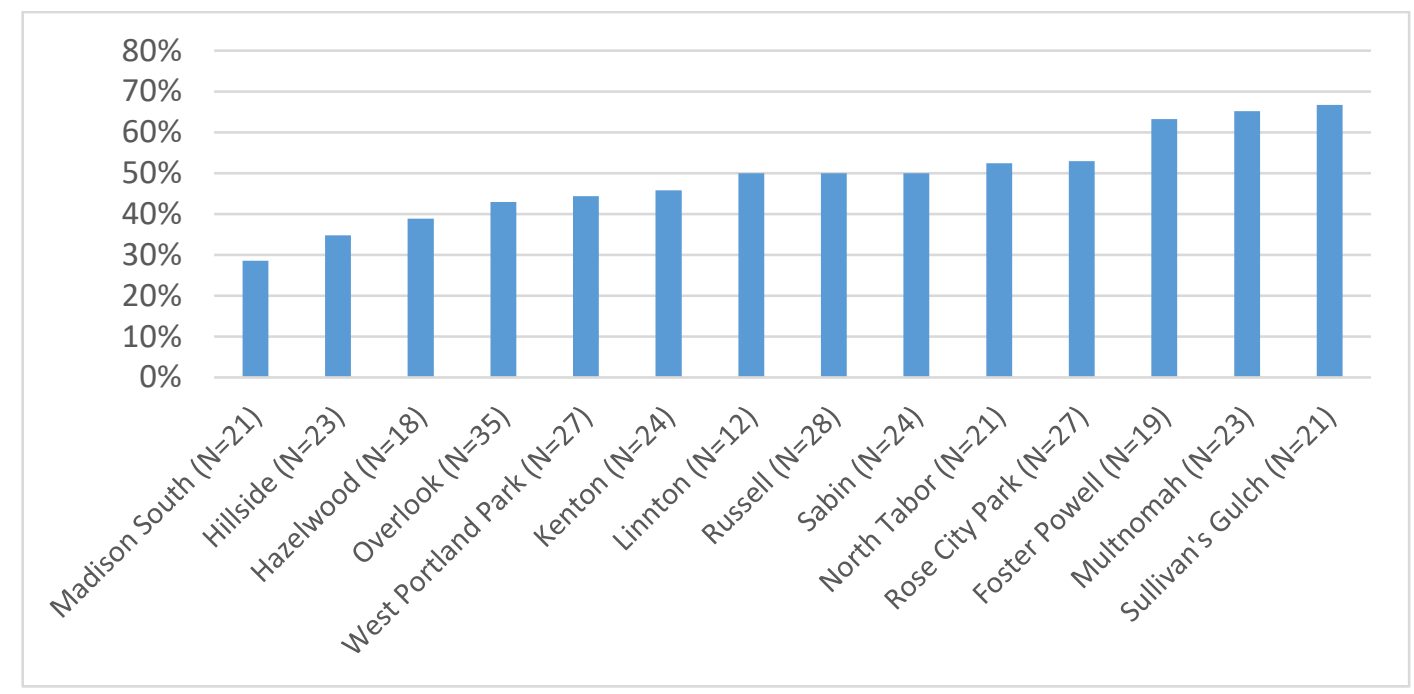

Figure 5.2 [Q9] Distribution of respondents from each neighborhood who stated they were very or extremely interested in having access to solar power at their place of residence. Sample size of each neighborhood is listed on the $x$-axis as well. Sullivan's Gulch, Multnomah, and Foster-Powell were the neighborhoods with the highest proportion of respondents interested in solar power, while Madison-South had the lowest; less than $30 \%$ of respondents said they were very or extremely interested.

\section{Perceived Barriers}

Q10. To explore what sorts of solar energy barriers are perceived among Portland residents, I asked the question, "How much do you agree or disagree that the following are barriers for you to pursue a home solar electricity system?" The most significant barriers perceived among respondents were lack of knowledge (about $70 \%$ agreed or were neutral), concerns about reliability and maintenance ( $72 \%$ agreed or were 
neutral), and high costs (over $80 \%$ agreed or were neutral). Barriers such as lack of interest, solar is too new, or "I rent my home" were insignificant. Table $\mathbf{5 . 1}$ displays the distribution of responses for each barrier.

Table 5.1[Q10] Response distributions of each barrier, organized ordinally from highest proportion of agreement to lowest. Higher proportion of agreement signifies that more respondents perceived the statement as a barrier.

\begin{tabular}{|lrrrr|}
\hline Barrier & Agree & Neutral & Disagree & N \\
\hline I don't know enough about home solar & $51.4 \%$ & $18.4 \%$ & $30.2 \%$ & 321 \\
\hline I'd have concerns about reliability and maintenance & $50.5 \%$ & $21.9 \%$ & $27.7 \%$ & 325 \\
\hline The costs are too high & $45.2 \%$ & $35.8 \%$ & $19.0 \%$ & 321 \\
\hline I don't plan to live in my home long enough for it to pay off & $32.5 \%$ & $25.1 \%$ & $42.4 \%$ & 323 \\
\hline My roof is not suited & $30.3 \%$ & $36.4 \%$ & $33.3 \%$ & 317 \\
\hline It'd be too much hassle & $26.5 \%$ & $32.1 \%$ & $41.4 \%$ & 321 \\
\hline I don't have the time & $23.3 \%$ & $24.9 \%$ & $51.7 \%$ & 317 \\
\hline I rent my home & $18.7 \%$ & $4.6 \%$ & $76.7 \%$ & 305 \\
\hline Solar is too new to the market & $12.1 \%$ & $29.7 \%$ & $58.2 \%$ & 323 \\
\hline I'm not interested in home solar & $9.0 \%$ & $14.6 \%$ & $76.4 \%$ & 322 \\
\hline
\end{tabular}

Familiarity of Solar Options

Q11. To gauge how aware my survey respondents were about various solar energy options, I asked the question, "Please rate your level of familiarity for each of the following options for solar electricity". I then provided four different options for accessing solar electricity: green utility programs (such as PGE's Green Future Solar program), community solar projects, leasing home solar panels, and owning home solar panels (O'Shaughnessy, 2014). Most survey participants were not very familiar with any of the options. Community solar and leasing solar were the two options that had the highest proportion of respondents stating they were unfamiliar $(89 \%$ and $81 \%$, respectively), while respondents were most familiar with utility programs (52.6\% were somewhat familiar or familiar). Figure $\mathbf{5 . 3}$ displays the distribution of responses. 


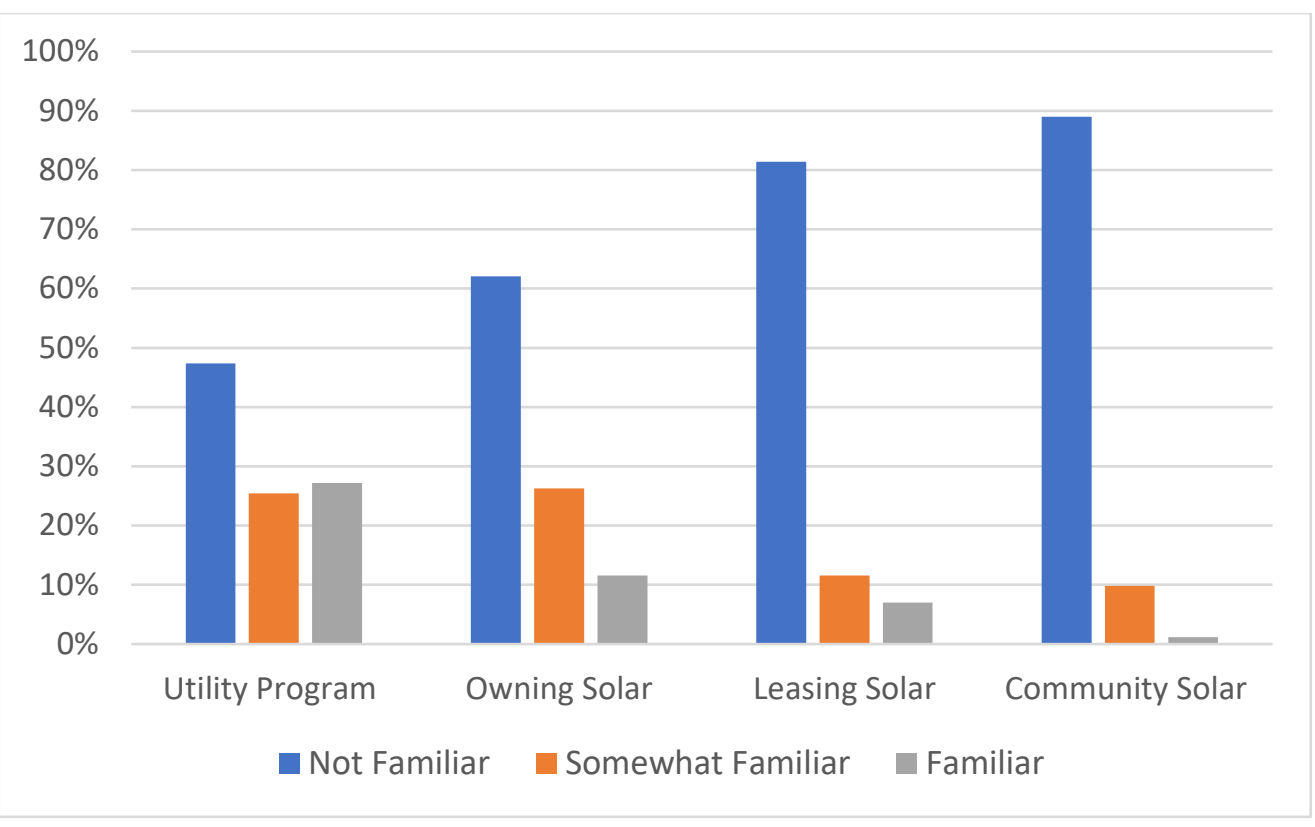

Figure 5.3 [Q11] Distribution of responses $(N=327)$. Most respondents were not very familiar with any of the options.

\section{Section six: Community Solar}

This section includes a summary of the responses to questions about community solar. Prior to this chapter in the questionnaire, I provided a one-page synopsis of community solar: the mechanics of a theoretical project, background information about the community solar program in Oregon, and the benefits that community solar brings to our energy system (See Figure 6.1). Further, I integrated a framing component within this supplemental information page to assess if the framing of community solar would impact a respondent's interest in joining a project. This chapter of the report summarizes prior knowledge about community solar, general interest in joining a project and timing of adoption, preferences for different project factors, willingness to participate in different scenarios based on changes in your electricity bill, influence of peer participation, and results of the framing experiment. 


\section{Why Community Solar?}

Oregon's "Clean Electricity and Coal Transition Plan" was passed in 2016 and directs the

Oregon Public Utility Commission to establish a community solar program through Investor-

Owned Utilities (PGE and Pacific Power) by the summer of 2017.

What is a Community Solar Project?

Community solar projects are solar-electric systems that provide power and financial benefits to multiple people and businesses (as opposed to rooftop solar, which typically only benefits the owner of the roof).

\section{What else is there to know about Community Solar?}

Where? Community solar arrays can be developed anywhere in the state.

How Big? Projects must be at least 25KW or enough to power about 3 to 5 homes.

Enrollment? Common options: monthly subscription or an upfront payment.

Other benefits? Participants will own the Renewable Energy Certificates (RECs) and may be eligible for federal tax credits as well as state solar incentives.

Figure 6.1 Supplemental information about community solar provided in the survey. A diagram depicting the mechanics of a community solar project was also supplied.

\section{Prior knowledge}

Q12. While I already investigated respondents' familiarity with community solar in the previous section, I wanted to further explore whether residents had any prior knowledge about this energy practice. Results of this question are displayed below in the pie chart (Figure 6.2). No respondents knew a great deal about community solar, while $1 \%$ knew a lot. $86 \%$ of respondents knew either nothing or a very small amount about community solar and $13 \%$ knew a moderate amount.

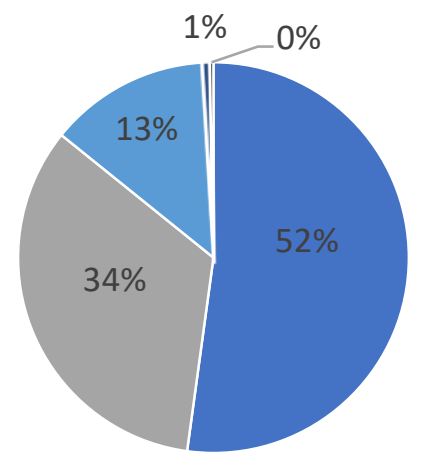

None at all

A little

A moderate amount

- A lot

A great deal

Figure 6.2 [Q12] Pie chart displaying response distribution to the question, "Prior to reading the information on the facing page, how much did you know about community solar?" $N=324$. 


\section{Interest in Community Solar}

Q13. The variable of interest that I'm testing against other survey variables (such as demographics, attitudes, awareness) is general interest in joining a community solar project. Interest was measured by two questions in my survey: Q13 (In general, how interested would you be in joining a community solar project?) and Q15 (see below). Figure 6.3 demonstrates the distribution of responses, organized by neighborhood. Overall, $11 \%$ of respondents were not at all or not very interested in joining a community solar project, while $29.6 \%$ were unsure about their interest. $59.3 \%$ of respondents stated they were moderately or very interested in joining a community solar project.

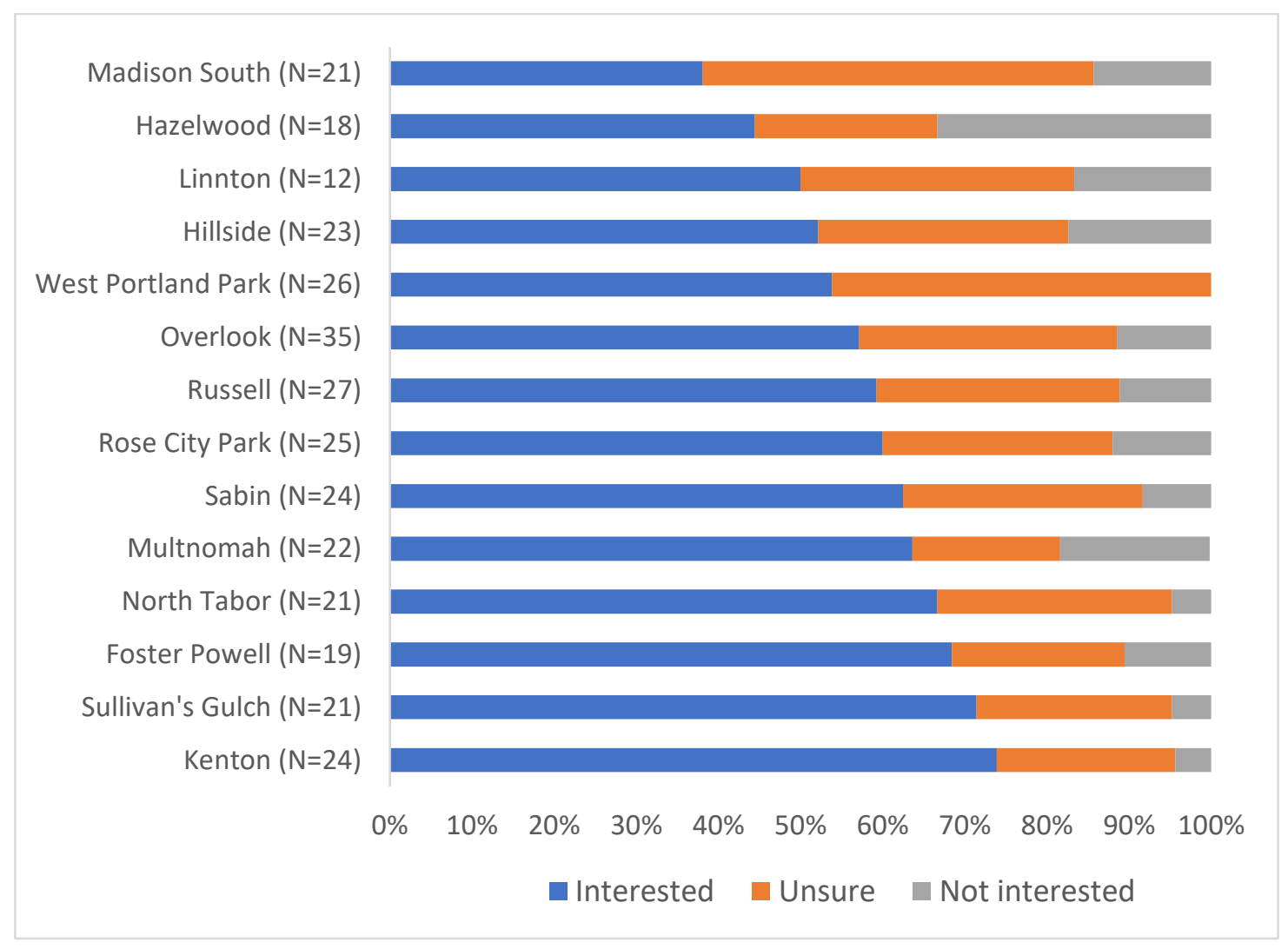

Figure 6.3 [Q13] Distribution of results for Q13, organized by neighborhood. Kenton, Sullivan's Gulch, and Foster-Powell had the highest proportion of respondents interested in community solar, while Madison South and Hazelwood had the lowest proportion. Proportion of interest ranged from less than $40 \%$ to over $70 \%$. Overall $N=324$.

Q15. To further assess a respondent's potential interest in community solar, I inquired about the hypothetical timing of enrollment: "If a community solar project was available to you right now, how soon do you think you would enroll?" Almost 7\% of respondents said they would immediately, while about $14 \%$ would likely never join. Another $80 \%$ 
would wait either a few months or a few years to conduct additional research or see how the program turns out. This group likely represents the early and late majority of the population of Portland (Faiers and Neame, 2006). Evidently, this trend points out that survey respondents mostly need more information about community solar before they decide to join a project. Figure 6.4 visualizes the distribution of responses for Q15.

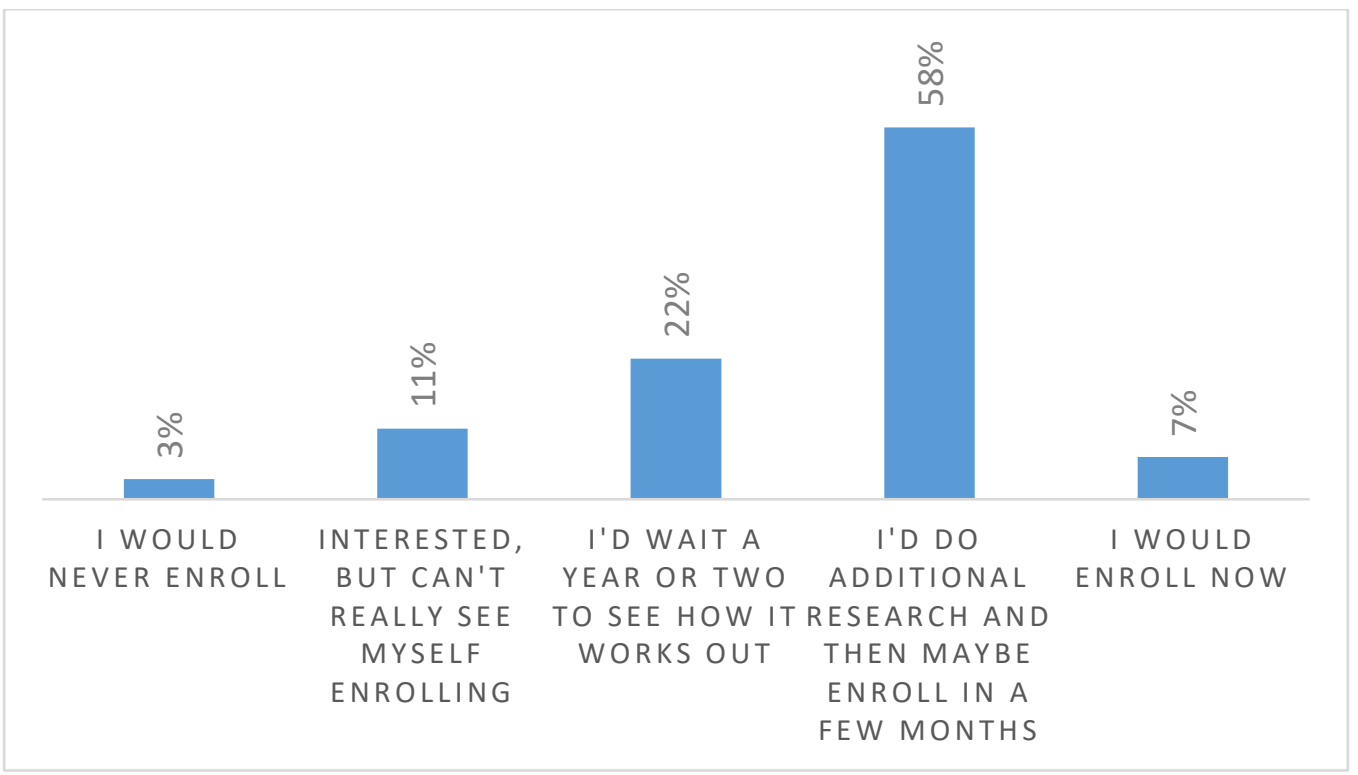

Figure 6.4 [Q15] Distribution of responses ( $N=321)$. Most respondents felt they would join a community solar project after a few months of additional research, while a small proportion stated they would immediately join. Another $22 \%$ would wait several years to observe how the projects turn out.

\section{Project preferences}

Q14. Community solar projects can be large or small, local or far, managed by a utility or a third-party, and funded through a subscription or ownership model. Together, these factors cause trade-offs as well as a diverse array of possible project scenarios. To gather information about attitudes towards these project factors, I provided various statements about community solar and asked each respondent how much he or she agrees or disagrees with them. Figure 6.5 displays the distribution of responses for each statement. The overall trend observed from these statements is that most respondents were neutral about these factors. Most respondents disagreed that community solar sounds too complex to work in their neighborhood. Almost half of all respondents agreed that projects should emphasize affordability, while less than $20 \%$ preferred projects to be small. The visibility factor was not important to survey respondents: $11 \%$ agreed that projects should be located within the community, visible to members, while $\sim 28 \%$ disagreed and $\sim 60 \%$ were neutral. "Community solar projects should be located 
wherever it's most affordable; even if it's out of sight" was the statement that most respondents agreed with.

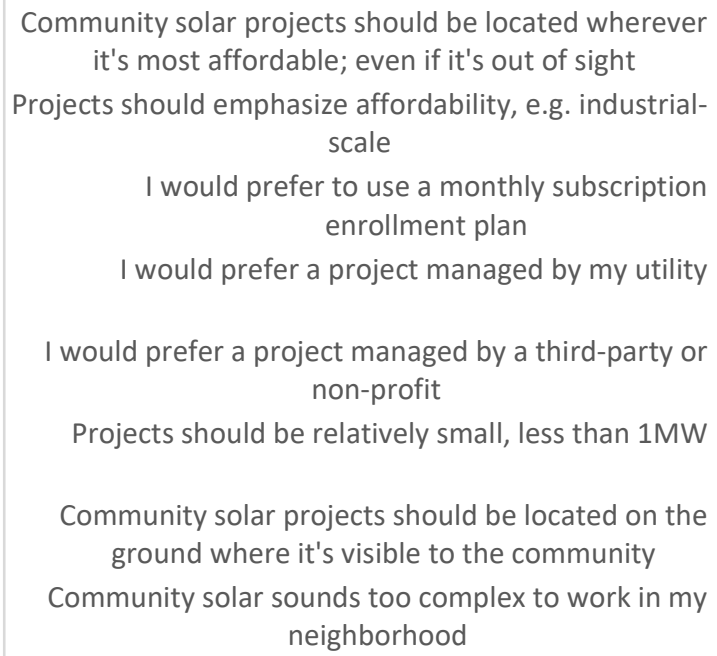

Figure 6.5 [Q14] Distribution of responses for each statement about community solar. $N$ ranged from 319 to 324.

\section{Willingness to Participate}

Q16. As mentioned earlier, community solar projects come with a balance of tradeoffs. Larger projects are typically cheaper than small-scale projects due to economies of scale, but industrial-scale projects require a substantial amount of land, which Portland doesn't have a lot of. There are many other trade-offs involved in the development of community solar, many of which are discussed in Section Two.

To reiterate, Project 1 is a small local solar array that's expensive to join upfront, Project 2 is moderate in price and size, and located in rural Washington county. Project 3 is a large project located in Eastern Oregon with an affordable upfront cost. I asked respondents to rate their willingness to join for each of these three projects, based on changes in their electricity bill. These bill savings or costs were provided in increments of $2.5 \%$, ranging from $10 \%$ lower to $10 \%$ higher. I combined "probably" and "definitely" willing to enroll responses into "willing to enroll" and "probably" and "definitely" not willing to enroll into an "unwilling to enroll" category. Figure $\mathbf{6 . 6}$ displays the results for the different project scenarios. 


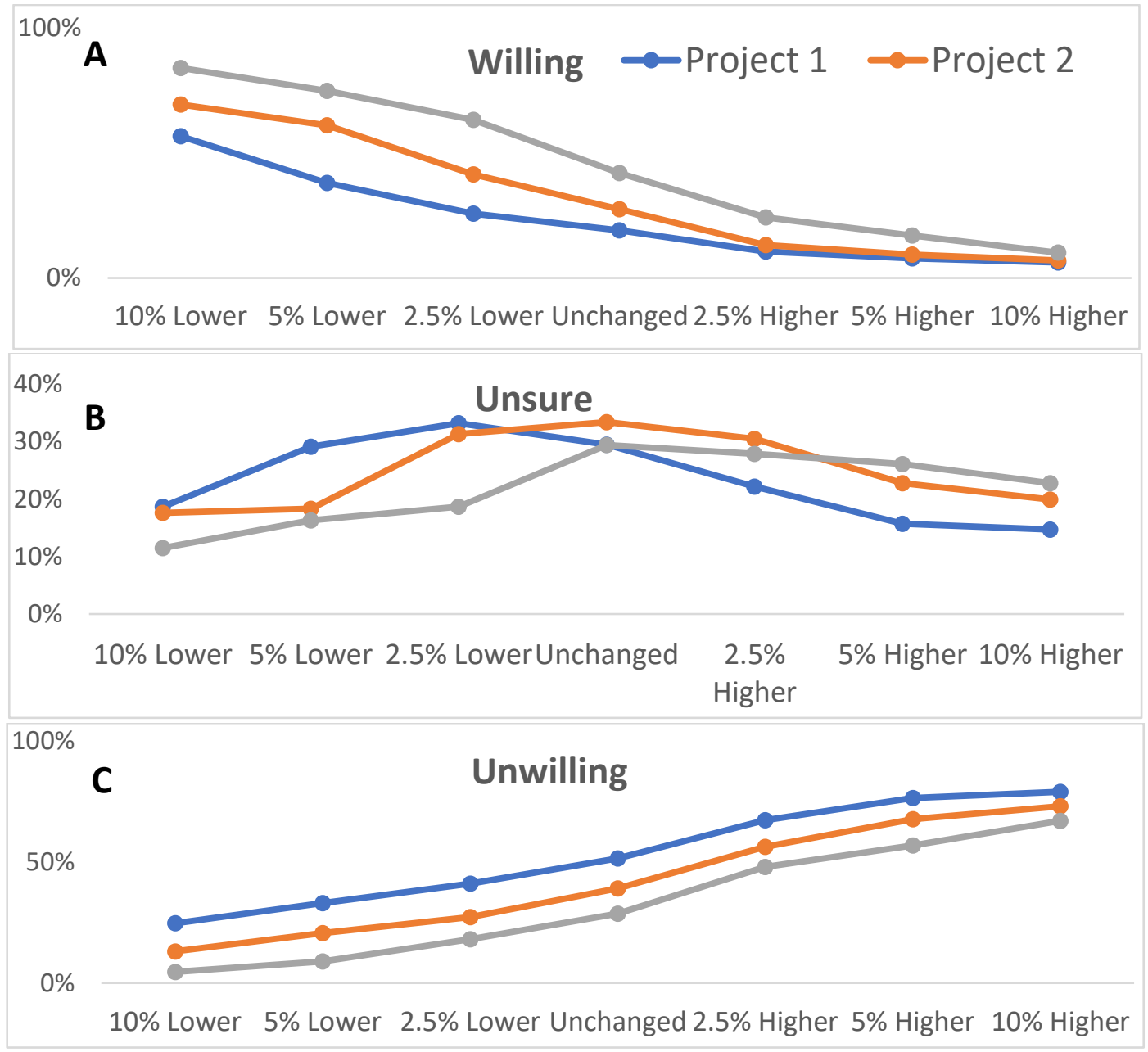

Figure 6.6 [Q16] Three graphs representing distribution of respondents who are willing (A), unsure $(\boldsymbol{B})$, and unwilling $(\boldsymbol{C})$ to join a community solar project. The three lines represent three different project scenarios. $Y$-axis is proportion of responses and $x$-axis is the change in the utility bill. Figure $\boldsymbol{A}$ shows a high proportion of respondents willing to join when the utility bill is $10 \%$ lower. That decreases to $10 \%$ or less when the bill is 10\% higher. Project 3 has the highest proportion of respondents willing to enroll. Figure $\mathbf{B}$ shows the distribution of respondents who are unsure about joining a community solar project. Uncertainty about joining is lower for all projects when bill savings or costs are more extreme, while there's a higher proportion of unsure respondents when the utility bill is unchanged. Lastly, Figure $\boldsymbol{C}$ shows the distribution of respondents who said they were unwilling to enroll in a community solar project. Project 1 has the highest proportion of respondents unwilling to join (ranges from $\sim 25 \%$ at a lower utility bill to almost $80 \%$ at a higher utility bill) and Project 3 has the lowest proportion of unwilling respondents. Monetary influences evidently sway most survey participants, but there's still a small proportion of respondents willing to pay more each month to join a community solar project (see Figure A). On the other hand, there's also still a small proportion of respondents unwilling to join even if the project is affordable (see Figure $C) .(N=297-316)$. 
Equity implications are apparent when comparing respondents' willingness to participate across the various bill savings. Comparing the demographics of the respondents willing to enroll in projects at a $10 \%$ lower utility bill with the demographics of the respondents still willing to enroll at a $10 \%$ higher utility bill says something about the market penetration potential of having a high bill credit rate (lower utility bill). If the bill credit rate is low, corresponding with a higher electricity bill, there will not only be a small number of residents willing to join ( $10 \%$ or less), but those residents would likely be highly educated, very politically liberal, and middle to high-income citizens. This demographic is already the market that's utilizing renewable energy the most. This is problematic because one of the goals of community solar is to expand access to solar energy to all segments of the population, including lower income residents. We see that a high bill credit rate (corresponding with monthly utility bill savings) is more appealing to a broader demographic.

For example, the group of respondents willing to join a community solar project even if it caused their bill to be $10 \%$ higher each month was almost $100 \%$ politically liberal and contained no residents who had only a high school diploma or less. When the electricity bill is $10 \%$ lower each month, on the other hand, that demographic is modified to include a mix of income levels, political ideologies, and educational attainments. Further, the group of respondents willing to join a community solar project at the $10 \%$ higher increment had a somewhat larger average home size (in square feet). House size can often times be considered a measure of class and income, suggesting that a higher income population would be the dominant segment of the market enrolling in community solar if the bill credit rate was low.

\section{Peer Influence}

Q17. I asked the question: "How much more likely would you be to participate in a community solar project if you knew that your neighbors, friends, or family were participating too?" to assess whether peer influence would impact intent to enroll.

Table 5.1 displays the distribution of responses. Most respondents felt that if they knew a peer who was enrolled in a community solar project, they would be somewhat more likely to join. About $27 \%$ of respondents believed their likelihood of joining would be a lot higher if they knew someone already enrolled, while $\sim 33 \%$ believed their enrollment decision wouldn't be influenced if they already knew someone participating in a project.

Table 5.1[Q17] Distribution of responses. $N=319$.

\begin{tabular}{|lccccc|}
\hline Likelihood & $\begin{array}{c}\text { Not at all } \\
\text { more likely }\end{array}$ & $\begin{array}{c}\text { Not much } \\
\text { more likely }\end{array}$ & $\begin{array}{c}\text { Somewhat } \\
\text { more } \\
\text { likely }\end{array}$ & $\begin{array}{c}\text { Much } \\
\text { more } \\
\text { likely }\end{array}$ & $\begin{array}{c}\text { Very much } \\
\text { more likely }\end{array}$ \\
\hline Distribution & $12.8 \%$ & $20.1 \%$ & $39.8 \%$ & $18.5 \%$ & $8.8 \%$ \\
\hline
\end{tabular}




\section{Framing}

To test if the framing of community solar would influence someone's intent to enroll, I provided two different frames in the supplemental information page about community solar. I divided my survey sample in half; randomly assigning half my participants one version and the other half a different version of the survey. The first version or "frame" was an economic frame that contained no emphasis on the environmental benefits of community solar projects (no mention of the word "environment" or "green"). The second version did emphasize the environmental benefits of community solar, such as including phrases like "decrease our reliance on fossil fuels" (Rosoff, 2011).

I then found the mean for my variables of interest between both versions to see if there was a significant difference between the two versions. For general interest in joining a community solar project, the mean for frame one (economic version) was 2.653 (0-4 scale, where 0 was not at all interested, 2 is unsure, and 4 is very interested), while it was 2.662 for the environmental frame. I conducted a two-sample t-test and the difference between the means was insignificant. I also looked at the difference between the means of the timing of adoption (Q15) to see if the framing influenced this variable. The mean for frame one was 2.577 ( $0-4$ scale, where 0 was never enroll, 2 was wait a couple years, and 4 was now) and the mean for frame two was 2.490. I conducted an additional $t$-test for this variable and the $p$-value was large, signifying that the groups were essentially the same.

I compared willingness to participate among respondents (for the three project scenarios) between the two versions as well and again, the differences between the means were insignificant. Therefore, the data suggests that the framing that I included in my survey did not heavily influence interest in community solar. The framing of community solar is likely still an important feature of the marketing of this energy practice. A possible reason why the frames included in this survey were insignificant was because they were very subtle; only several words were added to emphasize the environmental benefits of community solar. Further, the supplemental community solar information page may have been perceived as lengthy to some survey participants, thus they may have skimmed over some of the information (and framing) about community solar.

\section{Section seven: Climate change}

As community solar is a mechanism that can help mitigate climate change, I thought it was appropriate to assess resident's attitudes towards climate change to test if it's a predictor variable for potential interest in community solar. Refer to Section Two for 
group comparisons of climate change beliefs and additional information about the relationship between climate change and community solar.

The subsections included in this part of the report summarize distributions of responses to climate change belief questions, questions about the impacts that climate change will have on Portland, and a familiarity question regarding the Portland Climate Action Plan.

\section{Beliefs}

Q18. The responses received from the climate change questions were fairly on point with Portland's environmental ethos. For this question, I provided several statements regarding climate change; some statements were climate change denial-affiliated, while others were related to climate change acceptance (Hamilton et al., 2015). The statement that climate change is a hoax had the highest proportion of respondents disagreeing (83\% strongly disagreed), while the statement; "climate change will have dire effects for all life if we do nothing" had the largest proportion of respondents agreeing (73\% strongly agreed). The distribution of responses are displayed below in Figure 7.1.

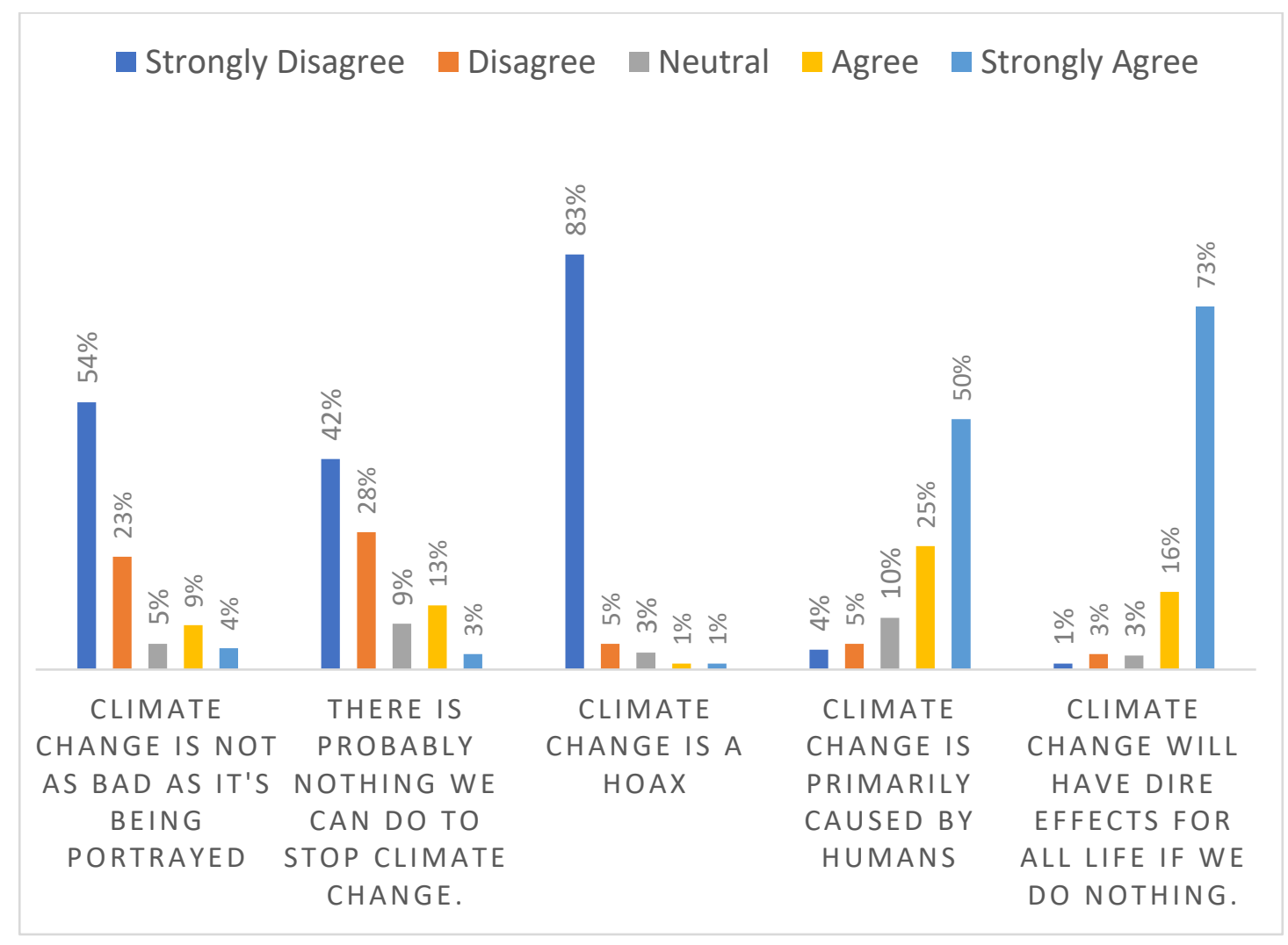

Figure 7.1[Q18] Distribution of responses to Q18. About 75\% of respondents disagreed with the statement: "climate change is not as bad as it's being portrayed", 70\% disagreed with "there is 
probably nothing we can do to stop climate change", and $75 \%$ agreed that climate change is caused primarily by humans. $N=313$ to 317 .

\section{Impacts on Portland}

Q19. To further explore attitudes about climate change, I narrowed the scope of the questions to focus on specific impacts on Portland. My reason for doing this was to make a connection between the local effects of global warming and the importance of local mitigation actions (adoption of community solar), because climate change affects communities on all spatial scales. Like Q18, I provided the respondent with several statements about the local impacts of climate change and asked them to rate their agreement on a Likert-scale. The distribution of these responses can be seen in Figure 7.2. There's a stronger neutral trend within these responses; most respondents felt neutral about the statements: "climate change will cause people to move to Portland", "climate change will cause people to leave Portland", and "climate change will improve the way I make a living". These neutral responses might be due to lack of knowledge or information about potential local climate change effects. Specific climate impact questions, such as hotter summers or wetter winters, had stronger responses ( $80 \%$ agreed that summers in Portland will be hotter and $\sim 56 \%$ agreed that winters will be wetter).

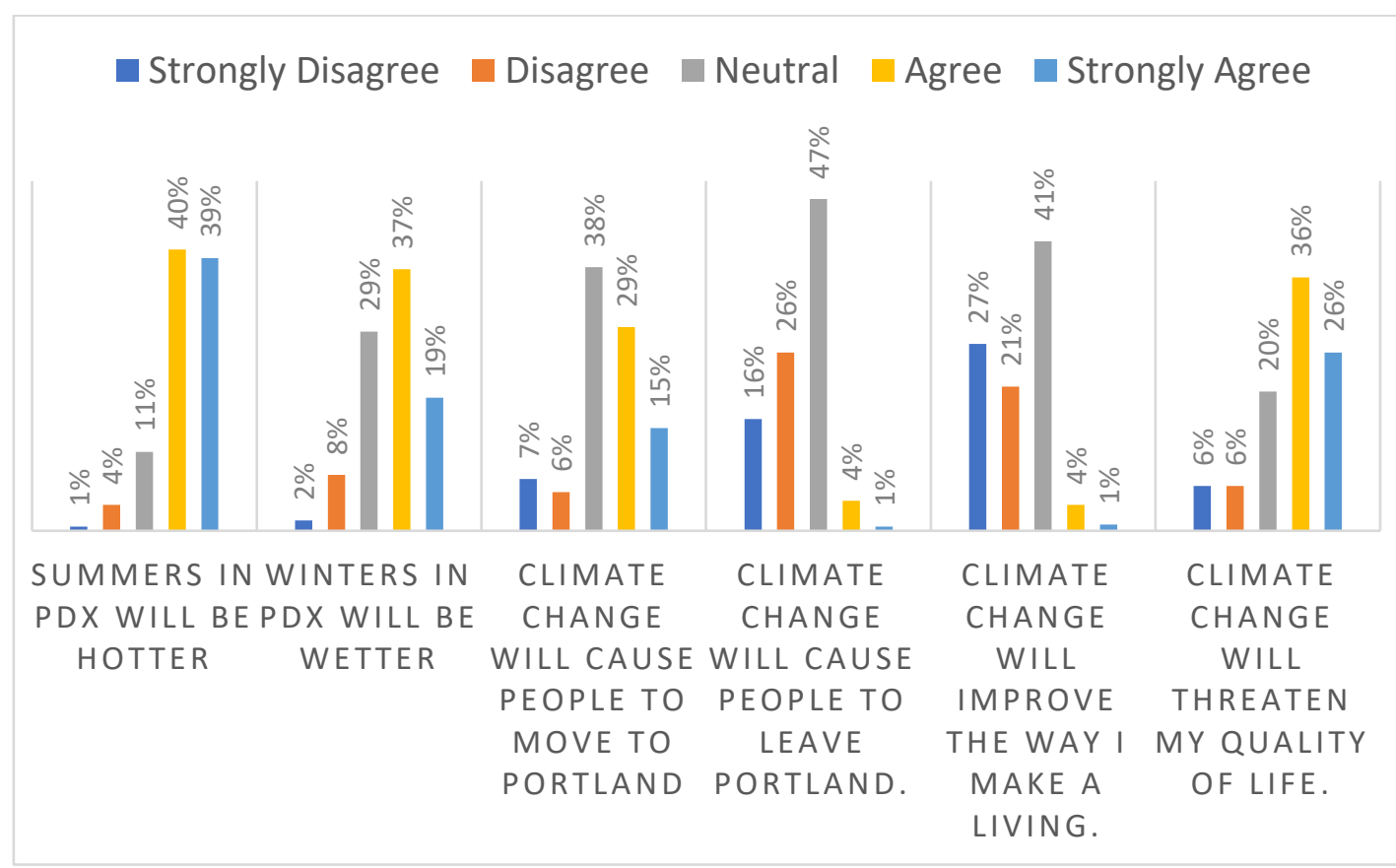

Figure 7.2 [Q19] Distribution of responses for Q19 (Likert-scale question about respondents' beliefs towards local climate change impacts). N=308 to 313. 


\section{CAP Awareness}

Q20. The Portland Climate Action Plan (CAP) is a comprehensive document outlining local objectives, mechanisms, and strategies to help reduce carbon emissions for all sectors. It's an informational instrument that citizens can read to learn about local impacts of climate change as well as ways to reduce individual carbon footprints (Anderson et al., 2015). I wanted to gauge how familiar Portland residents were about this plan, so I included the question: "The City of Portland and Multnomah County partnered to develop strategies that Portland and the region can take to address climate change. How informed are you about the Portland Climate Action Plan?" Almost 85\% respondents rated themselves as either not at all or not very informed about the Portland CAP, while less than $2 \%$ felt well or extremely informed about the plan. Figure 7.3 below displays the distribution of responses.

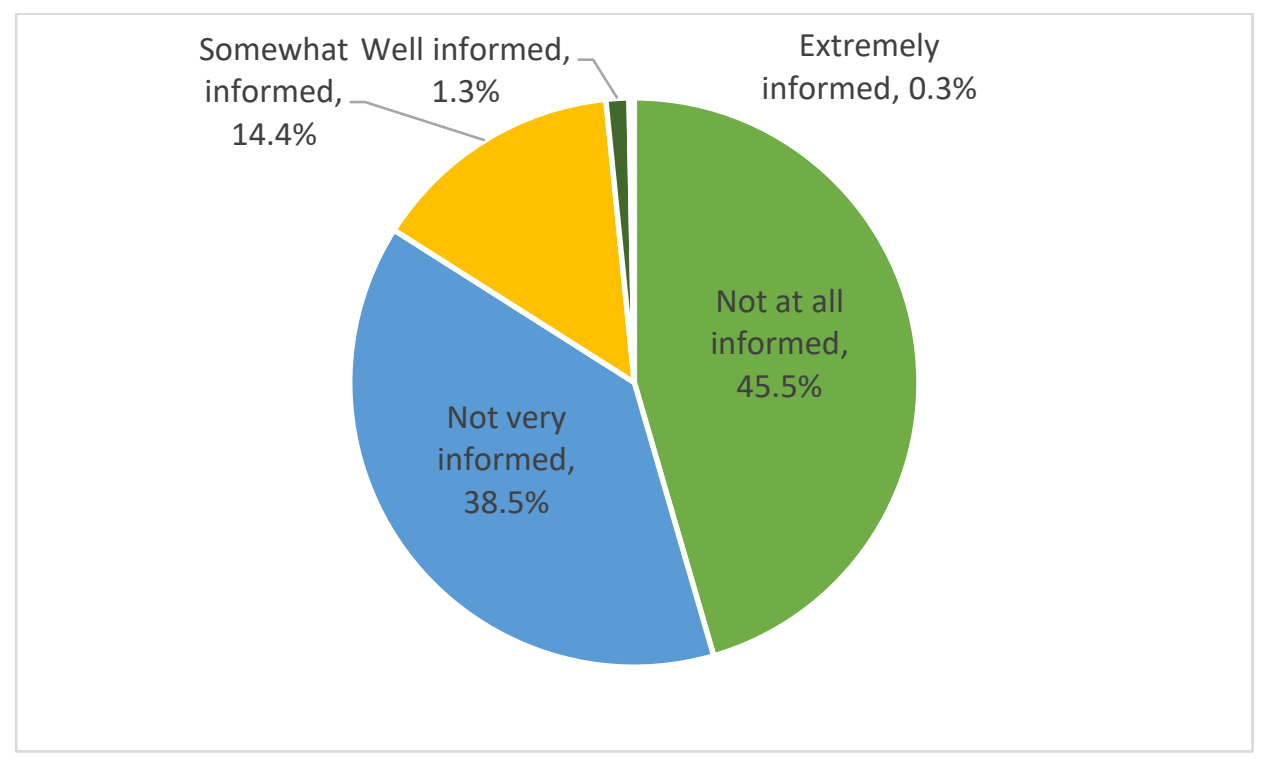

Figure 6.3 [Q20] Pie chart showing the distribution of responses for Q20; how informed respondents were about the Portland CAP. $N=319$.

\section{Section Seven: Energy use}

This section summarizes the responses to questions located in the energy use chapter of the questionnaire. To get additional information about the energy behavior exhibited by my survey respondents, I inquired about their heating and air-conditioning use. I scored their responses to categorize the respondent as either energy conscious, moderately energy conscious, or not very energy conscious, based on the settings that they use for heating and $\mathrm{AC}$. 
This section included questions about how important or unimportant respondents believe various attributes are for durable and daily goods, to get a better sense of their environmental behavior. Two other questions included in the energy use section were sources of energy information and what community activities respondents are involved in.

\section{Energy Behavior}

Q22. To assess both attitudes and behaviors of energy conservation, I included questions asking the respondent to rate how energy conscious they believe they are (see Section 3) and to report their own household energy use (through heating and AC, since those activities contribute significantly to residential carbon emissions). A resident who is more aware about the importance of conserving energy may be a more likely participant of a community solar project. Q22 asked: "when heating your home on a cold evening which of the following statements best applies?" I then provided several statements about heat settings, ranging from setting the heat below 65 degrees to setting the heat above 71 degrees (as well as an option for not having control over the heating settings of the household). I scored the response as either "not very energy conscious", "somewhat energy conscious" or "energy conscious" based on their chosen heating setting. The distribution of these scores can be seen in Figure 8.1A.

Q23. I also inquired about energy behavior in terms of AC usage. Residential air conditioning requires a tremendous amount of energy, resulting in significant carbon emissions. Residents who are more energy conscious are generally aware that high AC use consumes lots of energy. Because Portland has a climate that's mostly mild yearround, AC use isn't as prominent as in a climate such as Phoenix. Q23 asks: "when cooling your home on a hot evening which of the following statements best applies?" I also scored the responses based on the settings provided and the distribution of those scores can be seen in Figure8.1B. 


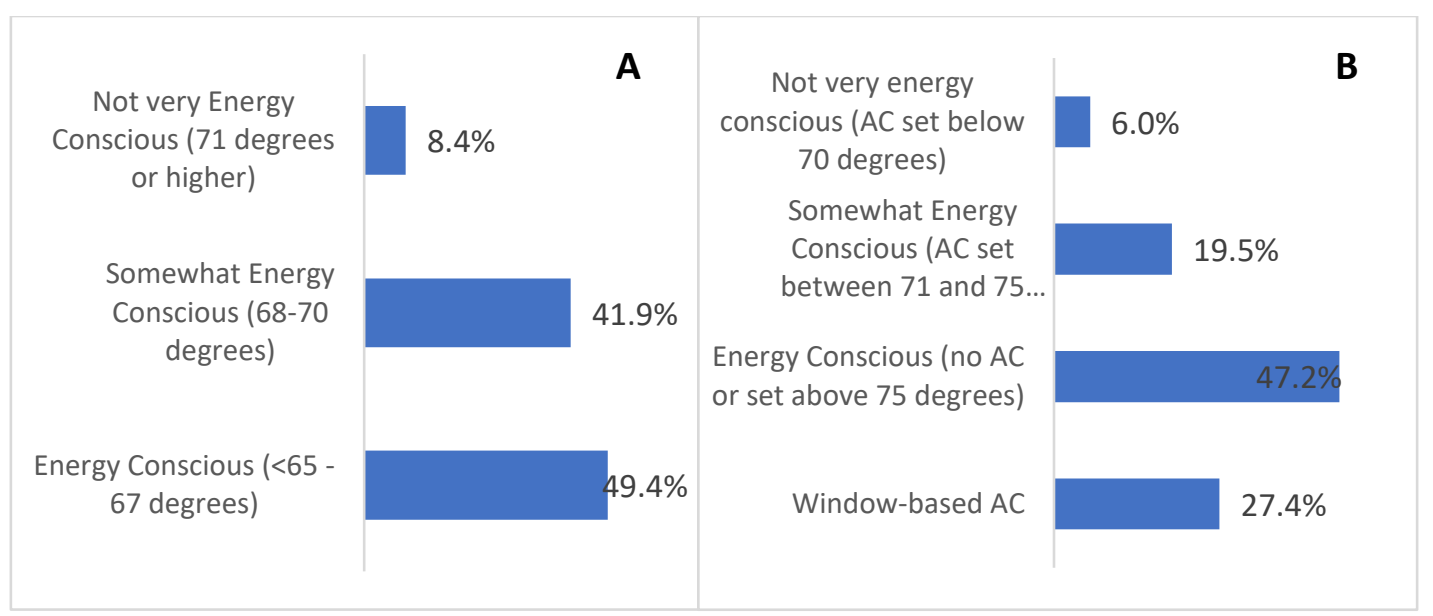

Figure 8.1 [Q22] \& [Q23] These two graphs display the distribution of energy behaviors exhibited by survey respondents in terms of heating and $A C$ use. Figure $\boldsymbol{A}(N=320)$ shows the energy conscious scores based on heating usage. 8.4\% of respondents stated they set the heat at 71 degrees or higher, which resulted in a "not very energy conscious" rating. Roughly $42 \%$ of respondents stated they set the heat between 68 and 70 degrees, which can be categorized as moderately energy conscious. Almost $50 \%$ of respondents stated they set the heat at 67 degrees or lower. Figure $B(N=318)$ shows similar scores, but in terms of AC usage. $\sim 27 \%$ of respondents use a window-based AC unit, while another $47 \%$ either don't own one or set it at 75 degrees or above on a hot night. About $20 \%$ of respondents earned a "somewhat" energy conscious score and 6\% exhibited behavior constituting unconservative energy use (setting the AC below 70 degrees).

\section{Product Attribute Ranking}

Q24 \& Q25. Green purchasing behavior may indicate a greater likelihood of participating in a community solar project; someone who rates the environmental impact of a product as important may be more inclined to behave in an environmentally-friendly manner (and thus purchase green products and services) (Gadenne et al., 2011). To gauge how respondents perceive various product attributes, for both daily goods (products that are quickly consumed) and durable goods (products or services that are generally long-lasting and more expensive), I asked the questions: "when purchasing goods that are quickly consumed, how important are the following to you?" and "when purchasing goods and services that last a long time and that are relatively more costly, how important are the following to you?" The distribution of responses for both questions are displayed in Figure $\mathbf{8 . 2}$ (daily goods) and Figure $\mathbf{8 . 3}$ (durable goods). 


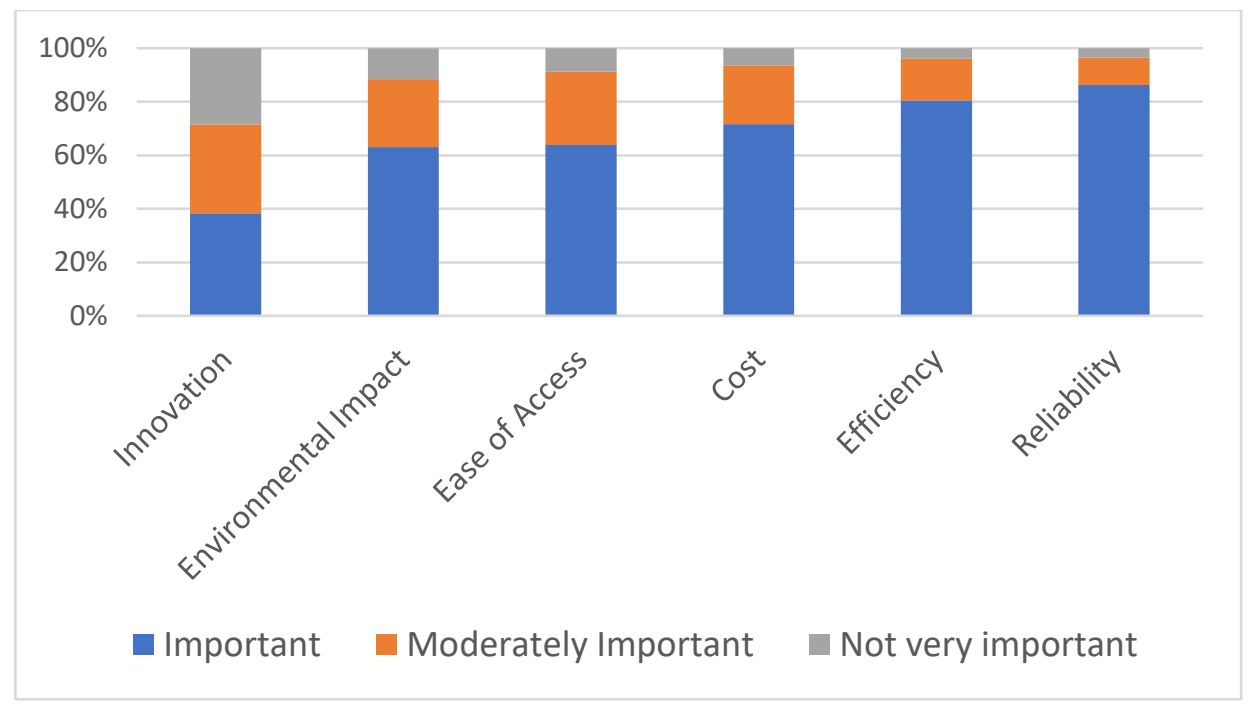

Figure 8.2 [Q24] Distribution of importance ratings for each attribute of daily goods: innovation, environmental impact, ease of access, cost, efficiency, and reliability. Innovation was the attribute that had the highest proportion of respondents rating it as moderately or not very important, while reliability was the most important product characteristic. Most respondents scored every attribute as important. $N=310$ to 312

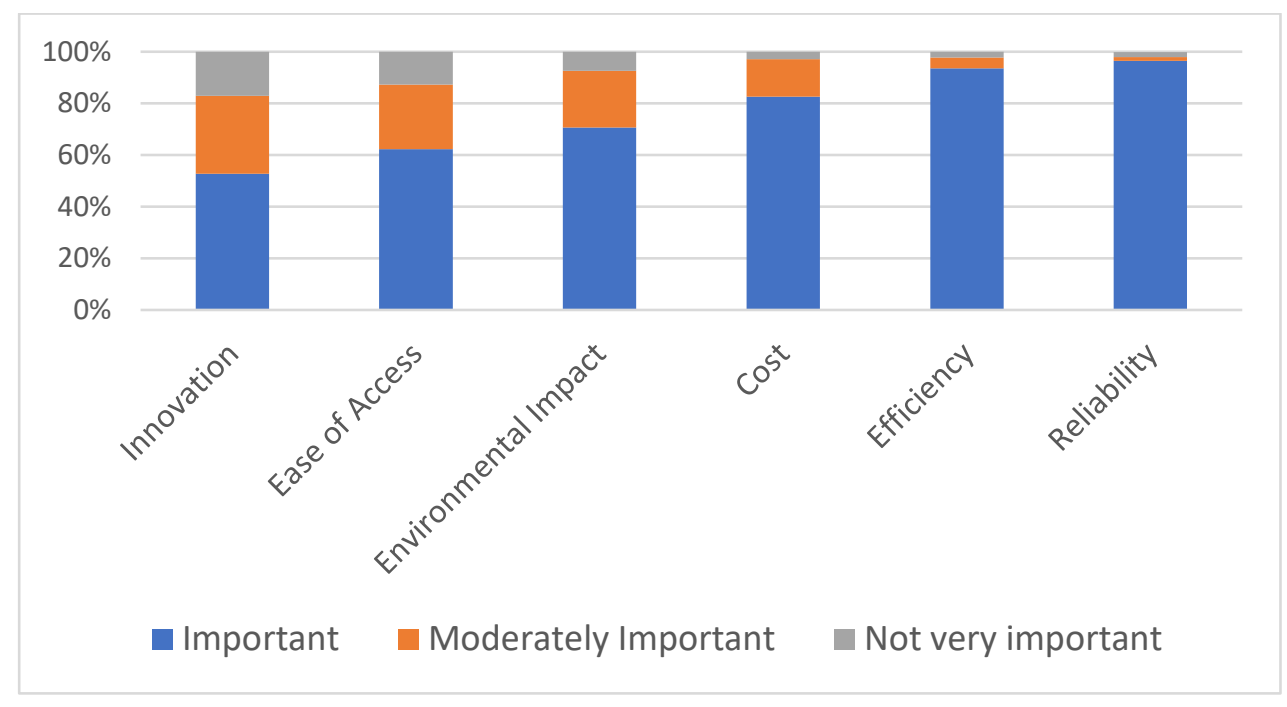

Figure 8.3 [Q25] Distribution of responses for each product attribute of durable goods. Like daily goods, innovation was the least important product characteristic, while reliability was the most. The environmental impact of a durable good is evidently more important than the environmental impact of a daily good (over $70 \%$ of respondents rated it as important or very important when making a purchasing decision). Efficiency was another characteristic rated as very important or important for most respondents (over 90\%). Efficiency can also be considered a green or sustainable characteristic. $N=308$ to 309 . 


\section{Energy Information}

Q26. I wanted to know where my survey respondents obtain their information and knowledge about energy, so I asked the question: "what source of information most strongly influences your opinions about energy?". I provided multiple sources of energy information (options listed below in Table 8.1) as well as the option to write in three influential sources. Most respondents chose the text-entry option. Answers ranged from books, radio stations such as NPR, news reports via the New York Times or the New Yorker, PBS, the Sierra Club, utility bill inserts, and movie or television documentaries (e.g. NOVA or an Inconvenient Truth). From these answers, it's evident that media outlets via newspapers, online publications, television programs, and radio broadcasting are the dominant sources of energy information.

Table 8.1 [Q26] Displays the proportion of responses for each source of energy information. Most respondents chose to write-in an entry describing their most influential sources of information. Among the listed sources, word-of-mouth through peer networking was the most frequently selected energy information source, while utility newsletters, websites, and newspapers were other frequently selected sources $(N=313)$.

\begin{tabular}{l|r}
\hline Energy Information Source & $\begin{array}{r}\text { Proportion } \\
\text { of responses }\end{array}$ \\
\hline Family, friends, neighbors, or coworkers through word-of-mouth & $9.6 \%$ \\
\hline Local utility & $8.6 \%$ \\
\hline Websites & $8.0 \%$ \\
\hline Newspaper or magazines & $8.0 \%$ \\
\hline Environmental organizations & $6.7 \%$ \\
\hline Television media & $5.1 \%$ \\
\hline Movies or documentaries & $4.2 \%$ \\
\hline Radio & $3.5 \%$ \\
\hline Social media & $2.2 \%$ \\
\hline School & $1.9 \%$ \\
\hline Advertisements & $0.3 \%$ \\
\hline Text-Entry & $41.9 \%$ \\
\hline mmunity involvement & \\
\hline To assess how community-oriented my survey respondents were, I asked the \\
\hline stion: “in the past year, approximately how often have you engaged in the following \\
\hline ities?". I then provided several community engagement activities and inquired \\
ut the frequency in which respondents participate in the activities. The activities
\end{tabular}


were: volunteering at a local library, attending neighborhood meetings, volunteering at a local school, volunteering at a community center, volunteering at a local nonprofit, and attending church. Figure $\mathbf{8 . 4}$ shows the distribution of responses for each community activity.

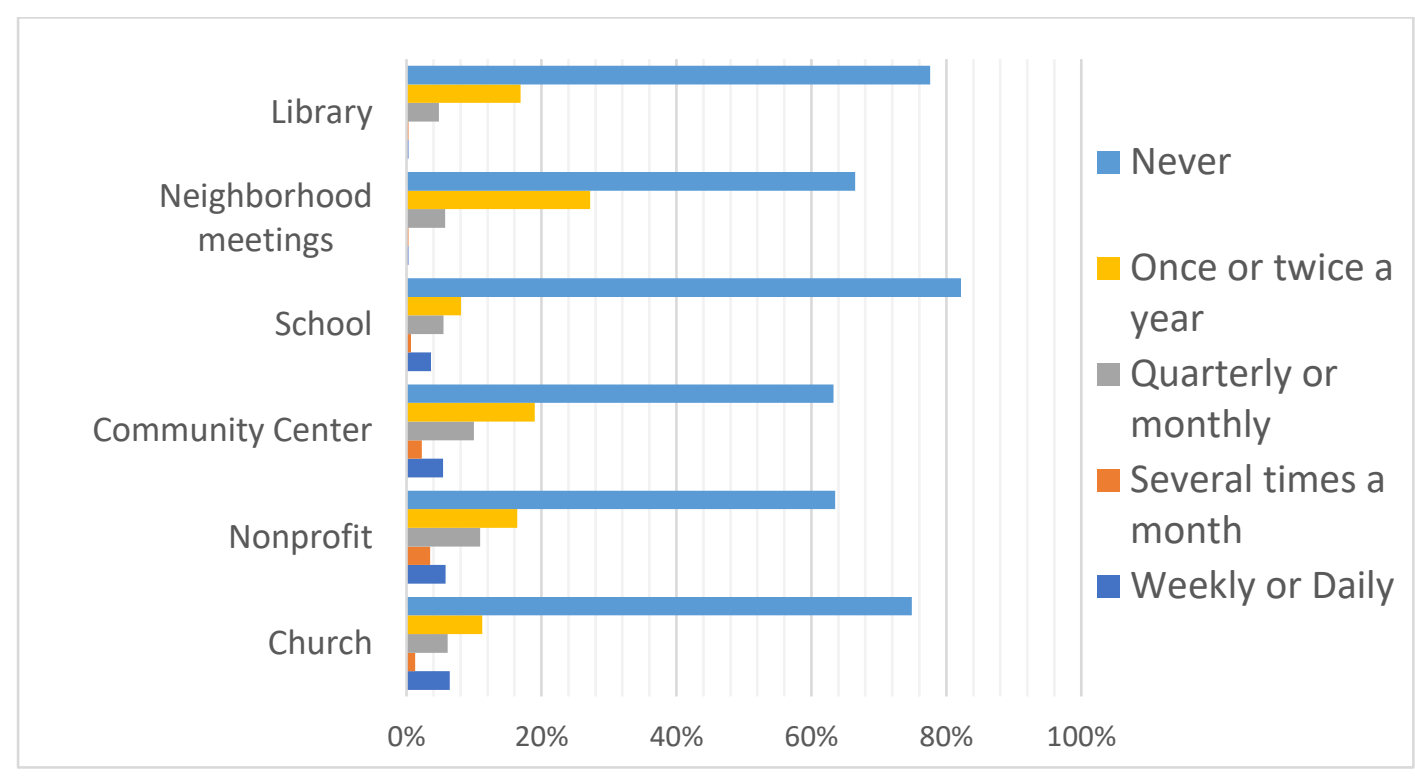

Figure 8.4 [Q27] This chart shows the frequency distributions of responses for each community activity. Most respondents stated they never participated in any of the listed activities over the past year ("never" was chosen among 60-80\% of responses for each activity). Almost 30\% of respondents attended neighborhood meetings once or twice this year. Volunteering at a local school was the least popular activity among survey respondents, while volunteering at a local nonprofit was more common ( $15 \%$ volunteered once or twice over the year, $10 \%$ volunteered quarterly or monthly, and another $10 \%$ volunteered several times a month or weekly). Attending church was the activity that had the highest proportion of "weekly" responses ( $N=308$ to 313).

To further explore the relationship between community involvement and interest in community solar, I divided my survey respondents into groups based on their total yearly participation in community activity (measured in days). I then calculated the mean level of community solar interest for each frequency group, displayed in Table 8.2. While there was not a lot of variation between these means, the highest level of interest came from the group that participated in community activity 6 to 25 days out of the year. The lowest level of community solar interest was in the group that spent 101 days or more on community activities. While these numbers may be surprising, there may be an underlying reason for this pattern. The respondents who were placed in the "101 days or more" group were mostly weekly church-goers, which causes their frequency score to be quite high. Church attendance may be an unlikely predictor for 
community solar interest. A possible explanation for the higher level of interest in the " 6 to 25 days" group is the frequency among these respondents for volunteering at nonprofit organizations, which was the activity selected the most for monthly or quarterly participation. Refer to Section Two for the frequency scoring methodology.

Table 8.2 Table comparing community involvement with mean level of interest in community solar. Interest was measured from 0 (no interest) to 4 (very interested), with 2 being unsure. Community involvement is measured in days; scoring for the total amount of days spent on community activity is described in Figure 2.10. These community activities are described above in Figure 8.4. Highest interest in community solar was among respondents who reported community activity during 6 to 25 days of the year.

\begin{tabular}{|c|c|c|}
\hline $\begin{array}{l}\text { Days spent on community activity last } \\
\text { year }\end{array}$ & $\begin{array}{l}\text { Mean Level of Interest in } \\
\text { CS }\end{array}$ & $\mathbf{N}$ \\
\hline 0 days & 2.71 & 84 \\
\hline 1-5 days & 2.68 & 97 \\
\hline 6-25 days & 2.73 & 56 \\
\hline 26 to 100 days & 2.59 & 57 \\
\hline 101 or more & 2.57 & 21 \\
\hline
\end{tabular}




\section{Literature Cited}

Anderson, S., M. Armstrong, I. Fish, M. Crim, K. Diesner, T. Evans, D. Williams-Rajee, and T. Lynch. 2015 Climate Action Plan. City of Portland and Multnomah County, Portland Bureau of Planning and Sustainability, Portland, Oregon, USA.

Bird, L., and J. Sumner. Consumer attitudes about renewable energy: trends and regional differences. Subcontract Report NREL/SR-6A20-50988. U.S. Department of Energy, National Renewable Energy Laboratory, Golden, Colorado, USA.

Claudy, M. C., M. Peterson, and A. O'Driscoll. 2013. Understanding the attitude-behavior gap for renewable energy systems using behavioral reasoning theory. Journal of Macromarketing 33:273-287.

Coughlin, J., J. Grove, L. Irvine, J. F. Jacobs, S. J. Phillips, L. Moynihan, and J. Wiedman. 2010. A Guide to Community Solar: Utility, Private, and Non-profit Project Development. Department of Energy.

Dillman, D. 2000. Mail and Internet Surveys: the Tailored Design Method. John Wiley and Sons, Inc., New York, NY.

Edenhofer, O., R. Pichs-Madruga, Y. Sokana, and K. Seyboth. 2011. Special Report on Renewable Energy Sources and Climate Change Mitigation- Summary for Policy Makers. Intergovernmental Panel on Climate Change.

Etter, J. F., and T. V. Perneger. 1997. Analysis of non-response bias in a mailed health survey. Journal of Clinical Epidemiology 50: 1123-1128.

Faiers, A., and C. Neame. 2006. Consumer attitudes towards domestic solar power systems. Energy Policy 34:1797-1806.

Feldman, D., A. M. Brockway, E. Ulrich, R. Margolis. Shared solar: current landscape, market potential, and the impact of federal securities regulation. Technical Report NREL/TP-6A2063892. U.S. Department of Energy, National Renewable Energy Laboratory, Golden, Colorado, USA.

Gadenne, D., B. Sharma, D. Kerr, and T. Smith. 2011. The influence of consumers' environmental beliefs and attitudes on energy saving behaviors. Energy Policy 39:7684-7694.

Hamilton, L. C., J. Hartter, M. Lemcke-Stampone, D. W. Moore, and T. G. Safford. 2015. Tracking public beliefs about anthropogenic climate change. PLOS One 10:e0138208.

Jager, W. 2006. Stimulating the diffusion of photovoltaic systems: A behavioural perspective. Energy Policy 34:1935-1943.

Levin, I. P., S. L. Schneider, and G. J. Gaeth. 1998. All frames not created equal: a typology and critical analysis of framing effects. Organizational Behavior and Human Decision Processes 76: 149-188.

Maize, K. 2015. Solar gardens: a fast-growing approach to photovoltaic power. Power: 30-33. 
O'Shaughnessy, E., J. Heeter, L. Chang, E. Nobler. Status and trends in the U.S. voluntary green power market (2014 data). Technical Report NREL/TP-6A20-65252. U.S. Department of Energy, National Renewable Energy Laboratory, Golden, Colorado, USA.

Price, J. C., I. A. Walker, and F. Boschetti. 2014. Measuring cultural values and beliefs about environment to identify their role in climate change responses. Journal of Environmental Psychology 37:8-20.

Rosoff, V. 2011. Framing Solar. Solar Today 25:62-66.

Steele, J., L. Bourke, A. E. Luloff, P. S. Liao, G. L. Theodori, and R. S. Krannich. 2001. The dropoff/pick-up method for household survey research. Journal of the Community Development Society 32: 238-250.

U.S. Census Bureau. 2010 Census.

Wüstenhagen, R., M. Wolsink, and M. J. Bürer. 2007. Social acceptance of renewable energy innovation: An introduction to the concept. Energy Policy 35:2683-2691. 


\section{APPENDIX D: HUMAN SUBJECTS APPROVAL}

\section{蛋 Portland State}

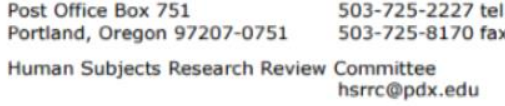

Date: November 14, 2016

To: $\quad$ Max Nielson-Pincus / Anne Weaver, Environmental Science and Management

From: Lindsey Wilkinson, HSRRC Chair

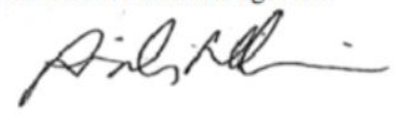

Re: HSRRC approval for your project \# 163840, entitled, "Social acceptance of community solar gardens: a Portland case study"

Approval-Expiration: November 14, 2016 - July 05, 2017

Notice of IRB Review and Approval-Amendment Expedited Review as per Title 45 CFR Part 46.110, 63 FR 60366, \# 6, 7

The amendment submitted on 11/08/2016 for the project identified above has been reviewed and approved by the Portland State University Institutional Review Board (IRB) and the Office of Research Integrity using an expedited review procedure. This is a minimal risk study. This approval is based on the assumption that the materials, including changes/clarifications that you submitted to the IRB contain a complete and accurate description of all the ways in which human subjects are involved in your research.

This approval is given with the following standard conditions

1. You are approved to conduct this research only during the period of approval cited below;

2. You will conduct the research according to the plans and protocol submitted (approved copy enclosed);

3. You will immediately inform the Office of Research Integrity within 5 days of any injuries or adverse research events involving subjects

4. You will immediately request approval from the IRB of any proposed changes in your research, and you will not initiate any changes until they have been reviewed and approved by the IRB,

5. You will only use the approved informed consent document(s) (enclosed)

6. You will give each research subject a copy of the informed consent document;

7. If your research is anticipated to continue beyond the IRB approval dates, you must submit a Continuing Review Request to the IRB approximately 60 days prior to the IRB approval expiration date. Without continuing approval the Protocol will automatically expire on 07/05/2017.

Portland State University and the Office of Research Compliance appreciate your efforts to conduct research in compliance with PSU Policy and the Federal regulations that have been established to ensure the protection of human subjects in research. Thank you for your cooperation with the IRB process

If you have questions or concerns, please contact the Office of Research Integrity at 503-725-2227.

Approved: Amended application/protocol version 11/08/2016, including shift to mail recruitment for final round; Mail recruitment letter version 11/08/2016 